\title{
Intimal hyperplasia in prosthetic vascular access
}

Citation for published version (APA):

Lemson, M. S. (2000). Intimal hyperplasia in prosthetic vascular access: the effect of flow variation and anastomotic geometry on its development. [Doctoral Thesis, Maastricht University]. Universiteit Maastricht. https://doi.org/10.26481/dis.20000414ml

Document status and date:

Published: 01/01/2000

DOI:

$10.26481 /$ dis. $20000414 \mathrm{ml}$

Document Version:

Publisher's PDF, also known as Version of record

\section{Please check the document version of this publication:}

- A submitted manuscript is the version of the article upon submission and before peer-review. There can be important differences between the submitted version and the official published version of record.

People interested in the research are advised to contact the author for the final version of the publication, or visit the DOI to the publisher's website.

- The final author version and the galley proof are versions of the publication after peer review.

- The final published version features the final layout of the paper including the volume, issue and page numbers.

Link to publication

\footnotetext{
General rights rights.

- You may freely distribute the URL identifying the publication in the public portal. please follow below link for the End User Agreement:

www.umlib.nl/taverne-license

Take down policy

If you believe that this document breaches copyright please contact us at:

repository@maastrichtuniversity.nl

providing details and we will investigate your claim.
}

Copyright and moral rights for the publications made accessible in the public portal are retained by the authors and/or other copyright owners and it is a condition of accessing publications that users recognise and abide by the legal requirements associated with these

- Users may download and print one copy of any publication from the public portal for the purpose of private study or research.

- You may not further distribute the material or use it for any profit-making activity or commercial gain

If the publication is distributed under the terms of Article $25 \mathrm{fa}$ of the Dutch Copyright Act, indicated by the "Taverne" license above, 


\section{Intimal hyperplasia in prosthetic vascular access}

The effect of flow variation and anastomotic geometry on its development 



\title{
Intimal hyperplasia in prosthetic vascular access \\ The effect of flow variation and anastomotic geometry on its development
}

\author{
Proefschrift
}

ter verkrijging van de graad van doctor

aan de Universiteit Maastricht,

op gezag van de Rector Magnificus,

Prof.dr. A.C. Nieuwenhuijzen Kruseman,

volgens het besluit van het College van Decanen,

in het openbaar te verdedigen

op vrijdag 14 april 2000 om 14.00 uur

door

Margaretha Suzanna Lemson

Geboren op 4 augustus 1967 te Rotterdam 


\section{Promotores:}

Prof. dr. P.J.E.H.M. Kitslaar

Prof. dr. M.J.A.P. Daemen

Prof. dr. K.M.L. Leunissen

\section{Co-promotor:}

Dr. J.H.M. Tordoir

\section{Beoordelingscommissie:}

Prof. dr. J.W. Arends, voorzitter

Dr. H. Burger (Albert Schweitzer Ziekenhuis Dordrecht)

Prof. dr. J.M.A. van Engelshoven

Prof. dr. J.P. van Hooff

Studies in this theses were supported by a grant from the Dutch Kidney Foundation (C93.1327). Publication of this thesis was supported by the Dutch Kidney Foundation, W.L. Gore \& Associates and Janssen-Cilag.

(C) M.S. Lemson, Eindhoven 2000.

ISBN 90-9013585-5

Cover design: Uit de kunst! Vormgeving van communicatie, Rotterdam

Printing: Offset Service, Valkenswaard

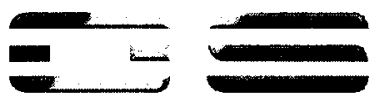


Aan mijn ouders

Aan Edwin 


\section{List of abbreviations}

\begin{tabular}{|c|c|}
\hline $\mathrm{Al}$ & Area Increase \\
\hline All & Angiotensin II \\
\hline ATI & Angiotensin receptor I \\
\hline AV & arteriovenous \\
\hline $\mathrm{BC}$ & Brescia-Cimino \\
\hline bFGF & basic Fibroblast Growth Factor \\
\hline BrdU & Bromo-2'-deoxyuridine (thymidine analogue) \\
\hline CAPD & Continuous Ambulant Peritoneal Dialysis \\
\hline CARIM & Cardiovascular Research Institute Maastricht \\
\hline CCPD & Continuous Cyclic Peritoneal Dialysis \\
\hline CSA & Cross-Sectional Area \\
\hline $\mathrm{D}$ & Diameter \\
\hline $\mathrm{DHV}$ & Denatured Homologous Vein \\
\hline DM & Diabetes Mellitus \\
\hline EC & Endothelial Cell \\
\hline ECM & Extracellular Matrix \\
\hline ETE & End-To-End (anastomosis) \\
\hline ETS & End-To-Side (anastomosis) \\
\hline HD & Hemodialysis \\
\hline HDM & Hemodialysis Monitor \\
\hline IEL & Inner Elastic Lamina \\
\hline IH & Intimal Hyperplasia \\
\hline $\mathrm{I}_{\mathrm{a}} / \mathrm{Ma}$ & Intimal/medial ratio in area \\
\hline $\mathrm{l}_{\mathrm{th}} / \mathrm{M}_{\mathrm{th}}$ & Intimal/medial ratio in thickness \\
\hline Inc & Incidence \\
\hline IQ & Interquartiles \\
\hline MMP & Matrix Metallo Proteases \\
\hline MRI & Magnetic Resonance Imaging \\
\hline $\mathrm{n}$ & number \\
\hline NO & Nitric Oxide \\
\hline NS & Not Significant \\
\hline Pat & Patient \\
\hline PDGF & Platelet Derived Growth Factor \\
\hline (n)PSV & (normalised) Peak Systolic Velocity (normalised for diameter) \\
\hline PTA & Percutaneous Transluminal Angioplasty \\
\hline PTCA & Percutaneous Transluminal Coronary Angioplasty \\
\hline PTFE & Polytetrafluoroethylene (Teflon ${ }^{\circledR}$ ) \\
\hline py & patient-year \\
\hline$Q$ & Flow \\
\hline RD & Relative Distension \\
\hline RRT & Renal Replacement Therapy \\
\hline SEM & Standard Error of the Mean \\
\hline SSRE & Shear Stress Responsive Elements \\
\hline SVG & Saphenous Vein Graft \\
\hline TGF- $\beta$ & Transforming Growth Factor- $\beta$ \\
\hline tPA & tissue-type Plasminogen Activator \\
\hline UPA & urokinase-type Plasminogen Activator \\
\hline Vmean & mean Velocity \\
\hline VP & Venous Pressure \\
\hline VSMC & Vascular Smooth Muscle Cell \\
\hline WWDT & Vessel Wall Doppler Tracking \\
\hline WSR & Wall Shear Rate \\
\hline
\end{tabular}




\section{Contents}

Chapter $1 \quad$ Introduction and objectives ………...................................... 9

Chapter 2 Hemodialysis vascular access and fistula surveillance methods in the Netherlands.

Chapter 3 Intimal hyperplasia and venous cuffs.

Chapter 4 A new animal model to study intimal hyperplasia in arteriovenous fistulas

Chapter 5 Anastomotic geometry in PTFE arteriovenous fistulas: hemodynamic studies in the goat

Chapter 6 Effects of a venous cuff at the venous anastomosis of PTFE grafts for hemodialysis vascular access

Chapter 7 The effect of a venous cuff on the bloodflow hemodynamics of prosthetic arteriovenous fistulas for hemodialysis

Chapter 8 General discussion

Summary

Samenvatting 135

Dankwoord

Curriculum Vitae 



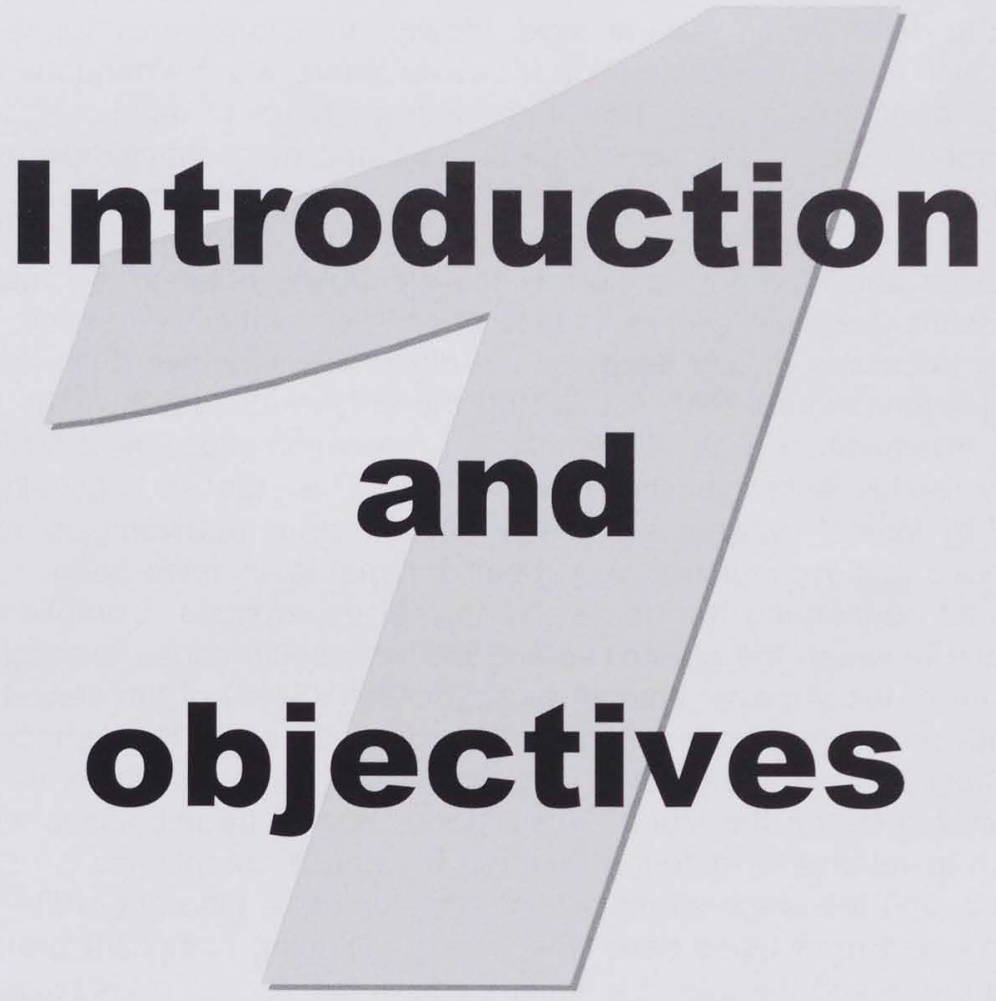




\section{General introduction}

Loss of kidney function causes uraemia and fluid overload in patients, leading to death within several days. Ideally, end-stage renal failure is treated with kidney transplantation, however, there is a tremendous shortage of donor kidneys ${ }^{1}$. Therefore, other methods of renal replacement therapy, like peritoneal dialysis and hemodialysis are used. In hemodialysis treatment, the patient's blood is guided through an artificial kidney 2 to 3 times a week for several hours, to withdraw metabolites and fluid and to correct the electrolyte balance. To make this possible, frequent access to the patient's circulation is needed. The vascular accesses mostly used are the direct radiocephalic (BresciaCimino) arteriovenous (AV) fistula and the polytetrafluoroethylene (PTFE) interposition graft AV fistula. The main complication of PTFE graft AV fistulas is thrombosis due to stenosis. This stenosis is usually caused by intimal hyperplasia, mainly in the venous anastomosis and in the venous outflow segment. A number of hypotheses have been developed concerning the causes of intimal hyperplasia. Compliance difference between the prosthesis and the vein could cause excessive stretching of the vascular smooth muscle cells (VSMC) of the vessel wall, inducing migration and proliferation of these cells. High shear stress may damage the endothelium, which can no longer apply its inhibitory effects on the VSMC. Also, adherence of thrombocytes will occur, with release of mitogen factors. To reduce compliance mismatch and the shear stress around anastomoses, different graft geometry and graft types have been used, including compliant grafts, tapered grafts and the use of a venous cuff at the venous anastomosis. The purpose of this study was to assess the effect of a venous cuff at the venous anastomosis on hemodynamic parameters and patency rates in prosthetic AV fistulas. The research was conducted at the Department of Surgery of the University Hospital Maastricht and the Cardiovascular Research Institute Maastricht (CARIM) of the Maastricht University in the Netherlands.

\section{Types of vascular access in hemodialysis treatment}

Although Kolff introduced hemodialysis treatment in $1943^{2}$, chronic hemodialysis treatment became only possible after the development of continuous vascular access in the sixties. Until that time, repetitive cannulation with glass cannulas was used, causing depletion of possible access sites because of damage to the arteries and veins. In 1960, Quinton and Scribner published their experiences of chronic hemodialysis treatment with the use of an external access ${ }^{3}$. They introduced a permanent external arteriovenous shunt, which did not clot due to the high flow and the use of Teflon vascular tips and silicone tubings. But the breakthrough in vascular access was the direct arteriovenous fistula between the radial artery and the cephalic vein, which was described by Brescia and Cimino in $1966^{4}$. The arterial flow 
and pressure dilates the vein, facilitating repetitive puncture. This dilatation of the vein is called maturation. The Scribner shunt and the $\mathrm{BC}$ fistula are so called primary accesses.

Although the $\mathrm{BC}$ fistula remains the access of first choice for chronic hemodialysis treatment ${ }^{5}$, it has its limitations. In about $10 \%$ of the patients, inadequate vessel conditions preclude placement of a BC fistula. In another $20 \%$, the BC fistula fails to mature. Finally, fistulas may fail due to the long-term treatment itself. The incidence of these problems with primary accesses increases. First of all this is due to the improvement of hemodialysis treatment, with more elderly patients entering in the dialysis program. These older patients frequently have cardiovascular problems and poor vessels. Also, the total number of patients on hemodialysis treatment increases ${ }^{1}$. Therefore an increasing number of patients will need secondary access.

A number of different types of secondary accesses have been developed over the years. One of these is the elbow fistula, for example the Gracz fistula, another direct arteriovenous fistula, with an anastomosis between the brachial artery and the medial cubital vein in the elbow ${ }^{6}$. Also, implantation of bridge grafts between an artery and a suitable vein is used as secondary access construction, in which the graft serves as puncture site. These grafts are implanted at different sites, but mostly in the forearm with anastomoses to the brachial artery and an elbow vein, with the graft in a loop configuration in the subcutaneous tissue of the forearm. Other types are the straight graft between the radial artery and an elbow vein in the forearm, a loop graft between the femoral artery and vein in the thigh, and the thoracic loop graft between the subclavian artery and vein ${ }^{7}$. Several types of graft material have been used, including autologous veins like the greater saphenous vein $^{8 ; 9}$, the basilic vein ${ }^{10-12}$, allografts like the bovine carotid $\operatorname{artery}^{13 ; 14}$, denatured homologous grafts (Varivas) ${ }^{15 ; 16}$ and human umbilical vein (Dardik) ${ }^{17}$, and grafts of prosthetic materials like polyethyleneteraphtalate (Dacron) ${ }^{18}$ and polytetrafluoroethylene (PTFE) ${ }^{19 ; 20}$. Nowadays PTFE grafts are commonly accepted as first choice conduits for secondary access ${ }^{21}$. On 1 January 19962842 patients were treated with hemodialysis for end-stage renal disease in the Netherlands. Of these patients, $60 \%$ was dialysed via a primary vascular access according to Brescia and Cimino, and 22\% (552 patients) had their hemodialysis via a PTFE graft fistula (see Chapter 2).

\section{Complications of vascular access}

Fistula function can be compromised by a number of complications.

The overall incidence of complications in PTFE graft AV fistulas in the Netherlands has been reported as high as 1.60 interventions per patient year $(p y)^{22}$. A study on vascular access morbidity in the USA showed that $72 \%$ of the patients remaining on hemodialysis over 2 years had at least one hospital admission for access-related complications in that period ${ }^{23}$. 


\section{Stenosis and Thrombosis}

The most common complication of PTFE graft AV fistulas is thrombosis ${ }^{24-26}$. The overall incidence of thrombotic events in PTFE graft AV fistulas is $0.54-0.95$ per $\mathrm{py}^{22}{ }^{27-29}$. The risk on fistula thrombosis increases when fistula volumeflow drops below $600 \mathrm{ml} / \mathrm{min}^{30}$. The main causes of lowered fistula flow and thrombosis are hypotension and stenosis.

During dialysis treatment, fluid is extracted, causing a decrease in blood pressure. Usually, blood pressure remains high enough to maintain a good fistula flow. But if severe hypotension occurs for some time, fistula thrombosis may evolve.

One year after implantation, almost all patients have a stenosis at the venous anastomosis of their PTFE graft AV fistula. Interventions for stenosis are performed 0.27 times per $\mathrm{py}^{22}$. The stenosis is caused by intimal hyperplasia, which is a major problem of all vascular interventions. Intimal hyperplasia is due to proliferation of medial VSMC and migration to the intima, where proliferation will continue and collagen, proteoglycans and elastin will be deposited.

Theoretically, this migration and proliferation can be caused by different mechanisms. A large mismatch in compliance between the PTFE prosthesis and the native vein causes excessive stretching at the anastomosis. This might stimulate the VSMC to migrate and proliferate. Also, shear stress exerted by the flowing blood on the vessel wall is hypothesised as a cause of intimal hyperplasia. High shear stress may cause damage to the endothelium, which can no longer exercise its inhibiting effect on VSMC proliferation. Moreover, thrombocytes may adhere to the damaged endothelium. They are activated and release proliferating and migrating factors, which stimulate the VSMC. On the other hand, low shear stress stimulates the endothelium to release mitogen factors to reduce the diameter and to keep the shear stress at an optimal level ${ }^{31}$.

While extensive research is being done on the mechanisms of restenosis after Percutaneous Transluminal Coronary Angioplasty (PTCA) and development of intimal hyperplasia after carotid artery surgery and in peripheral arterial bypasses, intimal hyperplasia development in AV fistulas remains under-exposed. Since AV fistulas produce a high flow system, the high shear rate may possibly play a role in the development of intimal hyperplasia, whereas in the normal flow (coronary and carotid artery) or low flow (peripheral bypasses) systems low shear rate may be of more importance as a stimulating factor.

\section{Infection}

The use of a prosthetic implant carries a risk of infection ${ }^{32}$. The frequent puncturing of the graft for hemodialysis further increases this risk. With the use of a proper and aseptic puncture technique the incidence of infections can be limited. The reported infection rates vary from 5 up to $25 \%$ per year ${ }^{20 ; 26 ; 33-37}$. An infected graft can only rarely be salvaged, and 
usually graft explantation and creation of a new fistula are required ${ }^{20 ; 37}$

${ }^{40}$. If a graft infection is not recognised in time, sepsis and even death can occur.

\section{Aneurysm}

Aneurysm formation used to be a frequent and dreaded complication of the allografts and the homologous grafts, because of the risk of life threatening bleedings from these aneurysms. On the other hand, aneurysms are very rarely seen in PTFE graft AV fistulas. A pseudoaneurysm is an accumulation of flowing blood through a disruption of the vessel or prosthetic wall, encapsulated by the surrounding tissue. Pseudoaneurysms do occur in $5-17 \%$ of the PTFE graft AV fistulas per year ${ }^{20 ; 24 ; 26 ; 33 ; 34 ; 36 ; 39}$. It is usually caused by an inadequate puncture technique, with repeated cannulation of a single site, or suboptimal postdialysis hemostasis ${ }^{21}$. If the pseudoaneurysm is large, surgical correction should be performed.

\section{Bleeding and hematomas}

Bleeding or hematomas can occur at a puncture site, but only rarely require surgical intervention. The incidence of interventions for hematomas and bleeding is about 0.06 per py in PTFE graft AV fistulas ${ }^{22}$.

\section{Venous hypertension}

Many patients on hemodialysis treatment previously have had subclavian vein catheters. These can lead to stenosis and finally occlusion of the subclavian vein, limiting the venous outflow of the $\operatorname{arm}^{41 ; 42}$. This results in venous hypertension in about $3 \%$ of the patients per year ${ }^{20 ; 39}$. Such patients will develop oedema of the arm, leading to discomfort and pain, impairment of fistula function and difficulties in cannulating the fistula and even chronic skin ulceration. The stenosis in the subclavian vein can be treated with percutaneous transluminal angioplasty (PTA) with or without a stent placement ${ }^{43}$, with a bypass ${ }^{44}$ or with jugular vein transposition ${ }^{45}$. If the obstruction can not be treated, the fistula can be left in situ or closed, depending on the magnitude of the complaints. To prevent these problems in patients to be placed on hemodialysis therapy, a permanent vascular access should be created before hemodialysis treatment is started. If this is not possible due to acute renal failure, jugular vein catheters should be preferred rather than subclavian vein catheters ${ }^{46}$.

\section{Seroma}

Seroma due to excessive plasma leakage of the graft occurs in about $0.5 \%$ of the implanted PTFE grafts ${ }^{47}$. It can be localised at one spot in the graft, possibly due to a manufacturing fault with increased porosity of the graft, or include the entire prosthesis due to an infiltrative response of the patient, with inadequate ingrowth of the prosthesis. 
Localised seromas can be excised in combination with repair of the graft with a patch. Generalised seroma demands removal of the complete graft and creation of a new fistula.

\section{Ischemia}

A rare but serious complication is limb ischemia distal from the fistula.

This is usually not seen in BC fistulas due to the good collateral circulation distal from the fistula. In $1-8 \%$ of the patients with PTFE graft AV fistulas ischemia of the hand will develop during dialysis, during exercise or continuously ${ }^{20 ; 24 ; 26 ; 33 ; 39}$. This is due to a higher flow and less adequate collaterals. Banding of the fistula can be performed to reduce the flow through the fistula, and to augment the flow to the distal tissues. If the complaints persist, the fistula must be sacrificed, since ischemic complications may lead to amputation of one or more digits and may seriously invalidate the patient.

\section{Neurologic complications}

Ischemia can lead to ischemic monomelic neuropathy. This presents as a severe, acute and painful weakness of the distal extremity with wristdrop, minimal wrist flexion and absence of activation of intrinsic musculature of the hand. It is caused by peripheral nerve ischemia, and it is often irreversible at the time of recognition ${ }^{39}$. Single nerve impairment can be caused by compression due to a hematoma, an abscess or an aneurysm. Another neurologic complication, more frequently seen in the hemodialysis population than in the normal population, is carpal tunnel syndrome. Compression of the median nerve at the wrist can develop due to elevated venous pressure, alterations in local hemodynamics and thickening of flexor synovium ${ }^{48}$.

\section{Cardiac failure}

An AV fistula for hemodialysis can produce a flow of up to $2 \mathrm{l} / \mathrm{min}$. This puts a great load on the cardiac function, especially since most hemodialysis patients already have a compromised cardiovascular status because of accelerated atherosclerosis. A large fistula flow can induce cardiac failure. This complication occurs in less than $1 \%$ of the hemodialysis patients per year ${ }^{24}$. Banding of the fistula can reduce the flow. If this fails, a permanent venous catheter should be considered rather than an AV fistula.

\section{Cuff technique}

Low flow and thrombotic occlusion due to stenosis are major problems, not only in vascular access surgery, but in all vascular interventions. Occlusion of peripheral arterial bypasses in the leg between one month and 2 years after implantation are usually attributed to graft-related stenoses and many of these can be ascribed to intimal hyperplasia ${ }^{49}$. Improvement of the patency of femoro-distal bypasses has been 
achieved with the construction of various types of venous cuffs and patches at the distal anastomosis. Most clinical experience has been accomplished with the Miller cuff, with good results reported in retrospective studies from different centres ${ }^{50-52}$. The Taylor patch, although hemodynamically more attractive, is only reported by Taylor himself $^{53-56}$. The St Mary's booth, described by Tyrrell and Wolfe, seems hemodynamically to be the most convenient ${ }^{57}$. In a pilot study using the St Mary's booth at the venous anastomosis of PTFE graft AV fistulas for hemodialysis, the incidence of occlusions and of stenoses at the anastomosis, as measured with Duplex ultrasonography, was reduced ${ }^{58}$.

\section{Methods of vascular access examination}

The arteriovenous fistula is the lifeline for the hemodialysis patient and maintenance of these fistulas is of the utmost importance. Since AV fistula function can deteriorate, frequent monitoring of the fistula might be useful. If complications are detected early, intervention may prevent fistula failure and prolong its patency ${ }^{59}$.

There are different methods currently used to monitor the function of vascular accesses. The most widely used method of surveillance of AV fistulas is angiography. Through a needle inserted in the fistula, contrast is injected with a proximal occluding cuff inflated to a suprasystolic pressure. The arterial tract will thus fill retrograde. Next, the cuff is released to visualise the venous outflow tract. After angiography, the patient is dialysed to remove the contrast ${ }^{60}$. Although angiography provides reasonable information on the anatomy of the fistula and stenoses, angiography is difficult to perform routinely and is only done on indication because of the need to use contrast medium and because of logistic difficulties.

As an alternative, Duplex ultrasonography of the fistula is becoming increasingly popular. Not only anatomical information is obtained, but also blood velocity and volume flow can be attested. The results and reproducibility of these measurements strongly depend on the experience of the vascular technologist performing the Duplex ultrasonography ${ }^{61 ; 62}$.

Venous pressure measurements have been proposed as an indicator for stenosis development ${ }^{28}$. If a stenosis in the fistula becomes more severe, the outflow is hampered and venous pressure will rise. The measurements are cheap and simple, since dialysis devices are standard equipped with a transducer that continuously measures the pressure in the venous needle. A number of different techniques and types of venous pressure measurements have been developed over the years $^{29 ; 63}$. However, venous pressure in the fistula does not only depend on the outflow resistance, but also on a number of other conditions, like central blood pressure. Therefore, its clinical importance is sometimes questioned $^{30 ; 64}$.

Low flow is a known risk for fistula occlusion. If the fistula flow is too low 
to deliver the required quantity of blood to the dialyser pump antegrade, retrograde flow will occur between the needles, called recirculation. This decreases the efficacy of the hemodialysis treatment.

Recirculation is usually calculated from urea concentrations in blood samples taken upstream and downstream of the artificial kidney and in a peripheral sample ${ }^{65-68}$. Although this method is rather simple, more and more doubt on its usefulness to signal early fistula malfunction is expressed, because recirculation probably occurs infrequently and only when fistula flow is extremely low $^{6 ; 70}$.

Recently, magnetic resonance imaging (MRI) has been proposed to measure fistula flow and to develop an image of the fistula ${ }^{71-73}$. Although the results are promising, data about the cost-effectiveness are not yet published.

The latest invention on fistula function surveillance is the Transonic Hemodialysis Monitor (HDM) ${ }^{74-76}$. This device uses an ultrasound dilution technique based on the difference in ultrasound characteristics of blood and saline. Ultrasound probes are clipped on the hemodialysis lines and produce a dilution curve of a bolus of saline, injected into the efferent hemodialysis line and returning into the afferent hemodialysis line. With this technique, fistula flow and recirculation can be measured easily. The early results are promising, but its value in clinical practise is still to be proven ${ }^{76-78}$.

Angiography, MRI and Duplex examination are difficult to perform routinely due to logistics and cost. If the HDM proves to be of clinical value, flow measurements every two weeks could be accomplished, while venous pressure and recirculation measurements could be obtained every hemodialysis treatment to monitor fistula function.

\section{Objectives and outline of this thesis}

This thesis will focus on the effects of alterations in graft geometry at the site of the venous anastomosis on the development of intimal hyperplasia in PTFE graft AV fistulas. Our hypothesis is that intimal hyperplasia occurs due to compliance mismatch and high shear stress. $A$ venous cuff at the venous anastomosis of PTFE graft AV fistulas would lead to a better transition of compliance and a reduced shear stress. This would induce less intimal hyperplasia and a better patency rate. Moreover, low flow reduces the shear stress occurring at the anastomosis and would also reduce the development of intimal hyperplasia. We hypothesised that

1. flow reduction in PTFE graft fistulas reduces shear stress near the venous anastomosis and the development of intimal hyperplasia,

2. a venous cuff at the venous anastomosis of PTFE graft AV fistulas reduces the compliance mismatch and reduces the shear stress at the venous anastomosis,

3. a venous cuff at the venous anastomosis of PTFE graft AV fistulas reduces the development of intimal hyperplasia and improves the 
patency rates.

Because of the results of the pilot study and the presumed hemodynamic better design of the St Mary's booth, we decided to use this type of cuff for our research project. To establish the magnitude of the problem, a survey of vascular access and surveillance practice in the Netherlands has been conducted. The effects of local vessel wall compliance and shear stress on the development of intimal hyperplasia was studied in an animal model, using a venous cuff at different flow levels. We also studied the hemodynamic changes that occur in an animal model after the construction of a venous cuff at the venous anastomosis of PTFE graft AV fistulas as compared to the direct anastomosis. To investigate the effect of a venous cuff at the venous anastomosis on the incidence and the development of intimal hyperplasia in PTFE graft AV fistulas in chronic hemodialysis patients, a randomised multicenter clinical study has been conducted. We analysed the effect of a venous cuff on the number of thrombotic complications and on the primary and secondary patency rates of the fistulas.

\section{Reference List}

1. Ramsteijn PG, Geerlings W, Krediet RT, Tjandra YI, de Charro FTh. Newsletter Registration Renal Replacement Therapy The Netherlands (Renine). 4, 1-28. 1996.

Rotterdam, Stichting Renine.

2. Kolff WJ, Berk HTJ, ter Welle M. The artificial kidney: a dialyzer with a great area. Acta Med.Scand. 1944;117:121131.

3. Quinton WE, Dillard DH, Scribner BH. Cannulation of blood vessels for prolonged hemodialysis. Trans.ASAIO 1960;6:104-113.

4. Brescia MJ, Cimino JE, Appel K, Hurwich BJ. Chronic hemodialysis using venipuncture and a surgicaliy created arteriovenous fistula. New Eng.J.Med. 1966;275:1089-1092.

5. Bay $W H$, van Cleef $S$, Owens $M$. The hemodialysis access: preferences and concerns of patients, dialysis nurses and technicians, and physicians. Am.J.Nephrol. 1998;18:373-378.

6. Gracz $K$, Ing $T$, Soung $L$, Armbruster $K$, Seim S, Merkel F. Proximal forearm fistula for maintenance hemodialysis. Kidney Int. 1977;11:71-74.

7. Knippenberg B, Geerlings W. Arteriovenous axillo-axillary PTFE (Gore-Tex) shunts after multiple access failures (thoraxloop). In: Bourquelot P, Angioaccess for hemodialysis. Proceedings of the
International Multidisciplinary Symposium held at Tours, France, June 3-5 1996. Paris: Gambro \& Guerbet, 1997;329.

8. May J, Tiller D, Johnson J, Steward J, Shell AG. Saphenous vein arteriovenous fistula in regular dialysis treatment. N.Engl.J.Med.1969;280:770.

9. Valenta J, Bilek J, Opantrnry K. Autogenous saphenous vein grafts as secondary vascular access for hemodialysis. Dial.Transplant. 1985;

10. Coburn MC, Carney WI. Comparison of basilic vein and polytetrafluoroethylene for brachial arteriovenous fistula. J.Vasc.Surg. 1994;20:896-902.

11. Rivers $S$, Scher L, Sheehan E, Lynn R, Veith $F$. Basilic vein transposition: an underused autologous altemative to prosthetic dialysis angioaccess. J.Vasc.Surg. 1993;18:391-397.

12. Hatjibaloglou $A$, Grekas $D$, Saratzis $N$, et al. Transposed basilic vein-brachial arteriovenous fistula: an alternative vascular access for hemodialysis. Artif.Organs 1992;16:623-625.

13. Chinitz JL, Tokoyama T, Brower R, Swartz $\mathrm{C}$. Self-sealing prosthesis for arteriovenous fistula in man. ASAIO Trans. 1972;18:452-457.

14. Haimov M, Jacobson JH. Experience with modified bovine arterial heterografting peripheral vascular 
reconstruction and vascular access for hemodialysis. Ann.Surg.1974;180:291295.

15. Masselot JP, Bonnaud P, Ciancioni $\mathrm{C}$, Claude JM, Zingraff J, Crosnier J. Blood access in haemodialysis: long term results. Proc.EDTA 1977;14:633634.

16. Bonnaud $P$, Messier D, Man NK. Manufactured homologous vein graft for creation of arterio-venous fistula. Proc.EDTA 1980;17:303-305.

17. Dardik HD, Ibrahim IM, Sprayregen $S$, Dardik II. Clinical experience with modified human umbilical cord vein for arterial bypass. Surgery 1976;79:618-624.

18. Flores L, Dunn I, Frumkin E, et al Dacron arterio-venous shunts for vascular access in hemodialysis. Trans.ASAIO 1973;19:33-37.

19. Baker LD, Johnson JM, Goldfarb D. Expanded polytetraftuoroethylene (PTFE) subcutaneous arteriovenous conduit: an improved vascular access for chronic hemodialysis.

Trans.ASAIO 1976;22:382-387.

20. Tordoir J, Herman J, Kwan TS, Diderich PM. Long-term follow-up of the polytetrafluoroethylene (PTFE)prosthesis as an arteriovenous fistula for haemodialysis.

Eur.J.Vasc.Surg.1988;2:3-7.

21. Albers FJ. Causes of hemodialysis access failure. Adv.Ren.Repl.Ther. 1994:1:107-118.

22. Bosman PJ, Blankestijn PJ, Graaf Yvd, Heintjes RJ, Koomans HA, Eikelboom $B C$. A comparison between PTFE and denatured homologous vein grafts for hemodialysis access: a prospective randomised multicentre trial.

Eur.J.Vasc.Endovasc. Surg. 1998;16:126-132.

23. Feldman HI, Held PJ, Hutchinson JT, Stoiber E, Hartigan MF, Berlin JA. Hemodialysis vascular access morbidity in the United States. Kidney Int. 1993;43:1091-1096.

24. Porter JA, Sharp WV, Walsh EJ. Complications of vascular access in a dialysis population. Curr.Surg. 1985;298-300.

25. Nakagawa $Y$, Ota $K$, Sato $Y$, Fuchinoue S, Teraoka S, Agishi T. Complications in blood access for hemodialysis.
Artif.Organs 1994;18:283-288.

26. Zibari GB, Rohr MS, Landreneau MD, et al. Complications from permanent hemodialysis vascular access. Surgery 1988;104:681-686.

27. Aman LC, Levin NW, Smith DW. Hemodialysis access site morbidity. Proc.Dial.Transpl.Forum 1980;10:277284.

28. Schwab SJ, Raymond JR, Saeed M, Newman GE, Dennis PA, Bollinger RR. Prevention of hemodialysis fistula thrombosis. Early detection of venous stenoses. Kidney Int. 1989;36:707-711.

29. Besarab A, Sullivan KL, Ross RP, Moritz MJ. Utility of intra-access pressure monitoring in detecting and correcting venous outlet stenosis prior to thrombosis. Kidney Int. 1995;47:1364-1373.

30. Bosman PJ, Boereboom FTJ, Eikelboom BC, Koomans HA, Blankestijn PJ. Graft flow as a predictor of thrombosis in hemodialysis grafts. Kidney Int. 1998;54:1726-1730.

31. Kraiss LW, Clowes AW. Response of the arterial wall to injury ant intimal hyperplasia. In: Sidawy AN, Sumpio BE, DePalma RG, Armonk NY, eds. The basic science of vascular disease. Futura Publishing Company Inc., 1997;289-317.

32. Palder SB, Kirkman RL, Whittemore AD, Hakim RM, Lazarus JM, Tilney NL. Vascular access for hemodialysis. Patency rates and results of revisions. Ann.Surg. 1985;202 :235-239.

33. Bartlett ST, Schweitzer EJ, Roberts $\mathrm{JE}$, et al. Early experience with a new ePTFE vascular prosthesis for hemodialysis. Am.J.Surg. 1995; 170:118-122.

34. Kherlakian $\mathrm{GM}$, Roedersheimer $\mathrm{LR}$, Arbaugh JJ, Newmark KJ, King LR. Comparison of autogenous fistula versus expanded polytetrafluoroethylene graft fistula for angioaccess in hemodialysis. Am.J.Surg. 1986;152:238-243.

35. Guillou P, Leveson S, Kester R. The complications of arteriovenous grafts for vascular access. Br.J.Surg. 1980;67:517-521.

36. Giacchino JL, Geis WP, Wittenstein $\mathrm{BH}$, Gandhi VC. Recent trends in 
vascular access. Am.Surg. 1982:48:501-504.

37. Bhat DJ, Tellis VA, Kohlberg WI, Driscoll B, Veith FJ. Management of sepsis involving expanded polytetrafluoroethylene grafts for hemodialysis access. Surgery 1980;87:445-450.

38. Adams MB, Johnson CP, Roza AM. Complications of vascular access. In: Bernhard VM, Towne JB, eds. Complications in Vascular Surgery. St.Louis, Missouri.: Quality Medical Publishing Inc., 1991;389-402.

39. Ballard JL, Bunt TJ, Malone JM. Major complications of angioaccess surgery. Am.J.Surg. 1992;164:229-232.

40. McMullen K, Hayes D, Hussey JL, Boudreaux JP. Salvage of hemodialysis access in infected arteriovenous fistulas. Arch. Surg. 1991;126:1303-1305.

41. Schwab SJ, Quarles LD, Middleton JP. Hemodialysis-associated subclavian. vein stenosis. Kidney Int. 1988;33:1156-1159.

42. Clarck DD, Albina JE, Chazan JA. Subclavian vein stenosis and thrombosis: a potential serious complication in chronic hemodialysis patients. Am.J.Kidn.Dis. 1990;15:265268.

43. Newman GE, Saeed M, Himmelstein S, Cohen RH, Schwab SJ. Total central vein obstruction: resolution with angioplasty and fibrinolysis. Kidney Int. 1991;39:761-764.

44. Piotrowski JJ, Rutherford RB. Proximal vein thrombosis secondary to hemodialysis catheterization complicated by arteriovenous fistula J.Vasc.Surg. 1987; 5:876-878.

45. Tordoir JHM, Leunissen KML. Jugular vein transposition for the treatment of subclavian vein obstruction in haemodialysis patients. Eur.J.Vasc. Surg. 1993;7:335-338.

46. Cimochowski GE, Worley E, Rutherford WE, Sartain J, Blondin J, Harter $H$. Superiority of the internal jugular over the subclavian access for temporary dialysis. Nephron 1990;54:154-161.

47. Borrero E, Doscher W. Chronic perigraft seromas in PTFE grafts. J.Cardiovasc. Surg. 1988;29:46-49.
48. Redfern AB, Zimmerman NB. Neurologic and ischemic complications of upper extremity vascular access for dialysis. J.Hand Surg. 1995;20A:199-204.

49. Tyrrell MR, Wolfe J. Vein collars make femorocrural grafts worthwhile. In: Greenhalgh R, Collier L, eds. The maintenance of arterial reconstruction. London: WB Saunders Co Ltd, 1991;45-55

50. Miller JH, Foreman RK, Ferguson L, Faris I. Interposition vein cuff for anastomosis of prosthesis to small artery. Aust.N.Z.J.Surg. 1984;54:283285.

51. Harris PL, Bakran A, Enabi L, Nott DM. ePTFE grafts for femoro-crural bypass--improved results with combined adjuvant venous cuff and arteriovenous fistula?

Eur.J.Vasc.Surg. 1993;7:528-533.

52. Raptis $\mathrm{S}$, Miller $\mathrm{JH}$. influence of a vein cuff on polytetrafluoroethylene grafts for primary femoropopliteal bypass. Br.J.Surg. 1995;82:487-491.

53. Taylor RS, Loh A, McFarland RJ, Cox $\mathrm{M}$, Chester JF. Improved technique for polytetrafiuoroethylene bypass grafting: long-term results using anastomotic vein patches. Br.J.Surg. 1992;79:348-354.

54. Loh A, Chester JF, Taylor RS. PTFE bypass grafting to isolated popliteal segments in critical limb ischemia. Eur.J.Vasc.Surg. 1993;7:26-30.

55. Taylor RS, McFarland RJ, Cox MI. An investigation into the causes of failure of PTFE grafts. Eur.J.Vasc.Surg. 1987;1:335-343.

56. Taylor RS. Les pontages prothétiques: pouvons-nous améliorer les résultats. J.Mal. Vasc. 1991;16:18-22.

57. Tyrrell MR, Wolfe J. New prosthetic venous collar anastomotic technique: combining the best of other procedures. Br.J.Surg. 1991;78:1016-1017.

58. Lemson MS, Tordoir JHM, Hofstra L, Leunissen KML. Veneuze cuffs bij PTFE arterioveneuze fistels voor hemodialyse. Ned.Tijdschr.Heelk. 1995;4:79-84.

59. Roberts AB, Kahn MB, Bradford S, et al. Graft surveillance and angioplasty prolongs dialysis graft patency. J.Am.Coll.Surg. 1996;183:486-492 
60. Staple TW. Retrograde venography of subcutaneous arteriovenous fistulascreated surgically for hemodialysis. Radiology 1973;106:223-224.

61. Tordoir $\mathrm{J}$, de Bruin $\mathrm{HG}$, Hoeneveld $\mathrm{H}$, Eikelboom BC, Kitslaar P. Duplex ultrasound scanning in the assessment of arteriovenous fistulas created for hemodialysis access: comparison with digital subtraction angiography. J.Vasc. Surg. 1989;10:122-128.

62. Middleton WD, Picus DD, Marx MV, Melson GL. Color Doppler sonography of hemodialysis vascular access: comparison with angiography. Am.J.Roentgenol. 1989;152:633-639.

63. Van Stone JC, Jones M, Van Stone J. Detection of hemodialysis access outlet stenosis by measuring outlet resistance. Am.J.Kidney Dis. 1994;23:562-568.

64. Besarab A, Dorrell S, Moritz M, Michael $H$, Sullivan K. Determinants of measured dialysis venous pressure and its relationship to true intra-access venous pressure. ASAIO Trans. 1991;37:M270-1.

65. Kobrin SM, Kriger FL, Raja RM. Measurement of hemodialysis access recirculation: a two-needle method at the start of dialysis. ASAIO.Trans. 1989;35:508-510.

66. Pederson JA, Dunlay R, Williams C, Llach $F$. Two-needle calculation of recirculation compared with the standard three-needle method. Clin.Nephrol. 1990;33:203-206.

67. Gibson S, von Albertini B, Bosch J. Reproducible measurement of recirculation without peripheral venipuncture. Kidney Int. 1990;37l:297-297.

68. Hosni N, Caillette A, Baretto S, Gimenez E, Labeeuw M. Evaluating the recirculation in hemodialysis without peripheral venipuncture. Clin.Nephrol. 1991;35:235-235.

69. Sherman RA, Levy SS. Assessment of a two-needle technique for the measurement of recirculation during hemodialysis. Am.J.Kidney Dis. 1991;18:80-83.

70. Tattersall JE, Farrington $\mathrm{K}$, Raniga $\mathrm{PD}$, et al. Haemodialysis recirculation detected by the three-sample method is an artefact. Nephrol.Dial.

Transplant. 1993;8:60-63.

71. Oudenhoven LF, Pattynama PM, De Roos A, Seeverens HJ, Rebergen SA, Chang PC. Magnetic resonance, a new method for measuring blood flow in hemodialysis fistulae. Kidney int. 1994;45:884-889.

72. Waldman GJ, Pattynama PM, Chang PC, Verburgh C, Reiber JH, De Roos A. Magnetic resonance angiography of dialysis access shunts: initial results. Magn.Reson.Imaging 1996;14:197200.

73. Bakker CJ, Bosman PJ, Boereboom FT, Blankestijn PJ, Mali WP.

Measuring flow in hemodialysis grafts by non-triggered 2DPC magnetic resonance angiography. Kidney Int. 1996;49:903-905.

74. Krivitski NM, Bosch JP, Barlee V, Valdecasas JG. Theory and validation of access flow measurement by dilution technique during hemodialysis Blood flow measurement during hemodialysis. Kidney Int. 1994;1:8388.

75. Krivitski NM. Novel method to measure access flow during hemodialysis by ultrasound velocity dilution technique. ASAIO.J. 1995:41:M741-M745.

76. Depner TA, Krivitski NM. Clinical measurement of blood flow in hemodialysis access fistulae and grafts by ultrasound dilution. Am.J.Kidney Dis. 1995;41:M745M749.

77. Sands JJ, Glidden D, Miranda C Hemodialysis access flow measurement: Comparison of ultrasound dilution and Duplex ultrasonography. J.Am.Soc. Nephrol. 1996;42:M899-M901.

78. Bosman PJ, Boereboom FTJ, Bakker CJG, et al. Access flow measurements in hemodialysis patients. J.Am.Soc.Nephrol. 1996;7:966-96. 


\section{Hemodialysis vascular access and fistula surveillance methods in the Netherlands

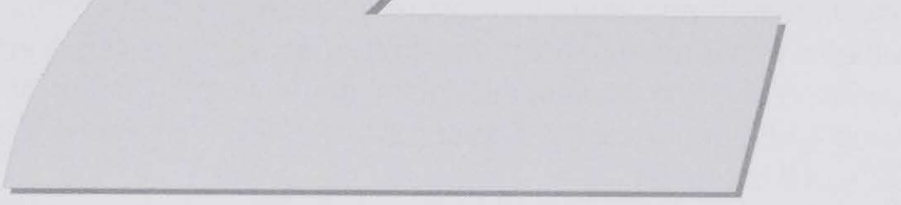

R. Ezzahiri ${ }^{1}$, M.S. Lemson ${ }^{1,3}$, P.J.E.H.M. Kitslaar ${ }^{1,3}$, K.M.L. Leunissen ${ }^{2,3}$, J.H.M. Tordoir, ${ }^{1,3}$.

Departments of ${ }^{1}$ Surgery and ${ }^{2}$ Nephrology, University Hospital Maastricht, ${ }^{3}$ Cardiovascular Research Institute Maastricht (CARIM), The Netherlands. 


\section{Abstract}

Introduction. As the mean age of hemodialysis patients is increasing, fewer patients will have suitable blood vessels for the creation of a Brescia-Cimino (BC) fistula and an increased use of graft implants is to be expected.

Methods. To assess the change in vascular access and the use of surveillance techniques, all hemodialysis centres in the Netherlands received a questionnaire regarding the types of vascular accesses and surveillance techniques used in their department on 31-12-1996. The results were related to a comparable study done in 1987, shown between brackets.

Results. The response of the hemodialysis staff was $96 \%$, and that of the vascular surgeons was $91 \%$. Sixty-two percent $(70 \%)$ of the patients had Brescia-Cimino fistulas, 21\% (13\%) had Polytetrafluoroethylene (PTFE) graft AV fistulas and $17 \%(17 \%)$ had other vascular accesses. Scheduled surveillance for stenosis detection was done by recirculation measurements in $6 \%$, venous pressure measurements in $31 \%$, Duplex scanning in $11 \%$ and angiography in $11 \%$ of the centres. When access problems occurred, $79 \%$ of the physicians performed recirculation measurements, $38 \%$ venous pressure measurements, $79 \%$ Duplex scanning and $100 \%$ angiography. In $46 \%$ of the centres PTA was done occasionally, and in $46 \%$ routinely for the treatment of stenotic complications in arteriovenous fistulas.

Conclusions. The use of PTFE grafts has increased at the expense of BC fistulas. Recirculation and venous pressure measurements are primarily done when problems occur and not according to a standard surveillance schedule. For visualisation of failing fistulas, $79 \%$ of the centres uses Duplex ultrasound analysis and $100 \%$ angiography. The popularity of PTA has increased from $46 \%$ to $92 \%$ of the centres. 


\section{Introduction}

Patients with end-stage renal failure require permanent vascular access for hemodialysis treatment. Renal transplantation is the ultimate therapy for patients with renal insufficiency. However the number of patients on the waiting list for kidney transplantation in The Netherlands is still increasing, from 883 in 1992 to 1005 in 1996 . Moreover, not all patients are eligible for transplantation. This results in 4128 patients with end-stage renal failure, 2955 of which depend on hemodialysis treatment ${ }^{1}$. Therefore maintenance of a functional vascular access for these patients remains essential ${ }^{2 ; 3}$. Due to the ageing of the Dutch population, more elderly patients with endstage renal disease are referred to the physician. With the improvements in hemodialysis techniques these older patients can be included in the hemodialysis program as well. As a result the hemodialysis population will increase both in age and in number. In the Netherlands the number of dialysis patients older than 75 years increased with $9.7 \%$ in 1996 compared to an increase of the total hemodialysis population of $3.4 \%{ }^{4}$. Older patients have more co-morbidities, like cardiovascular diseases and diabetes mellitus, and consequently an increase of vascular access problems due to poor vessels can be expected.

The Brescia-Cimino (BC) fistula remains the arteriovenous (AV) fistula of first choice $^{3-5}$. However due to the higher age of the hemodialysis patient population an increased need for secondary accesses like graft AV fistulas can be expected. Graft AV fistulas are known to have more thrombotic complications compared to $\mathrm{BC}$ fistulas ${ }^{2}$, and also a higher risk on infection and a lower patency rate. Early detection of failing grafts by means of a program of surveillance with subsequently elective intervention to prevent thrombotic occlusion, might have a favourable effect on the patency of these secondary access sites ${ }^{6 ; 7}$.

In the USA, more PTFE graft AV fistulas are implanted nowadays than BC fistulas ${ }^{8}$. To assess whether a change in $A V$ fistula type from native to graft AV fistulas has also occurred in the Netherlands, a questionnaire was distributed to all centres of renal replacement therapy (RRT). The results were compared with a similar survey done in $1987^{9}$. Also the number of complications, the types of interventions and methods of AV fistula surveillance were registered.

\section{Methods}

Two different types of questionnaires were mailed to all 52 dialysis centres in The Netherlands ( 8 academic dialysis centres, 38 dialysis centres in general hospitals and 6 other centres), one to the staff of the dialysis department and another to the surgeons.

The first questionnaire regarded the number of patients receiving hemodialysis treatment and the different types of vascular accesses used on December 31,1996 . The number of patients receiving single needle dialysis was recorded. The use of catheters (single lumen, double lumen and insertion location) was assessed along with the types and methods of fistula 


\section{Vascular access in the Netherlands}

surveillance (venous and/or arterial pressure measurements, recirculation measurements, Duplex scanning and angiography). The results of this questionnaire were compared to the results of a similar study, done in 1987 $(100 \% \text { response })^{9}$. The change in use of different accesses over time was analysed with the Chi-square test. A p-value of $<0.05$ was considered statistically significant.

A second questionnaire, to the surgeons performing fistula surgery, registered the number and types of new vascular access operations over the year 1996. The number of surgeons performing vascular access operations was noticed. The number of reinterventions performed on the different types of vascular accesses was assessed, as well as the number of Percutaneous Transluminal Angioplasties (PTA). The surgeon's first and second choice treatment of access stenosis was asked.

The total number of patients on RRT, their age distribution, the number of patients having diabetes mellitus and the mortality rates were retrieved from the newsletter of Renine (registration of kidney replacement therapy in the Netherlands).

\section{Results}

Ninety-six percent of the dialysis department staff and ninety-one percent of the surgeons responded to the questionnaires.

\section{Demography}

A total of 8283 patients were undergoing RRT in 52 centres. Of these patients, 2864 were on long-term hemodialysis (HD) and 1173 were on Continuous Ambulant Peritoneal Dialysis (CAPD) or on Continuous Cyclic Peritoneal Dialysis (CCPD). Ninety-one patients were receiving HD treatment at home and 4155 patients had a good functioning donor kidney, either from a postmortal donor or a living donor (table 2.1) $)^{4}$.

In the age group of $0-44$ years there were 868 patients $(21 \%)$ receiving dialysis therapy, in the age group of 45-64 years 1527 patients (37\%), and in the age group of 65 years and older there were 1733 patients $(42 \%)$ receiving dialysis therapy ${ }^{4}$. The total number of patients from all age groups does not correspond with the total number of the dialysis population, because the age of several patients in the Renine statistical report was unknown (table 2.2). From 1987 to 1996, the number of patients

Table 2.1

Types of Renal Replacement Therapy (RRT) in 1996 in the Netherlands.

\begin{tabular}{lc}
\hline Types of RRT & Number of patients \\
\hline long term hemodialysis & 2864 \\
CAPD+CCPD & 1173 \\
hemodialysis at home & 91 \\
functioning kidney transplant & 4155 \\
\hline total RRT & 8283 \\
\hline
\end{tabular}




\begin{tabular}{lcc}
\hline Age groups & Number of patients in 1987 (\%) & Number of patients in 1996 (\%) \\
\hline $0-44$ years & $724(26 \%)$ & $868(21 \%)$ \\
$45-64$ years & $1165(42 \%)$ & $1527(37 \%)$ \\
$\geq 65$ years & $898(32 \%)$ & $1733(42 \%)$ \\
\hline total & $2787(100 \%)$ & $4128(100 \%)$ \\
\hline
\end{tabular}

of 65 years and older has increased almost thrice as much as the number of patients in the age groups $45-64$ years and $0-44$ years (resp. $92 \%, 31 \%$ and $20 \%$ increase of the total number of patients). The outflow of patients on dialysis therapy was due to kidney transplantation or due to death. A total of 508 kidney transplantations were performed in 1996, 76 of living donors and 432 of postmortal donors. The mortality of patients on dialysis therapy has shown an increase from $16 \%$ in 1987 to $20 \%$ in 1996 . The main causes of mortality among the dialysis population were cardiac diseases $(34 \%)$, social causes $(14 \%)$, vascular diseases $(9 \%)$ and sepsis $(7 \%)$. The social causes meant that patients committed suicide, refused further dialysis treatment, or ended their treatment for other reasons.

Four-hundred-and-thirty patients receiving dialysis therapy (10\%) had Diabetes Mellitus (DM) as a primary cause of kidney failure, 251 had type I DM, 179 had type II DM. Other primary causes of kidney failure were renal vascular diseases, pyelonephritis, polycystic kidneys and glomerulonephritis ${ }^{4}$.

\section{Hemodialysis treatment and AV fistula surveillance techniques}

The single-needle hemodialysis treatment was never used in $79 \%$ of the patients, occasionally used in $7 \%$ of the patients and frequently used in $14 \%$ of the patients. In 1987 , these figures were $87 \%, 3 \%$ and $10 \%$ respectively. In $75 \%$ of the centres, the subclavian vein was the preferred location for temporary catheters, $16 \%$ of the centres used the jugular vein and $9 \%$ of the centres the femoral vein. Four centres had no preference for any of the different catheter locations. Fifty-four percent of the centres preferred double-lumen catheters and $46 \%$ single-lumen catheters. Two centres had no preference for single-lumen or double-lumen catheters. Eighty-nine percent of the centres used primarily polyurethane catheters and $11 \%$ of the centres used primarily silicone catheters.

In most HD centres no routine vascular access surveillance was performed. When AV fistula problems occurred, angiography was performed in all centres, $79 \%$ of the centres performed additional Duplex scanning or recirculation measurements and 38\% performed venous pressure (VP) measurements. Registration of the venous and/or arterial pressure during $\mathrm{HD}$ treatment at normal dialyser flow was common. However, measurement of a VP curve (using at least 3 different dialyser flows) was only used in 15\% 


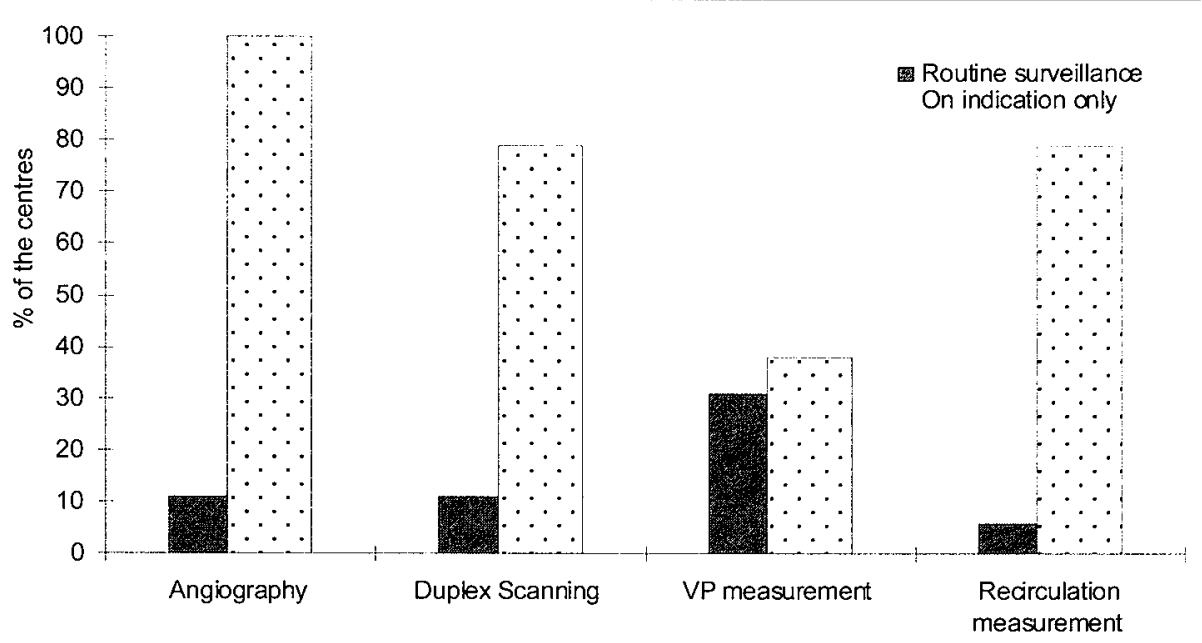

Figure 2.1 Percentage of dialysis centres using angiography, Duplex scanning, venous pressure (VP) measurements and recirculation measurements as routine surveillance and as diagnostic techniques on indication.

of the centres and the absolute VP (with dialyser flow is $0 \mathrm{ml} / \mathrm{min}$ ) was measured in $17 \%$ of the centres (fig 2.1).

\section{New vascular accesses in 1996 and interventions}

Of the new vascular accesses created in 1996, 916 (54\%) were BC fistulas, $503(30 \%)$ were PTFE grafts, 85 of which were Diastat ${ }^{\otimes}$ prostheses, $99(6 \%)$ were denatured homologous vein grafts (DHV), $91(6 \%)$ were elbow fistulas, $56(3 \%)$ were Scribner shunts, $19(1 \%)$ were autologous vein grafts (SVG) and three $(0.2 \%)$ were other vascular accesses.

A total of $1616(62 \%) \mathrm{BC}$ fistulas were indeed used on the hemodialysis unit, compared to $1517(70 \%) \mathrm{BC}$ fistulas in $1987(p<0.001)$. The number of PTFE graft AV fistulas increased from $274(13 \%)$ in 1987 to $552(21 \%)$ in $1996(p<0.001)$, while elbow fistulas decreased from $139(6 \%)$ in 1987 to $106(4 \%)$ in $1996(p<0.001)$. The use of DHV did not change from 1987 $(n=124,6 \%)$ to $1996(n=190,7 \%, p=N S)$. The number of SVG decreased from $63(3 \%)$ to $44(2 \%),(p<0.001)$. Other vascular accesses (including Scribner shunts) decreased from $53(2 \%)$ in 1987 to $7(0.3 \%)$ in 1996 $(\mathrm{p}<0.001$ ) (fig 2.2).

The vascular access operations were in $30 \%$ of the cases performed by one surgeon, in $56 \%$ by several surgeons, in $2 \%$ by any surgeon available and in $12 \%$ of the cases performed by residents.

Eight-hundred-and-fifty-six surgical interventions were needed to maintain the vascular access in a total of $\mathbf{4 7 2}$ vascular accesses. Homologous vein grafts had the highest number of interventions per vascular access (1.16 interventions per vascular access). In Diastat ${ }^{\oplus}$ grafts, 76 interventions were carried out (0.89 interventions per vascular access) and in PTFE grafts 302 interventions were performed ( 0.72 interventions per vascular access). 


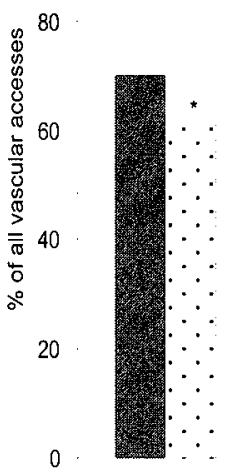

$\mathrm{BC}$

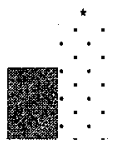

PTFE

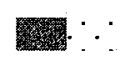

DHV $\cdot 31-12-96$

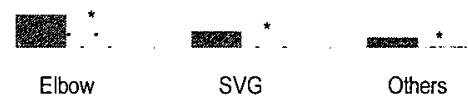

Figure 2.2 Percentage of different types of vascular accesses used on 31-12-1996 and on $31-12-1987 .{ }^{*}=$ significant change from 1987 to $1996(p<0.001)$.

Scribner shunts needed 39 interventions ( 0.70 interventions per vascular access), while autologous vein grafts ( 0.47 interventions per vascular access) and elbow fistulas (0.44 interventions per vascular access) underwent fewer interventions. BC fistulas needed the lowest number of operative interventions (289 interventions $=0.32$ interventions per vascular access) (table 2.3). Most physicians preferred PTA as treatment of first choice to maintain the AV fistulas, followed by patch-plasty and a jumpbypass. If PTA had failed, jump-bypasses were performed, followed by patch-plasty and other methods. PTA has been used in 402 instances. PTA was used in $46 \%$ of the centres regularly, in $46 \%$ occasionally and in $8 \%$ of the centres it was never used. This number is significantly higher than in 1987 , when only $36 \%$ of the centres used PTA regularly and $10 \%$ occasionally (fig 2.3 ).

Table 2.3 Percentage of operative intervention per type of vascular access in 1996.

\begin{tabular}{lcc}
\hline $\begin{array}{l}\text { Type of new created } \\
\text { vascular access in } 1996\end{array}$ & $\begin{array}{l}\text { Number of new created } \\
\text { vascular access in 1996 }\end{array}$ & $\begin{array}{l}\text { Number of interventions } \\
\text { (interventions per vascular access) }\end{array}$ \\
\hline Homologous veins & $99(6 \%)$ & $115(1.16)$ \\
Diastat ${ }^{\text {grafts }}$ & $85(5 \%)$ & $76(0.89)$ \\
PTFE prostheses & $418(25 \%)$ & $302(0.72)$ \\
Scribner shunts & $56(3 \%)$ & $39(0.70)$ \\
Autologous vein grafts & $19(1 \%)$ & $9(0.47)$ \\
Elbow fistulas & $91(6 \%)$ & $40(0.44)$ \\
BC fistulas & $916(54 \%)$ & $289(0.32)$ \\
\hline
\end{tabular}




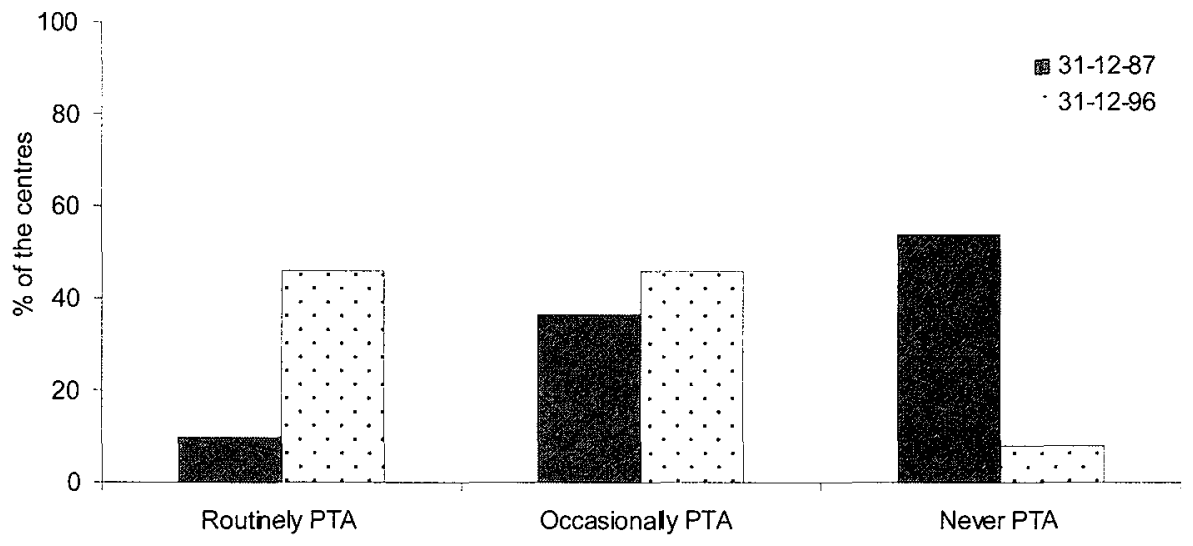

Figure 2.3 Percentage of dialysis centres using Percutaneous Transluminal Angioplasty (PTA) for the treatment of AV fistula stenoses routinely, occasionally and never on 31-12-1987 and on 31-12-1996.

\section{Discussion}

In the past decade the number of older dialysis patients ( $>65$ years), has increased significantly more compared to that of the younger patients. This can be explained by the fact that the average age of the Dutch population has increased. Also improvement of dialysis treatment has resulted in the inclusion of elderly patients into the dialysis programs. The percentage of Diabetes Mellitus as a primary cause of kidney failure among the dialysis population has increased from $7 \%$ in 1987 to $10 \%$ in 1996 . Diabetic patients are a difficult group for maintaining vascular access, because of comorbidities like cardiovascular and peripheral arterial diseases ${ }^{10-12}$. The upper extremity vessels of elderly patients are often not suitable for the construction of a primary AV fistula. Thus vascular access in this group of patients usually will be achieved with graft implantation, which leads to an increased usage of PTFE AV fistulas and a decrease in BC fistulas. This feature is supported by our findings that from 1987 until 1996 the use of PTFE prostheses significantly increased, while the number of $B C$ and elbow fistulas significantly decreased. The use of SVG and other vascular accesses (including Scribner shunts) decreased significantly as well. Scribner shunts are almost abolished due to numerous complications and the fact that it is unpractical for the patient. Moreover there are better alternatives available nowadays ${ }^{13}$.

Regarding vascular access usage, the situation in the USA is different from the situation in Europe. In the USA there are more graft implantations than native AV fistulas ${ }^{8}$. Recently Sands et al $^{14}$ reported an increase of the number and percentage of AV fistulas constructed with autologous material in their dialysis population. This increase was achieved through a concerted effort of nephrologists and access surgeons. Further studies are necessary to evaluate whether this increase will prolong access survival and decrease 
morbidity associated with access maintenance. The percentage of interventions per type of vascular access is higher in grafts compared to AV fistulas constructed with autologous material. This is due to the high incidence of stenosis, thrombosis, infection and wound complications in PTFE graft AV fistulas $2 ; 6 ; 15$.

Although routine surveillance and elective intervention can improve graft AV fistula patency ${ }^{6 ; 7}: 16 ; 17$, only few dialysis centres carry out a surveillance program. Most centres in the Netherlands rely on venous pressure measurements during hemodialysis treatment. If the venous pressure rises or other problems occur, all centres use diagnostic fistulography while $79 \%$ of the centres perform Duplex ultrasonography to detect and locate access stenosis. When stenosis occurs, most centres prefer PTA to correct it. The use of PTA as initial treatment of vascular access stenosis increased from $46 \%$ to $92 \%$ of the centres. If PTA fails or is not possible, a jump-graft or patch-plasty is performed depending on the location and length of the stenosis.

The results of our survey show an increase in single-needle hemodialysis from $13 \%$ in 1987 to $20 \%$ in 1996 . With the single-needle technique, recirculation may occur leading to less efficient hemodialysis treatment compared to the double-needle technique. Single-needle technique is mainly used when the double-needle method is not possible due to a short vessel traject for puncturing or refusal of the patient. The increased usage of singleneedle dialysis may indicate more problems with vascular access.

For central vein access more than half of the centres preferred double-lumen catheters. Double-lumen catheters cause less turbulence than single-lumen catheters, resulting in a decreased risk on stenosis. Less recirculation occurs with the double-lumen catheter ${ }^{18}$. Results from our survey showed that most centres prefer the subclavian vein to the jugular vein location for catheter insertion. It is well-known that subclavian vein catheters may cause subclavian vein stenosis, making the arm less suitable for later creation of AV fistulas. Venous hypertension, oedema, insufficient flow and thrombosis are important complications of subclavian vein stenosis. Some studies report a $90 \%$ stenosis rate due to subclavian vein catheters compared to no stenosis with jugular vein catheters ${ }^{19 ; 20}$. The subclavian vein catheter is still the most frequently used semipermanent access, because of the long-lasting experience gained with this catheter location. Furthermore, jugular vein catheters are inconvenient to the patient because of the location in the neck. Also the negative cosmetic effect of the jugular vein catheter compared to the subclavian catheter may play a role in preferring the subclavian vein location to the jugular catheter. Polyurethane and silicone catheters were used in most centres. The literature reports a lower incidence of subclavian vein stenosis with the use of silicone catheters compared to the use of polyurethane catheters (19\% versus $68 \%$ stenosis $)^{18}$. There are several advantages of silicone catheters over polyurethane catheters. They are more flexible and cause less kinking; also the damage of endothelium of the vessel wall is less severe and the incidence of infection is lower in silicone catheters compared to polyurethane catheters ${ }^{18}$. The main disadvantage of 
silicone catheters is the fact that they are more expensive than polyurethane catheters and difficult to insert.

\section{Conclusions}

The mean age of the dialysis population is increasing. This leads to an increased need for secondary access procedures. However, secondary accesses usually require more interventions to maintain their patency. Therefore BC fistulas should remain the vascular access of first choice. PTA as treatment for vascular access stenosis has doubled over nine years and is now used in most hemodialysis centres.

More attention should be paid to routine surveillance programs for the detection of stenosis and elective revisions to prevent graft thrombosis. Also the use of jugular vein catheters instead of subclavian vein catheters as an acute vascular access should be promoted.

\section{Acknowledgements}

All vascular access surgeons, nephrologists and hemodialysis personnel of the dialysis centres in the Netherlands are gratefully acknowledged for their participation. Furthermore we would like to thank the Renine foundation, which registers the patients on kidney replacement therapy in the Netherlands, for permitting us to use their data.

\section{Reference List}

1. Cohen B, Persein G, De Meester J. Kidney: donation, waiting lists and transplantation. Eurotranspl.Int. Found.Ann.Report 1996;27-63.

2. Palder $\mathrm{SB}$, Kirkman RL, Whittemore $A D$, Hakim RM, Lazarus JM, Tilney NL. Vascular access for hemodialysis. Patency rates and results of revisions. Ann. Surg. 1985;202:235-239.

3. Rohr MS, Browder W. Frentz GD, McDonald JC. Arteriovenous fistulas for long-term dialysis. Factors that influence fistula survival. Arch. Surg. 1978;113:153-155.

4. Ramesteijn DC, Geerlings W, Krediet RT, Tjandra YI, De Charro FTh. Registration Kidney replacement therapy, the Netherlands. Renine newsletter $1997 ; 4$.

5. Eikelboom BC. Which material should be used in secondary haemodialysis access surgery. Eur.J.Vasc.Surg. 1988;2:1-2.

6. Roberts $A B, K a h n M B$, Bradford $S$, Lee J, Ahmed Z, Fitzsimmons J, Ball D. Graft surveillance and angioplasty prolongs dialysis graft patency. J.Am. Coll. Surg. 1996;183:486-492.
7. Liou JY, Chiang $\mathrm{CH}$, Chang $\mathrm{CH}$, Hua J, Cheng J.The efficacy of percutaneous transluminal angioplasty in the treatment of failing vascular access in chronic hemodialysis patients. Chin.Med.J. 1996;58:335-340.

8. Hirth RA, Rurenne MN, Woods JD, Young EW, Port FK, Pauly MV, Held PJ. Predictors in type of vascular access in hemodialysis patients. JAMA 1996;276:1303-1308.

9. Burger $H$, Kootstra G, De Charro FTh, Leffers P. A survey of hemodialysis in The Netherlands. Nephr.Dial.Transplant. 1991;6:5-10.

10. Leehey DJ. Hemodialysis in the diabetic patient with end-stage renal disease. Review. Renal Failure 1994;16:547-553.

11. Zimmerman SW, Wakeen $M$, Armbrust M, Cole D, Kearney MA, Kalker A. Renal replacement therapy in diabetic nephropathy. Adv.Renal Repl.Th. 1994;1:66-74.

12. Friedlander MA, Hricik DE. Optimising end-stage renal disease therapy for the patient with diabetes mellitus. Sem.Nephr. 1997;17:331345. 
13. Alarabi $A$, Eklund $T$, Claesson $K$, Wilkstrom B, Danielson BG.

Experience with vascular access for acute renal failure: using Buselmeier shunt and femoral vessel catheter. Nephron 1991;58:192-195.

14. Sands J, Miranda CL. Increasing numbers of $A V$ fistulas for hemodialysis access. Clin.Nephr. 1997:48:114-117.

15. Taber TE, Maikranz PS, Haag BW, Gaylord GM, Diley RJ, Ehrman KO, Brown PB, Nelson DR, Kay DC, Roberts TL, Huse JM, Micon LT, Stevens LH. Maintenance of adequate hemodialysis access prevention of neointimal hyperplasia. ASAIO J. 1995;41:842-846.

16. Burger $\mathrm{H}$, Zijlstra JJ, Kluchert $S A$, Scholten AP, Kootstra G.

Percutaneous Transluminal Angioplasty improves longevity of arteriovenous shunts and fistulas for hemodialysis.

Nephrol.Dial.Transplant.1990;4:608611.

17. Hodges TC, Fillinger MF, Zwolak RM Walsh DB, Bech F. Longitudinal comparison of dialysis access methods: risk factors for failure. J.Vasc. Surg. 1997;26:1009-1019.

18. Beenen $L$, van Leusen $R$, Deenik $B$, Bosch FH. The incidence of subclavian vein stenosis using silicone catheters for hemodialysis. Artif. Org. 1994;18:289-292.

19. Cimochowski GE, Worley E, Rutherford WE, Sartain J, Blondin J, Harter $\mathrm{H}$. Superiority of the internal jugular over the subclavian access for temporary dialysis. Nephron 1990;54:154-161.

20. Leblanc M, Bosc JY, Pagani EP Canaud B. Central venous dialysis catheter dysfunction. Adv. Renal Repl.Ther.1997;4:377-389. 

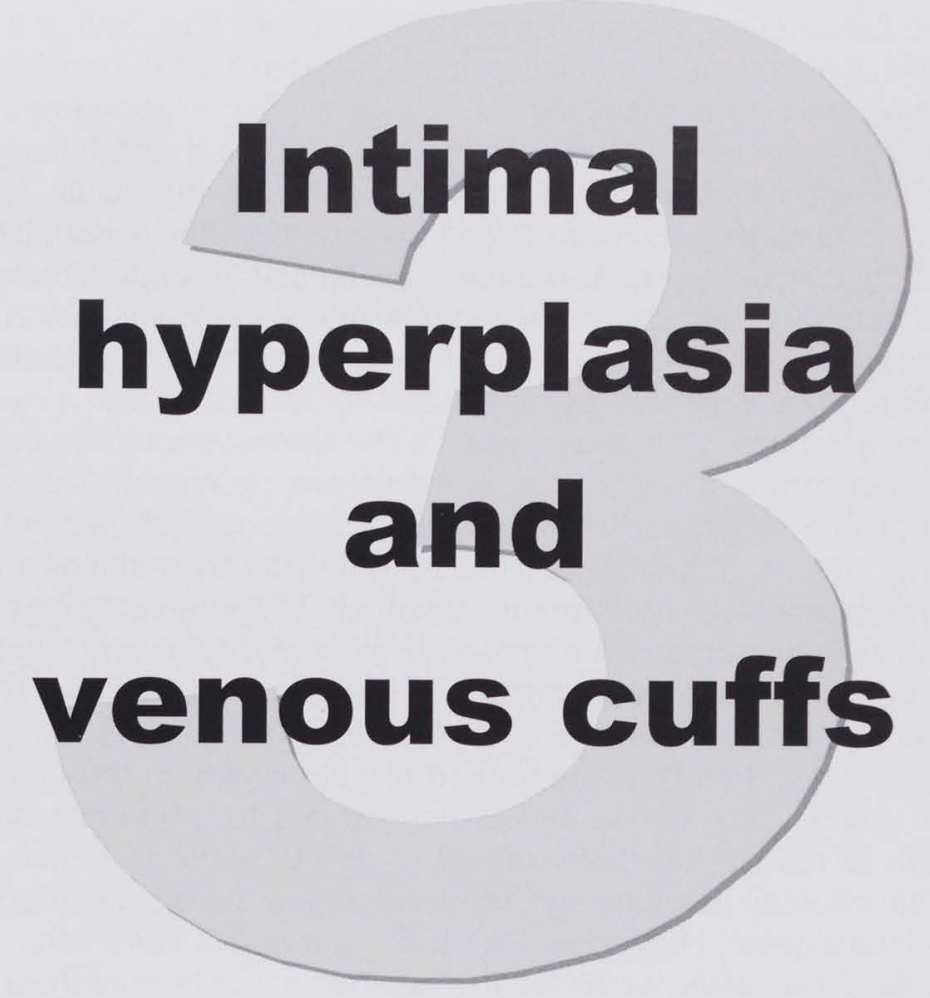

Parts of this chapter have been accepted for publication as: The influence of cuffs and patches on intimal hyperplasia in vascular prosthesis.

M.S. Lemson ${ }^{1,3}$, J.H.M. Tordoir ${ }^{1,3}$, M.J.A.P. Daemen ${ }^{2,3}$, P.J.E.H.M. Kitslaar $^{1,3}$

Departments of ${ }^{1}$ Surgery and ${ }^{2}$ Pathology, University Hospital Maastricht,

${ }^{3}$ Cardiovascular Research Institute Maastricht, The Netherlands. 


\section{Introduction}

The first report of anastomotic intimal thickening after transplantation of a vein into the arterial circulation was over 90 years ago: "within a few days after the operation, the stitches placed in making the anastomosis became covered with a glistening substance similar in appearance to the normal endothelium"1. Many reports have followed and intimal hyperplasia is now recognised as the main cause of thrombotic complications occurring between 2 and 24 months after a vascular intervention ${ }^{2}$. Intimal hyperplasia causes restenosis in approximately 30 to $50 \%$ of coronary and superficial femoral artery angioplasties, $20 \%$ of carotid endarterectomies, 20 to $30 \%$ of femoro-distal vein bypasses, 10 to $30 \%$ of coronary vein graft bypasses and 42 to $50 \%$ of the arteriovenous fistulas for hemodialysis ${ }^{2-8}$. The arteriovenous fistula is the lifeline for patients that depend on hemodialysis treatment. The incidence of thrombotic occlusion of these fistulas is 0.95 per patient year. Eighty percent of these occlusions are caused by a stenosis due to intimal hyperplasia $(\mathrm{IH})$. Furthermore, another 0.27 interventions per patient year are performed on stenoses to prevent occlusion'. Thus, intimal hyperplasia poses a significant impact on morbidity of hemodialysis patients and in the costs for treatment.

Extensive research has been performed to gain insight in the cell biology of intimal hyperplasia and to find targets for pharmacological intervention to reduce the development of $\mathrm{IH}$. Also, the influence of hemodynamic forces like flow and shear stress on the development of $\mathrm{IH}$ has been investigated. High as well as low shear stress has been indicated as a causative factor for $\mathrm{IH}$. Another possible contributing factor in the development of $\mathrm{IH}$ is mismatch in elastic properties between grafts and native vessels. Several anastomotic designs with the use of anastomotic cuffs and patches have been used over the years to influence the hemodynamic forces or to decrease the compliance mismatch. Although some constructs have had promising results with respect to improved patencies of peripheral bypass grafts ${ }^{10}$, the impact of intimal hyperplasia on all fields of vascular interventions remains high.

\section{The normal structure and function of a vein}

In the normal vein, the intima is composed of a thin layer of endothelial cells, beneath which is a fenestrated basement membrane, a subendothelial matrix of glycoproteins and connective tissue elements, and occasionally intimal cells. The internal elastic membrane is rudimentary, and the relative thin tunica media is composed of vascular smooth muscle cells (VSMC) arranged in two or more layers. Interlaced between the VSMC are bundles of collagen and elastic fibres. The adventitia forms the outer layer of a vein wall and is often thicker than the media and consists of a loose network of longitudinally orientated collagen bundles and scattered fibroblasts through which the vasa 
vasorum of the vein pass. The vasa vasorum of the veins form an anastomotic plexus that provides resistance to ischemic injury, that causes a local interruption of these vasa ${ }^{11 ; 12}$.

Veins appear to be highly susceptible to thrombosis, possibly through the lower blood velocity and hence lower shear stress in the venous circulation $^{13}$. Through its physical and chemical properties the venous endothelium provides an antithrombotic surface. The negative zeta potential or surface charge might play a role in preventing adherence of blood components and the secretory role of endothelium. Under physiological conditions, venous endothelium does not produce nitric oxide, but it does have a powerful fibrinolytic activity through the release of substances like urokinase-type plasminogen activator (UPA), tissue-type plasminogen activator (tPA) and prostacyclin. Other substances secreted by veins include bradykinin, angiotensin II, angiotensin I converting enzyme, adenonucleotides and endothelin 14; 15. The contraction of the human vein in response to noradrenaline and the relaxation in response to acetylcholine is dependent on the presence of normal venous endothelium ${ }^{16-18}$.

The compliance of the vein wall can be correlated with the intimal thickness of the vessel ${ }^{19}$. Pressure strain studies have shown veins to be highly compliant over the normal range of venous pressures, but relative inelastic, when exposed to normal arterial pressures ${ }^{20}$.

\section{Cell biology of intimal hyperplasia}

Intimal hyperplasia is thought to be due to a variety of injuries that always involve some endothelial damage ${ }^{21}$. It is composed of about $20 \%$ of vascular smooth muscle cells (VSMC) that have migrated from the media to the intima and have proliferated and deposited extracellular matrix, which comprises most (60-80\%) of the intimal area. Other components of the intima are macrophages and lymphocytes. The surface can be endothelialised or not, depending on the extent of and time passed since the initial damage ${ }^{21}$.

Research on the development of intimal hyperplasia is divided into two main regions: arterial restenosis after Percutaneous Transluminal Angioplasty (PTA) and intimal hyperplasia after implantation of a vascular graft. After grafting into the arterial circulation or after the creation of an arteriovenous fistula for vascular access, veins are exposed to very different hemodynamics than in the venous circulation. These altered conditions make models of femorodistal vein graft and vascular access intimal hyperplasia different from the arterial balloon injury models. However, it is generally thought that the sequence of events in vein grafts and prosthetic grafts is similar, but the events inducing the start of the sequence and the speed of development might be different ${ }^{12 ; 21 ; 22}$. Most of the research on the sequence of events that lead to intimal hyperplasia has been conducted in arterial balloon denudation models. 


\section{Intimal hyperplasia and venous cuffs}

First wave: VSMC proliferation in the media

Endothelial cell (EC) damage induces thrombus formation. Within 24 hours after thrombus formation, VSMC proliferation occurs. Normal endothelium produces factors like prostacyclin and heparan sulfate, which inhibit VSMC proliferation ${ }^{21}$. Damaged endothelium produces less heparan sulfate, and heparinolytic enzymes released from thrombocytes further decrease its concentration. Moreover the production of other VSMC proliferation inhibiting factors like Nitric Oxide (NO) and natriuretic peptides by the endothelium will decrease when the endothelium is damaged. Basic fibroblast growth factor (bFGF), which can be released by dying or damaged EC and VSMC, stimulate VSMC proliferation ${ }^{23 ;}$ 24. Angiotensinogen and the angiotensin receptor (ATI) expression are increased in IH lesions. Angiotensin II (AII) stimulates expression of PDGF-A, bFGF, TGF $\beta, c-m y c$ and $c-f o s$. These are all growth stimulating factors ${ }^{21}$. Possible other mediators for VSMC proliferation are catecholamines and thrombin, all released upon injury $^{25}$. Thus, damage of the vessel wall decreases production of growth inhibiting factors and increases the expression of growth stimulating factors, shifting the balance toward VSMC proliferation.

VSMC are present in 2 main phenotypes. The differentiated contractile phenotype mainly contains $\alpha$-actin and myosin and has a low proliferation rate of $<0.1 \%$. The synthetic phenotype strongly resembles the foetal VSMC and the fibroblast, with many cell organelles and abundant rough endoplasmatic reticulum, no myosin and an increase in $\alpha$-actin. These synthetic cells produce $4-5 \times$ more extracellular matrix than the differentiated phenotype and have an increased proliferation rate of at least $10 \%{ }^{21}$. In intimal hyperplasia an increase in the synthetic phenotype is found at the expense of the differentiated phenotype. This results in increased proliferation and matrix deposition in the intima. In the adventitia, extensive surgical exposure and dissection damages the vasa vasorum and the autonomic nerves. This leads to deendothelialisation within 6 hours after surgery, and stimulates intimal hyperplasia ${ }^{26}$. Possibly this damage might also play a role in the dedifferentiation of the VSMC.

Second wave: VSMC migration from media to intima.

VSMC are embedded in an extracellular matrix (ECM). The extracellular matrix includes the basement membrane, the inner elastic lamina and the interstitial matrix. The inner elastic lamina is produced by the EC and mainly consists of laminin, collagen type IV and heparan sulfate proteoglycans. The interstitial matrix is produced by the VSMC and is composed of fibronectin, thrombospondin, collagen I and II, chondroitin, dermatan sulfate, proteoglycans and elastin ${ }^{27}$. The ECM is continuously changing by altered patterns of matrix synthesis and by the actions of matrix metalloproteases (MMP's). An intact ECM prevents VSMC migration. Injury induces the production of tissue-type plasminogen activator (tPA) and urokinase-type plasminogen activator 
(UPA), which degrade the ECM and activate MMP's ${ }^{27}$. BFGF, PDGF, TGF $\beta$ and All, which increase after injury, all increase plasminogen activator. Heparan sulfate inhibits plasminogen production, but this inhibition is abolished because of EC damage and decreased heparan sulfate production. Fibroblast growth factors significantly contribute to the medial proliferation of VSMC while the presence of either endogenous or exogenous PDGF promotes migration to the intima ${ }^{28 ; 29}$. Several other mediators of both the tyrosine kinase (IGF-1, TGF- $\beta$, thrombin, interleukin-1) and G-protein (All, endothelin-1, serotonin) coupled membrane receptors have been shown to participate in these events $^{30}$. These circumstances produce a good environment for migration. VSMC migration from media to intima starts four days after injury, and continues up to 1 month after injury.

Recent experiments suggest that the adventitia might also play a role in delivering intimal cells. After angioplasty, adventitial myofibroblast have been shown to proliferate and migrate to the intima too ${ }^{31}$.

Third wave: intimal expansion

The third wave of intimal expansion probably occurs as a result of VSMC accumulation through proliferation, continued migration, or both, as well as relatively exuberant ECM synthesis. The processes of VSMC accumulation and volume of ECM production appears to be tightly linked, with fairly constant proportions of VSMC to ECM volumes, characterising the intimal lesions that arise after a variety of vascular injuries $^{32}$. The proportional contribution of VSMC and ECM volume to the overall intimal volume remains constant except directly beneath the endothelium, where both VSMC proliferation and the relative proportion of VSMC are higher. Not much is known about the control of matrix production in the intima. Growth factors such as TGF- $\beta$ and PDGF are also fibroplastic, i.e. they stimulate ECM production by VSMC. Thus, the same factors that stimulate VSMC proliferation simultaneously increase ECM production ${ }^{21}$.

\section{Intimal hyperplasia in venous and prosthetic grafts}

In the normal circulation a vein is subjected to low pressure, nonpulsatile flow and a shear stress of around 0.2 dyne $/ \mathrm{cm}^{2}$. Following grafting into the arterial system, the vein is exposed to high pressure, pulsatile flow and a shear stress of approximately 3-6 dynes $/ \mathrm{cm}^{233}$. Arterialised vein grafts obtained from humans in the early postoperative period ( $<24 \mathrm{hrs}$ ) show focal loss of endothelial cells, particularly at the perianastomotic areas, and fibrin deposition on the intima ${ }^{12}$. This results in a loss of endothelium dependent relaxation to acetylcholine and diminished contraction to $\alpha 2$-adrenergic agonists and serotonin ${ }^{16-18 ; 34}$. Alterations in shear stress influence the expression of endothelial adhesins. Vein grafting is followed by a rapid deposition of leucocytes, platelets and other blood components. These can release cytokines that may influence VSMC proliferation and migration ${ }^{33}$. Up to 2 months after 
implantation of vein grafts, an increased platelet activation was found ${ }^{35}$. Also, an increase in PDGF and bFGF production was found in the area of $1 \mathrm{H}^{36}$.

Specimens derived from occluded human bypasses indicated that intimal hyperplasia occurred at the heel, toe and floor of the anastomosis with the host artery and that it consists of myofibroblasts, fibrocollagen with cellular degeneration and proliferation ${ }^{37}$. Uniformly, $\mathrm{IH}$ occurred close to or at the anastomosis, where the veins were repeatedly handled by forceps. This trauma may have caused ischemia or breakdown of the vein wall, producing a hyperreaction of the vein to arterial pressure ${ }^{11}$.

In prosthetic grafts, the morphological sequence of the development of $\mathrm{IH}$ was described by Watastase ${ }^{22}$. He discerned 6 steps: 1) early thrombosis; 2) phagocytosis of thrombi; 3) appearance and proliferation of fibroblasts in the pseudointima; 4) appearance and extension of endothelial cells; 5) appearance of VSMC and 6) intimal hyperplasia by proliferation of fibroblasts and production of collagen fibrils.

In contrast to healing in injured arteries, intimal thickening in vascular grafts seems to take place beneath the endothelial layer ${ }^{38}$. This observation provides support for the conclusion that endothelial cells might serve as a source of growth factors ${ }^{2 ;} 39 ; 40$.

However, polytetrafluoroethylene (PTFE) grafts can also induce the production of VSMC growth factors in several ways: 1) foreign body response activates macrophages which excrete growth factors, 2) uncovered PTFE activates platelets which can release growth factors, 3) compliance mismatch at the anastomosis may lead to excessive stretching of the VSMC, causing the VSMC to proliferate, 4) turbulence occurs around the anastomosis, causing endothelial cell damage and release of growth factors, 5) zones of low shear and flow separation are present around the anastomosis, causing platelet adherence and activation which release growth factors ${ }^{2 ;} 41 ; 42$.

Hemodynamic injury at the downstream anastomosis due to high flow and turbulence in AV fistulas might increase endothelial permeability to blood products, including growth factors. The combination of injury to the vein and PDGF release in the graft may provoke $\mathrm{IH}^{4: 43}$. Although the sequence of events in the development of intimal hyperplasia in arteriovenous fistulas has not been examined, a prosthetic arteriovenous fistula can be assumed to be a combination of implantation of a prosthetic graft and implantation of a vein in the arterial circulation. Therefore, one may suggest that the mechanisms in the development of intimal hyperplasia in these separate situations can be combined to a hypothesis of the development of intimal hyperplasia in arteriovenous fistulas (fig 3.1). Implantation of the PTFE graft induces platelet and macrophage activation, which release migration and proliferation stimulating factors. Compliance mismatch and disturbed flow are contributing factors. The efferent vein 
is exposed to arterial pressure and flow, causing mechanical damage and high wall tension. The high wall tension stretches VSMC, which induces proliferation. Moreover, the mechanical trauma causes EC damage, inducing platelet adhesion and activation. The release of mediators from the involved cells induces proliferation of VSMC and degradation of ECM, promoting migration of VSMC into the intima. The VSMC can then deposit the ECM to complete the intimal hyperplastic lesion.

\section{Hemodynamics and intimal hyperplasia}

Shear stress and flow

Blood flowing through a vascular segment exerts a tangential directed shear stress at the luminal surface of endothelial cells. Wall shear stress is the product of wall shear rate, i.e. the radial derivative of the velocity near the wall, and the local blood viscosity. For parabolic velocity distribution, shear stress $(\tau)$ can be calculated according to Poiseulle's law:

$$
\tau=\frac{4 n}{\pi r^{3}}
$$

where $\eta=$ viscosity, $Q=$ volume flow and $r=$ internal vessel radius.

Wall shear stress has been shown to be an important determinant of the release of vasoactive compounds from the endothelial cells ${ }^{44 ; 45}$. Several vasoactive molecules stimulate the expression of adhesion molecules and chemokines involved in intima-media thickening ${ }^{46}$. Wall shear stress is related to flow and inversely related to diameter. If a vein is positioned in the arterial circulation, the flow through the vein increases, but so does the diameter. Whether the actual shear stress will be increased or lowered depends on the proportional increase of diameter and flow. Since diameter is to the 3rd power (see the above equation), its influence is larger and shear stress will usually be lowered. Normal vessels respond to low flow by constricting, and this response is an endothelial dependent process. In rigid PTFE grafts where vasoconstriction cannot occur, low flow is correlated with increased intimal thickening and may represent an attempt on the part of the endothelial cells to maintain shear stress within the physiological range 32. The hypothesis that low flow and low shear stress increase intimal hyperplasia has been confirmed by many studies. After implantation of $3 \mathrm{~mm}$ diameter PTFE prostheses in the abdominal aorta or inferior caval vein in albino rabbits, $\mathrm{IH}$ occurred much faster in the prosthesis in the venous position than in the arterial position, although the morphologic changes were mostly identical ${ }^{22}$. Creation of an arteriovenous (AV) fistula distal from a prosthetic bypass increases the flow through the bypass. In animal studies, these high flow bypasses developed less $\mathrm{IH}$ than the normal flow bypasses ${ }^{32 ; 47-49}$. Closure of the AV fistula or banding of the prosthesis lead to a decrease in flow. This induced an increase of $\mathrm{IH}^{32 ; 48 ; 50}$. Distal AV fistulas also lead to a better patency of prosthetic peripheral bypasses in humans ${ }^{51}$. In bilateral venous bypass grafts of the 


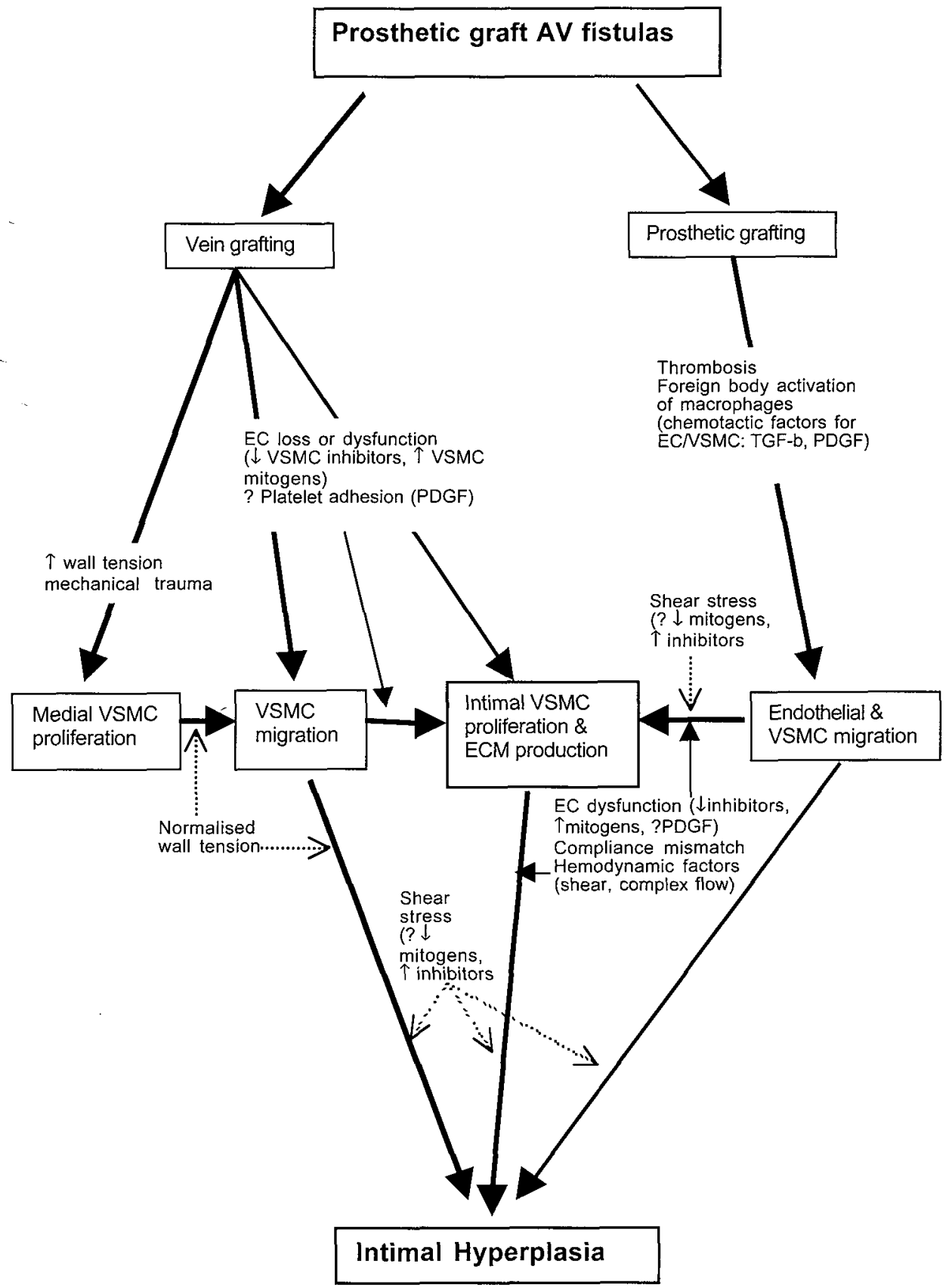

Figure 3.1: Hypothesis on the development of intimal hyperplasia in prosthetic arteriovenous fistulas (modified from Kraiss \& Clowes $^{21}$ ) 
femoral artery in dogs, one femoral artery was left patent to induce lower flow through the venous bypass, and on both sides the mid-portion of the graft was covered with a restraining Marlex ${ }^{(k)}$ cuff to prevent dilatation. Low blood flow was best associated with the formation of intimal hyperplasia and deformation of the vessel wall in a circumferential direction was best associated with medial thickening ${ }^{20 ; 52}$ 53. In monkeys, AV fistulas were created unilaterally to increase the flow through the iliac artery. In this study, no increase in $\mathrm{IH}$ was found, but the wall shear stress was equal on both sides. It was concluded that wall shear stress, and not the flow rate, might be the essential hemodynamic factor in $\mathrm{IH}^{54}$. Also, Zarins et al. ${ }^{55}$ found no increase in intimal thickness after creation of an AV fistula on one side of the iliac artery to increase flow, although tangential wall tension and tangential wall shear stress were increased. They suggested that increased flow resulted in arterial dilatation and normalisation of wall shear stress and that artery lumen diameter might serve to regulate wall shear stress. Hofstra et al. ${ }^{56}$ found low local flow velocities to be associated with stenotic lesions in human PTFE peripheral bypasses as well as in human AV fistulas.

Although the above studies suggest that low flow and low shear stress induce intimal hyperplasia and high flow and high shear stress inhibit intimal hyperplasia, a number of other studies claim the opposite. Implantation of $1-\mathrm{cm}$ segments of inferior caval vein into the abdominal aorta in Lewis rats caused the intima-media area of the vein graft to increase significantly with time. Reimplantation of the venous segment into the venous circulation, caused a significant decrease of the vein graft intima-media area in 8 weeks ${ }^{36}$. AV fistulas had a higher mean blood flow and higher shear stress than venous bypass grafts in the same animals, and developed less $\mathrm{IH}^{53}$. Also, in PTFE AV loop fistulas created between the femoral artery and the femoral vein of dogs, intimal-medial thickness was $50 \%$ less in the banded (normal flow) than in the unbanded (high flow) side ${ }^{57}$. In high flow renal-artery-to-caval-vein anastomoses a significant intimal thickening occurred 3 months after implantation $^{54}$. In humans, in vivo measurements of peak systolic velocities, normalised for diameter (nPSV), 2 weeks after implantation of graft AV fistulas indicated that initial local nPSV values at the site of later stenoses were higher in the fistulas developing a stenosis than in non-stenotic fistulas ${ }^{58}$.

In experimental models, following exposure to the arterial environment, endothelial cells experience severe stretching and increased tangential stress both of which contribute to endothelial cell damage ${ }^{12 ; 59}$. Moreover, it has been observed that cyclic stretching of VSMC stimulates synthesis of collagen and other matrix components ${ }^{42}$. This results in wall thickening, even after reendothelialisation has occurred. How endothelial cells or VSMC transduce shear and wall stress into a biochemical response that controls smooth muscle growth is still unclear. Several mechanisms have been proposed, including ion channel with activation influenced by shear stress or stretch, 
mechanical disruption of cell-cell contacts, alteration of focal adhesion dynamics by forces transmitted via the cytoskeleton and changes in the surface concentrations of extracellular agonists ${ }^{60}$. Moreover, positive and negative shear stress responsive elements (SSREs) have recently been identified in the promotor regions of genes involved the development of intimal hyperplasia, such as PDGF-A and B and TGF-b. These SSRE can either upregulate or downregulate the transcription of these genes in response to changes in shear stress ${ }^{61}$.

To explain the contradicting hypotheses on high and low shear stress as a cause for intimal hyperplasia, several simulation and flow visualisation models have been developed to gain more insight into the distribution of flow velocities and shear stress and the occurrence of $\mathrm{IH}$ in vivo. Fei et $\mathrm{al}^{62}$ created a 3D-numerical model with static flow. Within the anastomosis the velocity profile was skewed toward the floor with a stagnation point opposite the mid-portion of the graft lumen. A vortex was formed just upstream. Skewed velocity profiles in end-to-side (ETS) anastomoses produced low or even reversed velocities along the wall in the proximal artery and regions of anastomotic toe and heel, while producing elevated forward velocities along the distal outer wall of the artery. This coincides with flow visualisation studies in an anastomotic model created from in vivo peripheral anastomoses ${ }^{63}$. Using a higher Reynolds number to simulate high flow, high wall shear rates were found at all locations as compared to simulations with a low Reynolds number. However, recent studies on flow visualisation and numerical simulation models with pulsatile flow indicate that high temporal and spatial wall shear stress gradients, and not the absolute wall shear stress is associated with $\mathrm{IH}^{64-66}$. The high flow and low flow hypotheses as cause of intimal hyperplasia do not rule out each other. It seems that there is an optimal shear stress, whether it is absolute or a gradient, at which no intimal hyperplasia occurs. High flow will induce flow disturbances at the anastomosis, inducing a high gradient of wall shear stress. Low flow will actually produce reversed flow at the anastomosis, creating a negative wall shear stress. Both circumstances are thought to increase the development of intimal hyperplasia. Moreover, regions of high wall shear stress could cause local vessel wall damage. The vasoactive substances released from these regions might exert their action in regions of low wall shear stress, where a better interaction with the vessel wall is possible due to the longer residence time.

\section{Influence of graft geometry and compliance}

End-to-side (ETS) anastomoses develop more IH than end-to-end (ETE) anastomoses ${ }^{20 ; 67}$. However, an ETS distal anastomosis is usually necessary to maintain antegrade and retrograde perfusion. Lengthening of the anastomosis reduces shear stress on the floor of the arterial wall, but not the flow disturbances at the heel and toe of the anastomosis. Since endothelial cells are orientated in the direction of the flow in a shingle-like configuration, flow disturbances can lift up the 
endothelium, thus exposing the subendothelium to the blood elements (platelets etc.). This could induce smooth muscle cell migration and proliferation $^{43}$.

Variation of graft diameter in ETS anastomoses of venous femoropopliteal bypasses in sheep had no influence on the development of $1 \mathrm{H}^{68}$. This undermines the theory of Madras et al. ${ }^{69}$ who stated that a mismatch in diameter at the anastomosis causes energy dissipation which would lead to physical stress transmitted through the adjacent vascular wall. This stress would be cyclic, synchronous with the heartbeat, inducing VSMC proliferation. Numerical simulation models indicate that the optimal diameter ratio for graft to native vessel is $1.6-2: 1^{70}$. The effect of graft diameter and geometry is demonstrated by Fillinger et al. in graft arteriovenous fistulas created between the iliac artery and femoral vein in dogs ${ }^{71}$. With a 4-7 $\mathrm{mm}$ tapered graft (4 $\mathrm{mm}$ diameter at the arterial side and $7 \mathrm{~mm}$ diameter at the venous side), significantly less $\mathrm{IH}$ developed at the distal anastomosis as compared to $6 \mathrm{~mm}$ grafts. This was explained by less flow disturbance and turbulence at the distal anastomosis of the tapered graft.

A lot of research has been conducted on the angle of the anastomosis. Thus far, no correlation has been found between the angle of the proximal anastomosis and $\mathrm{IH}^{72}$. In numerical simulation and flow visualisation models, a lower angle $\left(20^{\circ}\right)$ of the distal anastomosis produced less flow disturbance and a lower range of shear stress variation than higher angles $\left(30^{\circ}, 45^{\circ} \text { and } 60^{\circ}\right)^{62 ; 70 ; 73}$. In a flow visualisation model, the $45^{\circ}$ angle was found to be superior, with lowest absolute normalised shear rates and flow separation ${ }^{74}$.

Another factor that might influence $\mathrm{IH}$ is compliance mismatch. In a flow visualisation model based on an AV loop graft between the femoral artery and vein of a dog, compliant and non-compliant PTFE grafts were tested. Anastomotic flow patterns were directly affected by the compliance of the graft conduit. In less compliant grafts, flow reversal and vortex formation were more pronounced than in more compliant grafts $^{75}$. Comparing iliofemoral bypass grafts of greater saphenous vein (GSV) to PTFE grafts in dogs showed a larger suture line IH in PTFE than in GSV grafts, whereas the $\mathrm{IH}$ at the arterial floor was comparable. It was concluded that suture line $\mathrm{IH}$ represented vascular healing. Greater prominence of $\mathrm{IH}$ in prosthetic grafts may be related to compliance mismatch. Arterial floor $\mathrm{IH}$ was unrelated to graft type and developed in regions of flow oscillations and relatively low shear rate ${ }^{63}$. Decreasing the compliance of venous bypass grafts with a Dacron ${ }^{68}$ or Phynox ${ }^{76}$ mesh tube resulted in an increase of $1 \mathrm{H}^{77}$. Applying a tight PTFE wrap to reduce the luminal diameter and the tangential wall shear stress, reduced total cross-sectional wall area, smooth muscle cell volume and matrix deposition. A loose wrap, that did not decrease the tangential wall shear stress, did not have these effects ${ }^{78}$. However, Mehta et al. recently reported that a loose macroporous velours polyester external stent reduced intimal and medial thickening in venous bypass 
grafts in pigs. This reduction was associated with a reduced expression of PDGF and a reduced proliferation rate. Since the stented grafts also had a greatly increased vascularity of the neoadventitia that developed between the bypass and the stent, it was postulated that reduced intimal and medial thickening was caused by a decrease of hypoxic damage ${ }^{79}$. In humans, measurement of GSV compliance before implantation as a femorodistal bypass demonstrated that a lower initial compliance increased the risk on the development of a stenosis. Moreover, GSV with pre-existent moderate to severe $\mathrm{IH}$ had lower compliance than GSV with no to mild $\mathrm{IH}^{19}$. In vivo measurements of elastic properties, expressed as area increase (Al) during a cardiac cycle, have been performed with ultrasound. It was found that a decline in Al occurred at the arterial anastomosis of PTFE AV fistulas, whereas an increase of Al occurred at the venous anastomosis. The authors stated that since an increase in $\mathrm{Al}$ is associated with flow disturbances, the mismatch in elastic properties may contribute to the predisposition of the venous anastomosis for $\mathrm{IH}^{80}$. However, after comparing the initial elastic properties to the follow-up data on stenosis, a better initial ( 2 weeks postoperative) match was found around the venous anastomosis of AV fistulas, which developed stenosis as compared with the non-stenotic fistulas ${ }^{58}$.

Numeric simulation model studies of a distensible ETS anastomosis confirmed the fact that compliance mismatch was not an important factor in the development of intimal hyperplasia. Only minor changes in overall wall shear stress patterns were observed. It is suspected that the effects of wall distensibility are less pronounced than those brought about by changes in arterial geometry and flow conditions ${ }^{64}$. It is understandable that vein graft compliance does not play an important role in the development of $\mathrm{IH}$ when one considers that vein grafts are almost rigid at arterial pressure and the compliance of the anastomotic region resembles that of the artery rather than that of the vein $^{20}$.

\section{Anastomotic cuffs and patches to prevent IH}

In an attempt to improve the patency of peripheral arterial bypasses, a number of different anastomosing techniques have been developed. In these techniques, venous material is used in a transverse orientation to create a gradual transition of elastic properties and to facilitate the anastomosing of two vessels of different diameter and wall structure.

\section{Miller cuff}

The venous cuff was first described by Siegman in 1979 to make a smooth connection between a venous or Dacron bypass and the thickened atherosclerotic artery and to make the anastomosis technically easier (fig.3.2a) ${ }^{81}$. Miller adopted this technique and found that it also had a positive effect on graft patency which he ascribed to a better transition in elastic properties ${ }^{10 ;} 82$. 
Although no controlled trial was conducted, the "Miller cuff" was embraced by vascular surgeons to improve the poor results of femorodistal PTFE bypasses. Multiple reports on their achievements have been published, mostly with improved patency rates as compared to the literature or historic controls. The one-year patency rates of bypasses with a Miller cuff vary from $47 \%$ to $83 \%$ compared to $66 \%$ without a venous cuff ${ }^{83-85}$. Three year patencies vary between $29-38 \%$ with cuff and from 7 to $19 \%$ without cuff ${ }^{84 ; 86-90}$. In a retrospective study an increase in 1 year patency rates was reported from $38 \%$ in PTFE bypasses with an arteriovenous fistula at the distal anastomosis $(n=76)$ to $62 \%$ by adding a Miller cuff $(n=43)$. It seemed that the cuff and arteriovenous fistula acted synergistically rather than simply additive. The arteriovenous fistula increases flow, thus decreasing thrombosis, but it induces instability of flow and the development of intimal hyperplasia. It is supposed that the cuff compensates for these adverse effects ${ }^{91}$. However, one retrospective study reported poor results with the vein cuff. Brumbe et $a^{92}$ found that infragenual bypasses with PTFE and a venous cuff had a 1 year patency of $40 \%$, whereas in normal anastomosed bypasses this was $61 \%$. Above the knee even greater differences were found: $66 \%$ patency without and $14 \%$ with cuff. Recently a prospective randomised study showed that the Miller cuff did not improve the patency of femoropopliteal grafts, but it did improve the patency of femorocrural bypasses. This was attributed to the fact that the Miller cuff simplified the anastomosing technique of a stiff prosthesis to a small calibre crural vesse ${ }^{93}$.

Despite these controversies, the Miller cuff is now widely used by surgeons in various vascular reconstructions ${ }^{94 ; 95}$.

\section{Taylor patch}

In the early eighties, Taylor developed a venous patch that was stitched into the distal anastomosis to prevent intimal hyperplasia and thus improve patency rates of PTFE bypasses (fig. 3.2b). Since the proximal anastomosis was also prone to develop intimal hyperplasia, a different type of patch was developed in this position (fig.3.2c) ) $^{96-98}$. In a subsequent publication on the causes of failures of PTFE grafts, $19 \%$ of which was due to intimal hyperplasia, Taylor states that "The development of a technique to insert vein patches across the anastomoses appears to eliminate the significance of intimal hyperplasia"7. However, no literature or data were shown to support this statement.

Five years later Taylor published very good patency rates of PTFE peripheral bypasses (5-year patency rate of $71 \%$ for femoropopliteal and $54 \%$ for infrapopliteal grafts). These results were considerably better than published previously by others (patency $0-49 \%$ overall) and historical series from Taylor's own clinic (21 infragenual femoropopliteal grafts had a 2 year patency of $81 \%$, the first 45 patched bypasses of $94 \%)^{99}$. A subanalysis of PTFE grafts to an isolated popliteal segment 


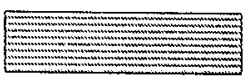

$=$ graft

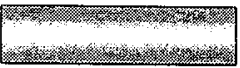

$$
\text { = artery }
$$

$=$ vein patch

Legend

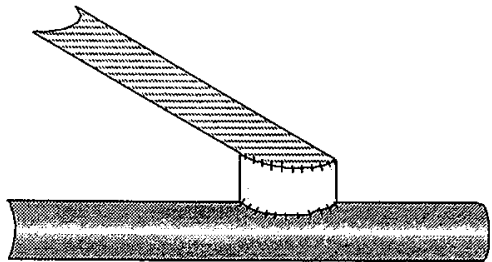

3.2a Miller cuff
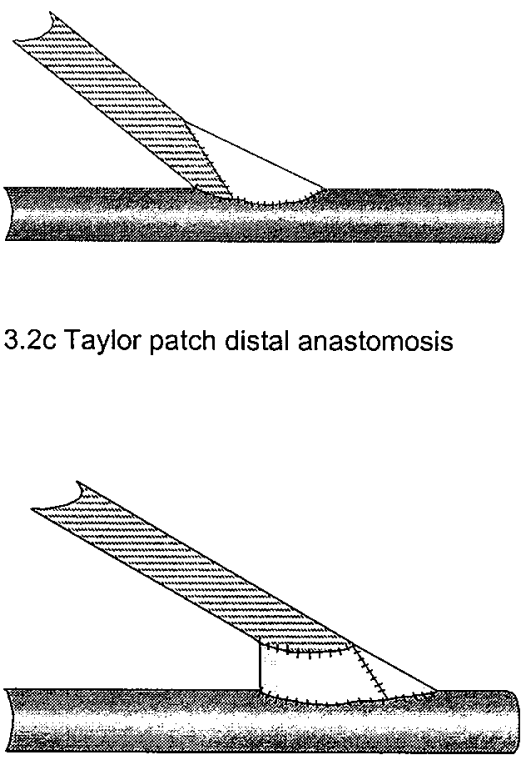

3.2e St Mary's boot

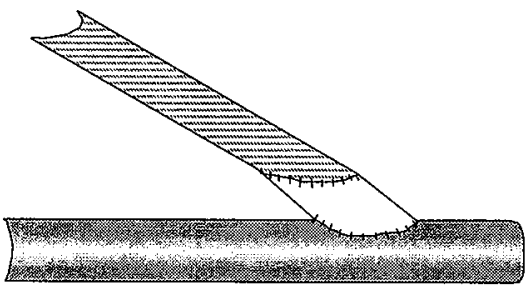

$3.2 \mathrm{f}$ Karacagil's cuff

Figure 3.2 Types of venous cuffs used to decrease anastomotic intimal hyperplasia. 
showed even better results: the cumulative patency was $84 \%$ at 1 year and $76 \%$ at 3 years, whereas the literature reports patency rates of $48-$ $53 \%$ at 1 year and $24-35 \%$ at 3 years ${ }^{100}$. However, no randomisation was performed and the results of the Taylor patch are single-centre.

Therefore extrapolation to the general peripheral bypass population is difficult ${ }^{101}$.

\section{Linton Patch}

Batson et al. ${ }^{102}$ described a patch technique in which the native artery is patched with a venous segment of $4-5 \mathrm{~cm}$ length. In the proximal part of the vein patch, an incision is made to connect the graft (fig.3.2d).

Femoropopliteal and femorodistal bypasses created with this technique had a one-year patency of $74 \%$ and $2-4$ years patency of $65 \%$.

\section{St Mary's Boot}

Although the Miller cuff and Taylor patch seemed successful in preserving long-term patency in infragenual PTFE bypasses the development went on. The rectangular angle that connects the Miller collar to the recipient vessel produces considerable turbulence when examined by Duplex scanning.

The Taylor patch has a hemodynamically smoother transition. However, it has a considerable area of PTFE connected directly to the artery. If this connection and the compliance mismatch do play a role, intimal hyperplasia remains likely at this site. Therefore, Tyrrell and Wolfe designed a new venous collar that incorporated the advantages and eliminated the disadvantages of both techniques (fig.3.2e) ${ }^{103}$. Although their "how we do it" was published 5 years ago, no clinical results have been reported as yet.

Based on the hypothesis that the geometric alteration and not the interposition of venous material is important in the supposed beneficial effect of the cuff, Brennan et $\mathrm{al}^{104}$ manufactured a cuffed prosthesis by using balloon dilatation of the distal segment. Recently, a prosthesis based on this design became commercially available and the early results are promising ${ }^{105}$.

\section{Karacagil's modified cuff}

Karacagil too recognised the hemodynamically unfavourable rectangular angle of the Miller cuff and made his own modification: a $V$-shaped patch is sutured first to the prosthesis and then to the artery. In this way an oblique angle connection is made. Also, suturing the cuff first to the graft and then to the artery is easier than the other way around, as is done with Miller and Tyrrell cuffs (fig.3.2f). Patency rates of the first 21 patients were $75 \%$ at six months and $69 \%$ at 12 months. All anastomoses were to the below-knee arteries ${ }^{106}$. Again, the advantages can only be assessed by a prospective randomised study. 


\section{Research on anastomotic cuffs and patches}

In vitro experiments

Beard et $\mathrm{al}^{107}$ were the first to examine the hemodynamics of the Miller cuff in vitro. They embedded anastomotic complexes of PTFE prostheses to cadaver internal mammarian arteries with or without a Miller cuff into silastic foam and perfused it with whole human citrated blood through a hydraulic system. Flow was measured proximal to the anastomosis. Anastomoses with a Miller cuff had significantly higher bloodflows than standard anastomoses, especially when the recipient artery was smaller than $2 \mathrm{~mm}$. The investigators hypothesised that this hemodynamic advantage was caused by the compliant vein cuff that allowed more distension of the anastomosis and reduced anastomotic resistance.

However, Tyrrell et al ${ }^{108}$ could not reproduce these results. One of the possible explanations is that in the in vitro setting as described above, there always is sutureline leakage. As the sutureline of the Miller cuff is longer than of the standard anastomosis, the former would have more leakage. Flow measurements proximal to the anastomosis, as Beard et al. did, could have been biased by the leakage. Tyrrell et al measured flow in the recipient artery to overcome this problem and found no difference in flow. The volume flow was correlated to the diameter of the vessel at the toe of the anastomoses with a Miller cuff and a Taylor patch but not in the direct anastomosis. The authors concluded that the direct anastomosis has an increased resistance to flow as compared to the anastomosis with a Miller cuff or a Taylor patch. To assess this, silicon casts of the anastomoses were manufactured and maximal and minimal diameter were measured. The roundness of the anastomoses was calculated by division of these two dimensions. As a perfect circle has the greatest cross-sectional area for any given circumference, less roundness indicates a higher resistance. The median roundness was less for direct anastomoses $(81 \%)$ than either for the Miller cuff $(92 \%)$ or patch $(93.5 \%)$ anastomoses ${ }^{109 ; 110}$. The direct anastomoses had a higher resistance, which may lead to a reduced volume flow and may cause more flow disturbances. The reduced resistance of Miller cuffs was confirmed by an in vitro study with impedance measurements in ETS anastomoses with different angles and with or without a Miller cuff. The Miller cuff reduced the anastomotic impedance at any anastomotic angle and flow. Also, increase of the anastomotic angle increased the impedance ${ }^{111}$.

Local hemodynamics within a Miller cuff were also studied in an in vitro model. During most of the cardiac cycle a unidirectional coherent vortex developed in the cuffed anastomosis. This vortex had a high velocity with greater shear stress exertion on the vessel wall than laminar flow. In view of the hypothesis that low shear stress would induce intimal hyperplasia, the increase in shear stress could explain the beneficial effect of a cuff on anastomotic $\mathrm{IH}^{112}$. In numerical simulation models, the Taylor patch had a less disturbed flow and a lower wall shear stress 
gradient than a standard anastomosis. This was associated with larger anastomotic surface areas, smoother curvatures at and near the anastomosis and smaller anastomotic angles, with approximately $10^{\circ}$ being superior ${ }^{70}$.

Another feature of the cuff was examined using greater saphenous vein specimens. Pressure dependent changes in diameter indicated that the fresh long saphenous vein was anisotropic, with a mean longitudinal strain $7.2 x$ that of the circumference. Cutting the vein lengthwise and stitching it decreased this ratio to 1.95. The Miller cuff and Taylor patch are likely to take maximum advantage of these mechanical characteristics since the long axis of the vein and arteriotomy are aligned. This may improve PTFE graft patency ${ }^{109 ; 113}$.

A cuff or patch at the venous anastomosis reduces anastomotic resistance, which could increase volume flow and reduce flow disturbances. Also, due to the better transition of mechanical characteristics, less flow disturbances are expected.

\section{Animal studies on mechanical properties and histology}

In a study on the development of intimal hyperplasia in the infrarenal aorta of rabbits, prosthetic patches induced more intimal hyperplasia than venous patches. Largest intimal hyperplasia was induced in regions of the arterial wall that were subjected to the highest stress. According to the Law of Laplace (wallstress $={ }^{*} \Delta p^{*} r$ ) the arterial wall stress increases with patch width. To limit intimal hyperplasia, venous patches should be used and they should not increase the total circumference by more than $30 \%^{82}$. In a canine model, Taylor patched anastomoses of prosthetic arteriovenous fistulas developed less intimal hyperplasia than standard anastomoses ${ }^{114}$.

Suggs et al. ${ }^{115}$ implanted PTFE bypasses in carotid arteries of dogs, with venous cuffs on the proximal and distal anastomosis at one side and normal anastomoses on the other side. The average diameter $1 \mathrm{~mm}$ distal to the graft toe was significantly smaller in non-cuffed than in cuffed grafts. The authors stated that inhibition of stenosis formation by the vein cuff might be caused by inhibition of proliferation of smooth muscle cells due to a wider distribution of kinetic energy (less compliance mismatch) or due to interposition of venous endothelium which offers a humoral protection.

The effect of the mechanical properties of the Miller cuff on the development of intimal hyperplasia was studied in bilateral PTFE carotid artery bypasses in dogs ${ }^{116}$. On one side the expandability of the vein cuff was limited by making a PTFE jacket around it, on the other side a normal Miller cuff was created. No difference in intimal hyperplasia thickness was found. To assess whether the angle played a role, a Miller cuff anastomosis was created on one side with a vein and on the other side with PTFE. Bilateral graft thrombosis occurred in $80 \%$ of the animals suggesting that the perpendicular anastomotic angle was not protective. From these results the authors concluded that the 
protective effect of the vein cuff was not mechanical in origin. Possibly the autogenous endothelium provided a humoral protective effect. This might also explain the effectivity of the Taylor patch, since in the Taylor patch, part of the prosthesis is directly connected to the native artery $^{116}$. This part would not benefit from a mechanical effect of the vein patch. However, if the venous endothelium releases substances that decrease $\mathrm{IH}$, the whole anastomotic area might profit.

Sottiurai ${ }^{43}$ performed a series of experiments to assess the cause and prevention of distal anastomotic intimal hyperplasia. Using a Linton patch, he found that in the rigid standard PTFE grafts, Doppler waveforms and patency were better than with a direct anastomosis. In thin-walled PTFE grafts, the Doppler waveforms and patency were adversely affected by a cuff. Intimal hyperplasia did occur in the cuffed rigid PTFE anastomoses, but less pronounced compared to prostheses without a venous cuff $^{117}$.

\section{Risk factors and pharmacological interventions}

Factors associated with failure of vascular reconstructions include patient-related factors like continued smoking of cigarettes and hyperlipidaemia, and local factors like reconstruction of relatively small vessels with low blood flow, excessive vessel distension during preparation of the conduit (vein graft) or substantial injury during the reconstruction 2 38; 118 .

In animal studies, pharmacological interventions had variable success in diminishing the development of $\mathrm{IH}$. Dietary supplementation with Larginine in hypercholesterolemic New Zealand white rabbits reduced intimal thickness with $24 \%$. EC function improved, but not the hypercholesterolemia-associated VSMC phenotype ${ }^{119}$. The antioxydant Lazaroid decreased the mean intimal thickness-increase by $41 \%$ in New Zealand white rabbits with an external jugular vein interposition bypass in the carotid artery. However, the luminal diameter and medial thickness did not alter, nor did the $3 \mathrm{H}$-thymidine incorporation in VSMC in vitro ${ }^{120}$.

Dobrin et al ${ }^{20}$ found a significant decrease in intimal area in vein femorodistal bypass grafts in dogs treated for 3 months with aspirin and dipyramidole as compared to non-treated animals. However, the ACEinhibitor Cilazapril, given to baboons with aorto-iliac bypasses, did not decrease $\mathrm{IH}$ at the site of graft anastomosis ${ }^{121}$. In a sheep model, low molecular weight heparin reduced formation of $\mathrm{IH}$ on a Dacron graft inserted in the common carotid artery ${ }^{122}$.

In humans, a reduction of the incidence of restenosis following PTCA in vivo has been achieved with an antibody to GPIIb-IIla, an adhesion molecule, necessary for platelet aggregation ${ }^{123}$. However, antithrombotic approaches in humans using drugs like aspirin, dipyridamole, ticlopidine, dextran, and coumarin have produced little or no benefit ${ }^{2}$. 


\section{Treatment of stenosis due to intimal hyperplasia}

Since neither improvement of graft geometry nor pharmacological therapy has yet led to prevention of intimal hyperplasia, treatment of stenoses and thrombotic occlusions remain the most important means to maintain graft patency.

Current methods of graft salvage are either surgical or endovascular. Surgical techniques include thrombectomy and graft revision with patch angioplasty or jump graft extension ${ }^{124}$. If the stenosis is near the anastomosis and sufficient graft length remains, a reanastomosis can be performed. Other short stenoses can be treated with removal of the hyperplastic tissue and closure of the vessel wall with a venous or prosthetic patch. Lesions that are long or difficult to reach can be bypassed with a jump graft extension.

Percutaneous endovascular techniques have a number of advantages over surgical treatment: due to its technical simplicity and no need for general anaesthesia, hospital stay and morbidity are reduced. Moreover, it can be applied in patients in bad physical condition, in whom surgery is contraindicated.

However, the use of PTA is limited to stenoses shorter than $5 \mathrm{~cm}$. Occlusions can be treated pharmacomechanically or mechanically ${ }^{125}$ : ${ }^{126}$, although this has less success and less long-term patency and a greater number of complications. Complications include haemorrhage and pseudoaneurysm formation at the puncture site, subintimal dissection or perforation at the angioplasty site and distal embolisation ${ }^{127}$. Recurrence or recoil of the stenosis can be treated with an intravascular stent ${ }^{128}$.

In animal experimental studies, radiation therapy suppressed the development of intimal hyperplasia ${ }^{129}$. Recently, endovascular brachytherapy has been introduced clinically to reduce restenosis after PTA. The results are promising, although no prospective trials have been published yet ${ }^{130}$.

\section{Conclusions}

Intimal hyperplasia remains one of the major obstacles to long-term graft patency. It appears to be the response of the vascular smooth muscle cells to a combination of physical, cellular and humoral factors accompanied by dysfunctional endothelial regulation ${ }^{2 ; 54}$. It is now apparent that any form of endothelial trauma will produce a thickened neointima as part of the healing response. It has to be appreciated that neointimal hyperplasia occurs at different sites following different procedures, but will not always have the same sequelae ${ }^{131}$. Given the multifactorial etiology of intimal hyperplasia it may be that a single pharmacological agent will not prove capable of controlling smooth muscle cell proliferation ${ }^{132}$. However, since the geometry of the ETS anastomosis induces $\mathrm{IH}$, and this geometry cannot be easily altered, pharmacological control of $\mathrm{IH}$ might be the only way to actually prevent 
$\mathrm{IH}^{43}$. Changes in anastomotic geometry and other hemodynamic conditions can improve but not abolish the occurrence of $\mathrm{IH}$. At present, the only approach for treatment of $\mathrm{IH}$ is surgery, angioplasty and brachytherapy ${ }^{2}$.

However, IH not only poses a mechanical obstruction. Assuming that the vessel wall has lost its normal endothelial layer, at least transiently, and that the VSMC are transformed from a quiescent contractile state to a proliferative non-contractile phase, many normal physiological functions of the vessel wall are also altered ${ }^{131}$. To diminish endothelial dysfunction, endothelial cell injury, endothelial denudation and smooth muscle cell injury, the "no touch" technique should be applied, where there is minimum manual and instrumental contact with the vessel ${ }^{133}$. However, this does not influence the effects of flow, shear stress and compliance on the endothelium. There is still controversy whether high or low shear stress induces $\mathrm{lH}$. The high shear stress and low shear stress theories are probably not mutually exclusive. The stresses in the high shear regions may induce secretion of growth factors that accumulate in the low flow regions causing $\mathrm{IH}^{74}$. Possibly there is an optimum for flow and/or shear stress with minimal development of $\mathrm{IH}$, whereas anastomotic hyperplasia does occur when flow is unusually slow or rapid. This hypothesis was already postulated in the early years of research on intimal hyperplasia and it seems to be still topical ${ }^{134}$. Moreover, not the absolute wall shear stress, but the temporal and spatial gradient of wall shear stress might be of more importance. Based on this hypothesis, numerical simulation models have calculated an optimal anastomotic design with minimal flow disturbance and low wall shear stress gradient. The optimal anastomosis has a 1.6-2:1 graft-toartery diameter, a heel angle between $10^{\circ}$ and $15^{\circ}$ and at the toe a gradual transition in curvature and cross-sectional area ${ }^{70}$. However, there are no clinical data available on this design.

A number of different anastomosing techniques have been introduced over the last 40 years to influence the hemodynamic conditions. All seem to have their own advantages and disadvantages, with varying clinical results. There is a wide variability in indication for operation, site of distal anastomosis and quality of the run-off. Also there is a marked difference in reporting the results, which were mainly retrospective and sometimes reported as only primary, or also secondary patencies. A number of in vitro and animal studies were performed trying to resolve the mystery of cuffs and patches. Less oval distortion of the anastomosis, better compliance match and interposition of venous endothelium were mentioned as possible positive effects. Since the actual causes of intimal hyperplasia are still unclear, these are mere speculations. Only a prospective randomised trial can resolve the controversy that still exists as to whether the different anastomotic techniques improve patency and what technique induces the best patency results. Taylor has challenged Tyrrell and Wolfe to perform a randomised trial to compare the Taylor patch to the Miller cuff ${ }^{98}$. In a 
letter to the editor, John Ligush convocated vascular surgeons to perform prospective randomised trials on the effect of Taylor patch, using the experience gained from the large carotid surgery trials ${ }^{101}$. Although more authors have announced prospective studies with different types of cuffs ${ }^{91 ; 92}$, only one trial has been published and found improved patency in femorocrural bypasses but not in femoropopliteal bypasses $^{93}$. The Columbus Vascular Surgery Society Taylor Patch Study is also conducting a prospective trial. The objective is to compare 5year patency rates of infragenual PTFE grafts with or without Taylor patch. Until February 1996 about $1 / 3$ of the aimed number of patients (225) were included in 18 months ${ }^{135}$. Results of this study are not yet published.

In the light of the controversies on the effect of a venous cuff and of high shear stress on the development of intimal hyperplasia we conducted a prospective randomised trial to study the effect of a venous cuff on the patency of prosthetic arteriovenous fistulas and the development of stenoses. Also, the effects of local vessel wall compliance and shear stress on the development of intimal hyperplasia was studied in a new animal model, using a venous cuff and different flow levels.

\section{Reference List}

1. Carrel A, Guthrie CC. Uniterminal and biterminal venous transplantations. Surg.Gynecol. Obstet. 1906;266-286.

2. Clowes AW. Intimal hyperplasia and graft failure. Cardiovasc. Pathol. 1993;2 (Suppl):179S$186 \mathrm{~S}$.

3. Tordoir J, Herman J, Kwan TS, Diderich PM. Long-term follow-up of the polytetrafluoroethylene (PTFE)prosthesis as an arteriovenous fistula for haemodialysis. Eur.J.Vasc. Surg. 1988;2:3-7.

4. Swedberg SH, Brown BG, Sigley R, Wight TN, Gordon D, Nicholls SC. Intimal fibromuscular hyperplasia at the venous anastomosis of PTFE grafts in hemodialysis patients. Clinical, immunocytochemical, light and electron microscopic assessment. Circulation 1989;80:1726-1736.

5. Motwani JG, Topol EJ. Aortocoronary saphenous vein graft disease: pathogenesis, predisposition, and prevention. Circulation 1998;97:916-931.

6. Clowes AW, Reidy MA. Prevention of stenosis after vascular reconstruction: pharmacologic control of intimal hyperplasia--a review. J.Vasc. Surg. 1991;13:885-891.

7. Taylor RS, McFarland RJ, Cox MI. An investigation into the causes of failure of PTFE grafts. Eur.J.Vasc.Surg. 1987;1:335-343.

8. Jenkins A, Buist T, Glover S. Medium-term follow-up of forty autogenous vein and forty polytetrafluoroethylene (GoreTex) grafts for vascular access. Surgery 1980;88:667-672.

9. Bosman PJ, Blankestijn PJ, Graaf Yvd, Heintjes RJ, Koomans HA Eikelboom BC. A comparison between PTFE and denatured homologous vein grafts for hemodialysis access: a prospective randomised multicentre trial. Eur.J.Vasc. Endovasc.Surg. 1998;16:126-132.

10. Miller JH, Foreman RK, Ferguson L, Faris I. Interposition vein cuff for anastomosis of prosthesis to small artery. Aust.N.Z.J.Surg. 1984;54:283-285. 
11. Cheanvechai $C$, Effler DB, Hooper $\mathrm{JR}$, et al. The structural study of the saphenous vein.

Ann. Thor.Surg. 1975;20:636-645.

12. Cox JL, Chiasson DA, Gotilieb Al. Stranger in a strange land: the pathogenesis of saphenous vein graft stenosis with emphasis on structural and functional differences between veins and arteries. Prog. Cardiovasc.Dis. 1991;35:45-68.

13. Manderson JA, Campbell GR. Venous response to endothelial denudation. Pathology 1986;18:7787.

14. Dormandy JA. Influence of blood cells and blood flow on venous endothelium. Int.Angiol. 1996;15:119-123.

15. Bailliart $O$, Boudaoud $L$, Bonnin Ph, Bal Dit Sollier C, Roussi J, Carayon A. Differences between upper and lower limbs in venous endothelial reactivity in humans. Phlébologie 1994;Suppl:10-14.

16. Thulesius $O$. Vein wall characteristics and valvular function in chronic venous insufficiency. Phlébologie 1993;8:94-98.

17. Miller VM, Reigel MM, Hollier $\mathrm{LH}$, Vanhoutte PM. Endotheliumdependent responses in autogenous femoral veins grafted into the arterial circulation of the dog. J.Clin.Invest. 1987;80:13501357.

18. De Mey JG, Vanhoutte PM. Heterogeneous behavior of the canine arterial and venous wall. Importance of the endothelium. Circ.Res. 1982;51:439-447.

19. Davies AH, Magee TR, Baird RN, Sheffield E, Horrocks M. Vein compliance: a preoperative indicator of vein morphology and of veins at risk of vascular graft stenosis. Br.J.Surg. 1992;79: 1019-1021.

20. Dobrin PB, Littooy FN, Golan J, Blakeman B, Fareed J. Mechanical and histologic changes in canine vein grafts. J.Surg.Res. 1988;44:259-265.
21. Kraiss LW, Clowes AW.

Response of the arterial wall to injury ant intimal hyperplasia. In: Sidawy AN, Sumpio BE, DePalma RG, Armonk NY, eds. The basic science of vascular disease. Futura Publishing Company Inc., 1997;289-317.

22. Watase M, Kambayashi J, Itoh T, et al. Ultrastructural analysis of pseudo-intimal hyperplasia of polytetrafluoroethylene prostheses implanted into the venous and arterial systems. Eur.J.Vasc.Surg. 1992;6:371-380.

23. Jawien A, Bowen Pope DF, Lindner $V$, et al. Platelet derived growth factor promotes smooth muscle migration and intimal thickening in a rat model of balloon angioplasty. J.Clin.Invest. 1992;89:507.

24. McNeil PL, Muthukrishnan L, Warder $E_{1}$ et al. Growth factors are released by mechanically wounded endothelial cells. J.Cell Biol. 1989;109:811.

25. Vashisht R, Sian M, Franks PJ, et al. Long-term reduction of intimal hyperoplasia by the selective alpha-1 adrenergic antagonist doxazosin. Br.J.Surg. 1992;1285.

26. Chignier E, Eloy R. Adventitial resection of small artery provokes endothelial loss and intimal hyperplasia. Surg.Gynecol. Obstet. 1986;163:327-334.

27. Murphy JG, Doherty Aj. The matrix metalloproteinases and their inhibitors. Am.J.Respir. Cell Mol.Biol. 1992;7:120.

28. Lindner V, Lappi DA, Baird A. Role of basic fibroblast growth factor in vascular lesion formation. Circ.Res. 1991;68:106.

29. Lindner V, Reidy MA. Proliferation of smooth muscle cells after vascular injury is inhibited by an antibody against basic fibroblast growth factor. Proc.Natl.Acad. Sci.U.S.A. 1991;88:3739.

30. Davies MG, Hagen PO. Pathophysiology of vein graft failure: a review. Eur.J.Vasc. Endovasc.Surg. 1995;9:7-18. 
31. Wilcox JN. Restenosis and related proliferative vasculopathies. Adventitial remodelling associated with restenosis. J.Vasc.Surg. 1998;27:1162-1164.

32. Kohler TR, Kirkman TR, Kraiss LW, Zierler BK, Clowes AW. Increased blood flow inhibits neointimal hyperplasia in endothelialized vascular grafts. Circ.Res. 1991;69 :1557-1565.

33. Golledge J. Vein grafts: haemodynamic forces on the endothelium - a review. Eur.J.Vasc.Endovasc.Surg. 1997;14:333-343.

34. Park TC, Harker CT, Edwards JM, Moneta GL, Taylor LM, Porter JM. Human saphenous vein grafts explanted from the arterial circulation demonstrate altered smooth-muscle and endothelial responses. J.Vasc.Surg. 1993;18:61-69.

35. Gershlick AH, SyndercombeCourt YD, Murday AJ, Lewis CT, Mills PG. Platelet function is altered by autogenous vein grafts in the early postoperative months. Cardiovasc.Res. 1984;18:119-125.

36. Sterpetti AV, Cucina A, Lepidi S, et al. Progression and regression of myointimal hyperplasia in experimental vein grafts depends on platelet-derived growth factor and basic fibroblastic growth factor production. J.Vasc. Surg. 1996;23:568-575.

37. Sottiurai $\vee$, Yao J, Flinn W, Batson R. Intimal hyperplasia and neointima:an ultrastructural analysis of thrombosed grafts in humans. Surgery 1983;93:809817.

38. Clowes AW, Kirkman TR, Clowes MM. Mechanisms of arterial graft failure. II. Chronic endothelial and smooth muscle cell proliferation in healing polytetrafluoroethylene prostheses. J.Vasc.Surg. 1986;3:877-884.

39. Golden MA, Au YP, Kirkman TR, et al. Platelet-derived growth factor activity and mRNA expression in healing vascular grafts in baboons. Association in vivo of platelet-derived growth factor mRNA and protein with cellular proliferation. J.Clin.Invest. 1991;87:406-414.

40. Clowes AW, Gown AM, Hanson SR, Reidy MA. Mechanisms of arterial graft failure. 1. Role of cellular proliferation in early healing of PTFE prostheses. Am.J.Pathol. 1985;118:43-54.

41. Ombrellaro MP, Stevens SL, Sciarrotta J, Freeman MB, Goldman MH. Effect of endoluminal PTFE graft placement on cell proliferation, PDGF secretion, and intimal hyperplasia. J.Surg.Res. 1996;63:110-114.

42. Sumpio B. Enhanced collagen production by smooth muscle cells during repetitive mechanical stretching. Arch.Surg. 1988;123:1233-1236.

43. Sottiurai VS. Biogenesis and etiology of distal anastomotic intimal hyperplasia. Int.Angiol. 1990;9:59-69.

44. Ando J, Ohtsuka A, Katayama Y, Korenaga R, Ishikawa C, Kamiya A. Intracellular calcium response to directly applied mechanical shearing force in cultured vascular endothelial cells. Biorheology. 1994;31:57-68.

45. Hecker $M$, Mulsch A, Bassenge $E$, Busse R. Vasoconstriction and increased flow: two principal mechanisms of shear stressdependent endothelial autacoid release. Am.J.Physiol. 1993;265:H828-H833.

46. Busse R, Fleming I. Pulsatile stretch and shear stress: physical stimuli determining the production of endothelium-derived relaxing factors. J.Vasc.Res. 1998;35:7384.

47. Calligaro $K D$, Ascer $E$, Torres $M$, Veith FJ. The effect of adjunctive arteriovenous fistula on prosthetic graft patency: a controlled study in a canine model. J.Cardiovasc. Surg. 1990;31:646-650. 
48. Faulkner SL, Fisher RD, Conkle

DM, Page DL, Bender-HW J.

Effect of blood flow rate on

subendothelial proliferation in

venous autografts used as arterial

substitutes. Circulation

1975;52:1163-1172.

49. Mattsson EJ, Kohler TR, Vergel

SM, Clowes AW. Increased blood flow induces regression of intimal hyperplasia. Arterioscler. Thromb. Vasc.Biol. 1997;17:2245-2249.

50. Geary RL, Kohler TR, Vergel S, Kirkman TR, Clowes AW. Time course of flow-induced smooth muscle cell proliferation and intimal thickening in endothelialized baboon vascular grafts. Circ.Res. 1993;74:14-23.

51. Jacobs MJ, Gregoric ID, Reul GJ. Prosthetic graft placement and creation of a distal arteriovenous fistula for secondary vascular reconstruction in patients with severe limb ischemia.

J.Vasc. Surg. 1992;15:612-618.

52. Dobrin PB, Littooy FN, Endean

ED. Mechanical factors

predisposing to intimal hyperplasia and medial thickening in autogenous vein grafts. Surgery 1989;105:393-400.

53. Schwartz LB, O'Donohoe MK, Purut CM, Mikat EM, Hagen PO, McCann R. Myointimal thickening in experimental vein grafts is dependent on wall tension. J.Vasc. Surg. 1992;15:176-186.

54. Chervu A, Moore WS. An overview of intimal hyperplasia. Surg.Gynecol.Obstet. 1990;171:433-447.

55. Zarins CK, Zatina MA, Giddens DP, Ku DN, Glagov S. Shear stress regulation of artery lumen diameter in experimental atherogenesis. J.Vasc. Surg. 1987;5:13-20.

56. Hofstra L, Tordoir JHM, Kitslaar PJEHM, Hoeks APG, Daemen MJAP. Enhanced cellular proliferation in intact stenotic lesions derived from human arteriovenous fistulas and peripheral bypass grafts. Does it correlate with flow parameters? Circulation 1996;94:1283-1290.

57. Fillinger MF, Reinitz ER, Schwartz RA, Resetarits DE, Paskanik AM, Bredenberg CE. Beneficial effects of banding on venous intimal-medial hyperplasia in arteriovenous loop grafts. Am.J.Surg. 1989;158:87-94.

58. Hofstra L, Bergmans DCJJ, Leunissen KML, et al. Anastomotic intimal hyperplasia in prosthetic arteriovenous fistulas for hemodialysis is associated with initial high flow velocity and not with mismatch in elastic properties. J.Am.Soc.Nephrol. 1995;6:1625-1633.

59. Davies MG, Klyachkin ML, Dalen $H$, Massey MF, Svendsen $E$, Hagen PO. The integrity of experimental vein graft endothelium - Implications on the etiology of early graft failure.

Eur.J.Vasc.Surg. 1993;7:156-165.

60. Barbee KA, Mundel T, Lal R, Davies PF. Subcellular distribution of shear stress at the surface of flow-aligned and nonaligned endothelial monolayers. Am.J.Physiol. 1995;268:H1765-H1772

61. Gimbron-MA J, Nagle T, Topper JN. Biomechanical activation: an emerging paradigm in endothelial adhesion biology. J.Clin.Invest. 1997;99:1809-1813.

62. Fei DY, Thomas JD, Rittgers SE. The effect of angle and flow rate upon hemodynamics in distal vascular graft anastomoses: a numerical model study. J.Biomech.Eng. 1994;116:331-336.

63. Bassiouny HS, White S, Glagov S, Choi E, Giddens DP, Zarins CK. Anastomotic intimal hyperplasia: mechanical injury or flow induced. J.Vasc.Surg. 1992;15:708-716.

64. Steinman DA, Vinh B, Ethier CR, Ojha M, Cobbold RS, Johnston $\mathrm{KW}$. A numerical simulation of flow in a two-dimensional end-toside anastomosis model. $J$. Biomech.Eng. 1993;115:112-118.

65. Ojha M, Cobbold RS, Johnston $\mathrm{KW}$. Hemodynamics of a side-to- 
end proximal arterial anastomosis model. J.Vasc.Surg. 1993;17:646655.

66. Henry FS, Collins MW, Hughes PE, How TV. Numerical investigation of steady flow in proximal and distal end-to-side anastomoses. J.Biomech.Eng. 1996;118:302-310.

67. Sottiurai VS, Sue SL, Feinberg EL, Bringaze WL, Tran AT, Batson RC. Distal anastomotic intimal hyperplasia: biogenesis and etiology. Eur.J.Vasc.Surg. 1988;2:245-256.

68. Trubel W, Schima $H$, Moritz A, et al. Compliance mismatch and formation of distal anastomotic intimal hyperplasia in externally stiffened and lumen-adapted venous grafts. Eur.J.Vasc. Endovasc.Surg. 1995;10:415-423.

69. Madras P, Ward C, Johnson W, Singh P. Anastomotic hyperplasia. Surgery 1981;90:922-923.

70. Lei M, Archie JP, Kleinstreuer C. Computational design of a bypass graft that minimizes wall shear stress gradients in the region of the distal anastomosis. J.Vasc. Surg. 1997;25:637-646.

71. Fillinger MF, Reinitz ER, Schwartz RA, et al. Graft geometry and venous intimalmedial hyperplasia in arteriovenous loop grafts. J.Vasc.Surg. 1990;11:556-566.

72. Rittgers SE, Karayannacos PE, Guy JF, et al. Velocity distribution and intimal proliferation in autologous vein grafts in dogs. Circ.Res. 1978;42:792-801.

73. Ojha M, Cobbold RS, Johnston $\mathrm{KW}$. Influence of angle on wall shear stress distribution for an end- to-side anastomosis. J.Vasc.Surg. 1994;19:1067-1073.

74. Keynton RS, Rittgers SE, Shu $M C$. The effect of angle and flow rate upon hemodynamics in distal vascular graft anastomoses: an in vitro model study. J.Biomech. Eng. 1991;113:458-463.

75. Wang LC, Guo GX, Tu R, Hwang $\mathrm{NH}$. Graft compliance and anastomotic flow patterns. ASAIO.Trans. 1990;36:90-94.

76. Zurbrugg HR, Wied M, Angelini GD, Hetzer R. Reduction of intimal and medial thickening in sheathed vein grafts. Ann.Thor.Surg. 1999;68:79-83.

77. Karayannacos $\mathrm{P}$, Hostetler J, Bond $M$, et al. Late failure in vein grafts. Mediating factors in subendothelial fibromuscular hyperplasia. Ann.Surg. 1978;187:183-188.

78. Kohler TR, Kirkman RL, Clowes AW. The effect of rigid external support on vein graft adaptation to the arterial circulation. J.Vasc. Surg. 1989;9:277-285.

79. Mehta D, George SJ, Jeremy JY, et al. External stenting reduces long-term medial and neointimal thickening and platelet derived growth factor expression in a pig model of arteriovenous bypass grafting. Nature Medicine 1998;4:235-239.

80. Hofstra L, Bergmans DC, Hoeks AP, Kitslaar PJ, Leunissen KM, Tordoir $\mathrm{JH}$. Mismatch in elastic properties around anastomoses of interposition grafts for hemodialysis access. J.Am.Soc. Nephrol. 1994;5:1243-1250.

81. Siegman FA. Use of a venous cuff for graft anastomosis. Surg.Gynecol.Obstet. 1979;148:930-930.

82. Bolduc ME, Simpson MA, Espanola C, Petscheck HE, Madras PN. The extend and morphology of intimal hyperplasia with the use of arterial patches. J.Cardiovasc. Surg. 1989;30:89-90.

83. Tyrrell MR, Grigg MJ, Wolfe J. Is arterial reconstruction to the ankle worthwhile in the absence of autologous vein? Eur.J.Vasc. Surg. 1989;3:429-434.

84. Morris GE, Raptis S, Miller JH, Faris IB. Femorocrural grafting and regrafting: Does polytetrafluoroethylene have a role? Eur.J.Vasc.Surg. 1993;7:329-334.

85. Raptis S, Miller JH. Influence of a vein cuff on polytetrafluoroethylene 
grafts for primary femoropopliteal bypass. Br.J.Surg. 1995;82:487-

491.

86. Yeager RA, Hobson RW, Jamil Z, Lynch TG, Lee BC, Jain K.

Differential patency and limb salvage for polytetrafluoroethylene and autogenous saphenous vein in severe lower extremity ischemia. Surgery 1982;91:99-103.

87. Rutherford RB, Jones DN, Bergentz $S$, et al. Factors affecting the patency of infrainguinal bypass. J.Vasc.Surg. 1988;8:236246.

88. Veith FJ, Gupta SK, Daly V. Management of early and late thrombosis of expanded polytetrafluoroethylene (PTFE) femoropopliteal bypass grafts: favorable prognosis with appropriate reoperation. Surgery 1980;87:581-587.

89. Rafferty TD, Avellone JC, Farrell $\mathrm{CJ}$, et al. A metropolitan experience with infrainguinal revascularisation. Operative risk and late results in northeastern Ohio. J.Vasc.Surg. 1987;6:365371.

90. Karacagil S, Holmberg A, Narbani A, Eriksson I, Bergqvist D. Composite polytetrafluoroethylene / vein bypass grafts: conventional distal vein segment or vein cuff? Eur.J.Vasc.Endovasc.Surg. 1996:12:337-341.

91. Harris PL, Bakran A, Enabi L, Nott DM. ePTFE grafts for femorocrural bypass--improved results with combined adjuvant venous cuff and arteriovenous fistula? Eur.J.Vasc.Surg. 1993;7:528-533.

92. Brumby SA, Petrucco MF, Walsh JA, Bond MJ. A retrospective analysis of infra-inguinal arterial reconstruction: three year patency rates. Aust.N.Z.J.Surg. 1992;62:256-260.

93. Stonebridge PA, Howlett $R$, Prescott R, Ruckley CV. Randomised trial comparing polytetrafluoroethylene graft patency with and without a Miller cuff. Br.J.Surg. 1995;82:555-556.
94. Thompson MM, Beard JD, Bell PRF. Subclavian-to-subclavian bypass facilitated by the use of an interposition vein cuff. Br.J.Surg. 1991;78:630-631.

95. Lemson MS, Tordoir JHM, Hofstra L, Leunissen KML. Veneuze cuffs bij PTFE arterioveneuze fistels voor hemodialyse. Ned.Tijdschr. Heelk. 1995;4:79-84.

96. Taylor RS. Les pontages prothétiques: pouvons-nous améliorer les résultats. J.Mal.Vasc. 1991;16:18-22.

97. McFarland RJ, Taylor RS. Une amélioration technique d'anastomose des prothèses artérielles fémoro-distales. Phlébologie 1988;41:229-233.

98. Taylor RS, Dormandy JA. Letter: Justifying arterial reconstruction to crural vessels - even with a prosthetic graft. and $\mathrm{New}$ prosthetic venous coliar anastomotic technique: combining the best of other procedures. Br.J.Surg. 1991;79:183-183.

99. Taylor RS, Loh A, McFarland RJ, Cox M, Chester JF. Improved technique for polytetrafluoroethylene bypass grafting: long-term results using anastomotic vein patches. Br.J.Surg. 1992;79:348-354.

100. Loh A, Chester JF, Taylor RS. PTFE bypass grafting to isolated popliteal segments in critical limb ischemia. Eur.J.Vasc. Surg. 1993;7:26-30.

101. Ligush J. Clinical trials a must. Letter to the editor. J.Vasc.Surg. 1995;21:707-708.

102. Batson RC, Sottiurai VS, Craighead CC. Linton patch angioplasty: an adjunct to distal bypass with polytetrafluoroethylene grafts. Ann.Surg. 1984;199:684-693.

103. Tyrrell MR, Wolfe J. New prosthetic venous collar anastomotic technique: combining the best of other procedures. Br.J.Surg. 1991;78:1016-1017.

104. Brennan JA, Enzler MA, da Silva AF, How TV, Harris PL. New graft 
design to inhibit myointimal hyperplasia in small vessel anastomosis. Br.J.Surg. 1996;83:1383-1384.

105. Scholz H, Petzold K, Kruger U, Settmacher U, Petzold M, Zanow J. Four years experience with arteriovenous patchprosthesis as access for hemodialysis. In: Tordoir JHM. Proc.3rd Int.congress on acces for dialysis, October 1997, Maastricht. 1997:61-62.

106. Karacagil $S$, Narbani A, Aimgren $B$, Bowald S, Bergqvist D. Modified vein cuff technique for distal polytetrafluoroethylene graft anastomoses: how we do it. Eur.J.Surg. 1995;161:47-48.

107. Beard JD, Benveniste GL, Miller $\mathrm{JH}_{1}$ Baird RN, Horrocks M. Haemodynamics of the interposition vein cuff. Br.J.Surg. 1986;73:823-825.

108. Tyrrell MR, Rampling MW, Woife J, Chester JF, Taylor RS. PTFE, collars, and patches.

J.Invest.Surg. 1992;5:25-34.

109. Tyrrell MR, Chester JF, Vipond MN, Clarke GH, Taylor RS, Wolfe J. Experimental evidence to support the use of interposition vein collars/patches in distal PTFE anastomoses.

Eur.J.Vasc.Surg. 1990;4:95-101.

110. Tyrrell MR, Wolfe J. Vein collars make femorocrural grafts worthwhile. In: Greenhaigh R, Collier L, eds. The maintenance of arterial reconstruction. London: WB Saunders Co Ltd, 1991;45-55.

111. Wijesinghe LD, Smye SW, Scott DJA. Impedance index measurements of in vitro PTFE end-to-side anastomoses: effect of angle and Miller cuff.

Eur.J.Vasc.Endovasc.Surg. 1998;16:65-70.

112. da Silva AF, Carpenter $T$, How TV, Harris PL. Stable vortices within vein cuffs inhibit anastomotic myointimal hyperplasia? Eur.J.Vasc. Endovasc.Surg. 1997;14:157-163.

113. Tyrrell MR, Clarke $G H$, Wolfe J. Consideration of the mechanical properties at the distal anastomosis of PTFE grafts may improve patency rates. $J$. Cardiovasc.Surg. 1989;30:91-91.

114. Gentile AT, Mills JL, Gooden MA, et al. Vein patching reduces neointimal thickening associated with prosthetic graft implantation. Am.J.Surg. 1998;176:601-607.

115. Suggs WD, Henriques HF, DePalma RG. Vein cuff interposition prevents juxtaanastomotic neointimal hyperplasia. Ann. Surg. 1988;207:717-723.

116. Norberto JJ, Sidawy AN, Trad KS, et al. The protective effect of vein cuffed anastomoses is not mechanical in origin. J.Vasc. Surg. 1995;21:558-566.

117. Sottiurai VS, Jones $R$, Nakamura YA, Boustany C, Sue SL, Batson $\mathrm{RC}$. The role of vein patch in distal anastomotic intimal hyperplasia: an histologic characterization. Int.Angiol. 1994;13:96-102.

118. Davies MG, Kim JH, Barber L, Dalen H, Svendsen E, Hagen PO. Systemic hypertension and hypercholesterolemia in vein grafts: effects on the function and morphology of experimental vein grafts. J.Surg.Res. 1994;57:106121.

119. Davies MG, Dalen $\mathrm{H}$, Kim JH, Barber L, Svendsen E, Hagen PO. Control of accelerated vein graft atheroma with the nitric oxide precursor: L-arginine. J.Surg.Res. 1995;59:35-42.

120. Davies MG, Dalen $H, B a r b e r L$, Svendsen E, Hagen PO. Lazaroid therapy (methylaminochroman: U83836E) reduces vein graft intimal hyperplasia. J.Surg.Res. 1996;63:128-136.

121. Hanson SR, Powell JS, Dodson T, et al. Effects of angiotensin converting enzyme inhibition with cilazapril on intimal hyperplasia in injured arteries and vascular grafts in the baboon. Hypertension 1991;18[suppl II]:11-70-11-76.

122. Ao PY, Hawthorne WJ, Coombs R, Fletcher JP. Suppression of intimal hyperplasia with low 
molecular weight heparin in a

sheep model. Int.Angiol.

1999;18:131-139.

123. Ferguson JJ. EPILOG and CAPTURE trials halted because of positive interim results [news]. Circulation 1996;93:637.

124. Marston WA. Surgical management of thrombosed dialysis access grafts. Am.J. Kidney Dis. 1998;32:168-171.

125. Cohen MA, Kumpe DA, Durham JD, Zwerdlinger SC. Improved treatment of thrombosed hemodialysis access sites with thrombolysis and angioplasty. Kidney Int. 1994;46:1375-1380.

126. Beathard GA. Endovascular management of thrombosed dialysis access grafts. Am.J.Kidney Dis. 1998;32:172175.

127. Davis RD. Percutaneous transluminal angioplasty. In: Sabiston DCjr, ed. Textbook of Surgery. Philadelphia: W.B. Saunders Company, 1991;16011602.

128. Turmel Rodrigues L, Pengloan J, Blanchier D, et al. Insufficient dialysis shunts: improved longterm patency rates with close hemodynamic monitoring, repeated percutaneous balloon angioplasty, and stent placement. Radiology 1993;187:273-278.
129. Hirai T, Korogi $Y$, Harada $M$, Takahashi M. Prevention of intimal hyperplasia by irradiation. An experimental study in rabbits. Acta Radiol. 1996;37:229-233.

130. Liermann DD, Bauernsachs $R$, Schopohl B, Bottcher HD. Five year follow-up after brachytherapy for restenosis in peripheral arteries. Semin.Interv.Cardiol. 1997;2:133-137.

131. O'Malley MK. Intimal hyperplasia. Eur.J.Vasc.Surg. 1992;6:343-345.

132. Mactier RA, Stewart WK, Parham $D M$, Tainsh JA. Acral gangrene attributed to calcific azotaemic arteriopathy and the steal effect of an arteriovenous fistula. Nephron 1990;54:347-350.

133. Gottlob R. The preservation of the venous endothelium by a dissection without touching and by an atraumatic technique of vascular anastomosis. Min.Chir. 1977;32:693-700.

134. Imparato AM, Bracco A, Kim GE, Zeff R. Intimal and neointimal fibrous proliferation causing failure of arterial reconstructions. Surgery 1972;72:1007-1017.

135. Wright JG. A randomized prospective clinical trial of the Taylor patch. Letter to the editor. J.Vasc.Surg. 1996;23:376-377. 


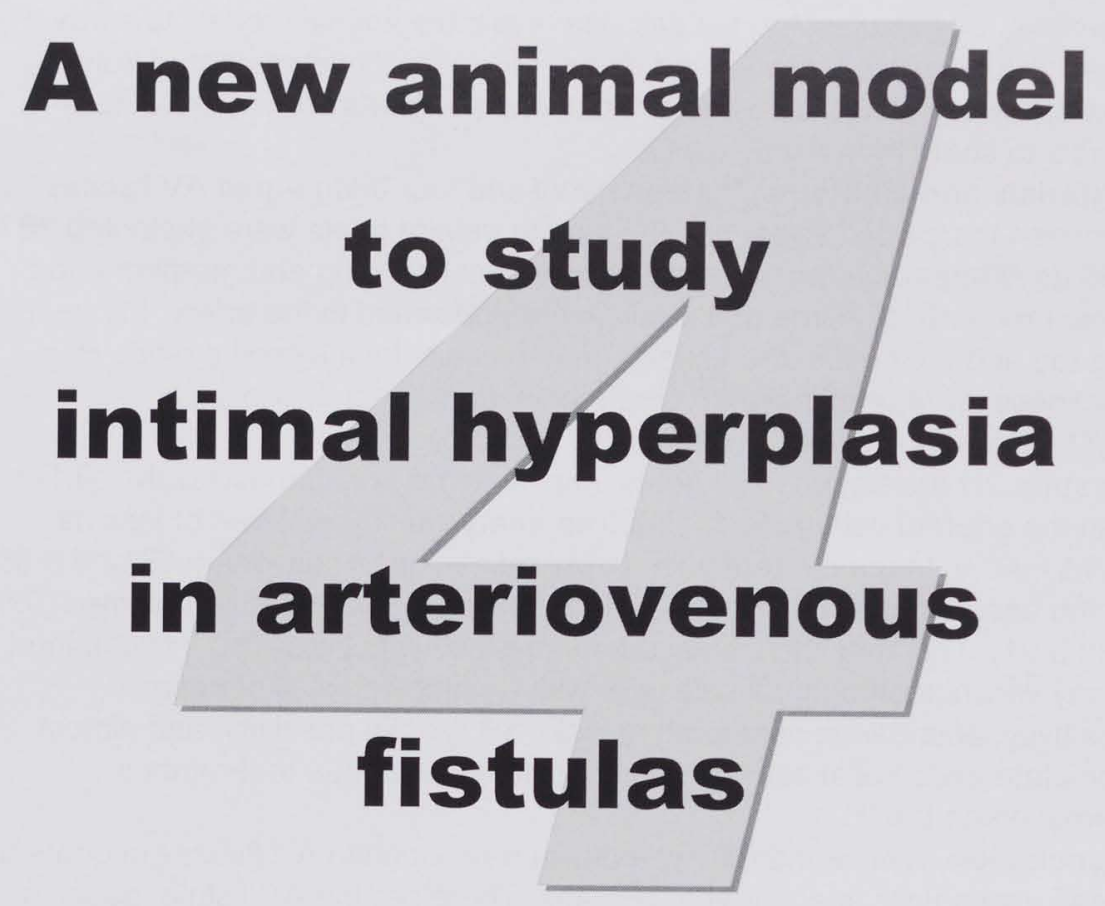

M.S. Lemson ${ }^{1,3}$; M.J.A.P. Daemen ${ }^{2,3}$; P.J.E.H.M. Kitslaar ${ }^{1,3}$; J.H.M Tordoir ${ }^{1,3}$. Departments of ${ }^{1}$ Surgery and ${ }^{2}$ Pathology, University Hospital Maastricht, ${ }^{3}$ Cardiovascular Research Institute Maastricht (CARIM), The Netherlands.

J.Surg.Res. 1999;85(1):51-58. 


\section{Abstract}

Background. Intimal hyperplasia $(\mathrm{IH})$ plays a key role in the failure of arteriovenous fistulas(AV) fistulas. The available animal models to study $\mathrm{IH}$ in AV fistulas are expensive and do not mimic the development of truly stenotic $\mathrm{IH}$. In this study we examined whether goats are a more suitable model to study $\mathrm{IH}$ in AV fistulas.

Materials and Methods. Thirteen direct and four bridge-graft AV fistulas between the carotid artery and the jugular vein of goats were explanted 10 to 195 days after creation. Immunohistochemical staining and morphometric measurements of intima and media were performed in the artery, the vein, the toe and the heel of the venous anastomosis. Intima-media ratios in thickness $\left(\mathrm{l}_{\mathrm{th}} / \mathrm{M}_{\mathrm{th}}=\right.$ Intimal thickness/medial thickness) and in area $\left(\mathrm{I}_{\mathrm{a}} / \mathrm{M}_{\mathrm{a}}=\right.$ Intimal area/medial area) were calculated.

Results. IH developed in all goats, mainly at the anastomosis $\left(\mathrm{I}_{\mathrm{a}} / \mathrm{M}_{\mathrm{a}}=0.17\right)$ and the efferent vein $\left(l_{a} / M_{a}=0.31\right)$. The artery was almost free of lesions $\left(I_{a} / M_{a}=0.03\right)$. In the efferent vein, $I_{\text {th }} / M_{\text {th }}$ ratios varied between 0.59 and 0.68 . In the anastomosis the largest $\mathrm{I}_{\mathrm{th}} / \mathrm{M}_{\mathrm{th}}$ ratio was found at the suture lines $(0.88$ and 0.91). The absolute intimal area increased with time. The $\mathrm{IH}$ contained many vascular smooth muscle cells with a patchy display of desmin positivity, abundance of smooth muscle cell $\alpha$-actin positivity, and almost complete endothelial cell coverage. Occlusion was due to thrombus formation on the $\mathrm{IH}$.

Conclusion. A clear intimal hyperplasia developed in AV fistulas in goats at locations comparable to that of humans. Therefore the AV fistula model in the goat may be seen as an effective model to study $\mathrm{IH}$ in hemodialysis AV fistulas. 


\section{Introduction}

Intimal hyperplasia plays a key role in the development of stenosis and subsequent thrombosis of coronary and peripheral arterial bypasses and of arteriovenous (AV) fistulas for hemodialysis. Over the years several animal models have been employed to obtain insight in the pathophysiological mechanisms of intimal development. These animal models are necessary because it is difficult to obtain human tissue for examination. Also, the effect of a surgical or pharmacological intervention can be studied more thoroughly in a controlled animal model. An adequate animal model is inexpensive, readily available, easy to use and develops lesions in a short time period ${ }^{1}$. The development of intimal hyperplasia in autologous venous bypasses has been studied in rats and rabbits. However, these animals are unsuitable to create prosthetic AV fistulas because of the high flow that is necessary to maintain patency, a flow that can not be obtained in these rather small animals.

For research on intimal development in peripheral prosthetic bypasses ${ }^{2-6}$ and polytetrafluoroethylene (PTFE) graft AV fistulas ${ }^{7-10}$, experiments have been performed in the carotid artery and the femoral vessels of larger animals like baboons, pigs and dogs. However, these animals are expensive and need separate homing. The lesions that develop in arteriovenous grafts in dogs are very similar to the hyperplastic lesions in humans. However, within the time periods studied, lasting up to 6 months, truly stenotic lesions are not encountered $^{11}$.

Therefore we searched for a new animal model. This model should have easily accessible vessels with dimensions that are comparable to humans. Goats were already used in a high-output cardiac failure model induced by creation of a direct AV fistula between the carotid artery and the jugular vein $^{12}$. From these studies we knew that the vessels in the neck of the goats were easy accessible, and the direct AV fistulas were readily available for histologic examination. The purpose of this study was to evaluate whether goats develop intimal hyperplasia and whether goats are a suitable model to study intimal hyperplasia in PTFE graft AV fistulas.

\section{Materials and Methods}

\section{Direct arteriovenous fistulas}

Thirteen Dutch landrace milkgoats weighing about $60 \mathrm{~kg}$ were anaesthetised with thiopentalnatrium $3 \mathrm{mg} / \mathrm{kg}$ (Nesdonal ${ }^{\circledR}$, Rhône-Poulenc Rorer, Amstelveen, The Netherlands), intubated endotracheally and inhalation anaesthesia was continued with $\mathrm{N}_{2} \mathrm{O} / \mathrm{O}_{2}(1: 2)$ and Halothane $(0.4 \%)$. The femoral artery was cannulated for continuous pressure monitoring and the femoral vein was used for i.v. administration of fluids. Through a longitudinal incision the common carotid artery and the jugular vein were dissected. Both vessels were clamped and the jugular vein was ligated. An end-to-side anastomosis was created using the full diameter of the jugular vein (usually about $1 \mathrm{~cm}$ ). Next, the carotid artery was ligated distal from the anastomosis. After 33 to 195 days, the goats were sacrificed and the arteriovenous fistula 
complexes were dissected and stored on $10 \%$ phosphate buffered formalin, $\mathrm{pH} 7.4$.

The Ethical Committee on Animal Experiments of the Maastricht University approved the design of the study. The animals were treated according to the Dutch Law on Animal Experimentation (WOD) and The European Directive for the Protection of Vertebrate Animals used for Experimental and other Scientific Purposes (86/609/EU).

\section{Pilot study with prosthetic arteriovenous fistulas}

In two Dutch landrace milkgoats weighing $20 \mathrm{~kg}$, PTFE graft arteriovenous fistulas were created on both sides of the neck between the common carotid artery and the jugular vein. Anaesthesia and peroperative monitoring was performed as described above. One dose of ceftiofur $250 \mathrm{mg}$ (UpJohn, Ede, The Netherlands) was given intravenously for antibiotic prophylaxis.

Through a longitudinal incision the common carotid artery and the jugular vein were dissected. A thin-walled stretch PTFE prosthesis (Gore-Tex ${ }^{\circledR}$, W.L. Gore \& Associates, Flagstaff, Arizona, USA) of $15 \mathrm{~cm}$ length and an internal diameter of $6 \mathrm{~mm}$ was tunnelled in a subcutaneous loop. The artery was clamped, an arteriotomy of 5-7 $\mathrm{mm}$ was made and the graft was anastomosed end-to-side to the artery with polypropylene monofilament $6 \times 0$ (Prolene $^{\circledR}$, Ethicon, Johnson \& Johnson Medical BV, Amersfoort, The Netherlands). Next, the jugular vein was clamped, a venotomy of $1.5-2 \mathrm{~cm}$ was made and the PTFE prosthesis was anastomosed to the vein. The same procedure was conducted contralaterally. In case of thrombotic occlusion of both prostheses, the goat was anaesthetised and the PTFE prosthesis with afferent artery and efferent vein were explanted and stored on formalin. Subsequently, the animal was sacrificed with an intravenous injection of $10 \mathrm{ml}$ euthesate (sodium pentobarbital $200 \mathrm{mg} / \mathrm{ml}$, Apharmo BV, Arnhem, The Netherlands). One goat died with patent grafts after 10 days. In the other goat, occlusion occurred after 4 weeks on one side and after 7 weeks on the other side.

\section{Histopathological examination}

The tissue specimens were fixed overnight in 10\% phosphate buffered formalin, $\mathrm{pH} \mathrm{7.4.} \mathrm{Rings} \mathrm{of} \mathrm{the} \mathrm{direct} \mathrm{arteriovenous} \mathrm{fistulas} \mathrm{and} \mathrm{of} \mathrm{the} \mathrm{PTFE}$ graft AV fistulas were processed and embedded in paraffin. To allow morphometrical evaluation, $4 \mu \mathrm{m}$ thick sections were immersed in Lawsons' solution (Boom, Meppel, The Netherlands) for 1 hour to stain the elastic fibres. Separate Hematoxilin-Eosin stained sections were used to discern intimal hyperplasia from organised thrombi.

Antibodies against desmin and $\alpha$-smooth muscle cell actin were used as vascular smooth muscle cell markers. After deparaffinising the sections, the endogenous peroxidase activity was blocked with $0.3 \% \mathrm{H}_{2} \mathrm{O}_{2}$ in methanol (15 minutes) and the tissue was predigested with pepsin $1 \mathrm{mg} / \mathrm{ml}$ (Boehringer, Mannheim, Germany) for 30 minutes. The slides were incubated with the primary antibody, either monoclonal mouse anti-Smooth Muscle Cell Actin (a-SMA 1:500, DAKO M 0851, Glostrup, Denmark) or 
monoclonal mouse anti-Desmin (1:100, Organon MDE II, Eurodiagnostics, Arnhem, The Netherlands) for 45 minutes. Next the slides were incubated with biotinated sheep anti-mouse IgG (1:250, Amersham, Life Science, England) for 30 minutes, followed by 30 minutes labelling with Avidin/Biotin complex conjugated to horseradish peroxidase (Brunschwig, Detroit, Miami, USA) for amplification, using 3,3' diaminobenzidine as the chromogen. All incubations were executed at room temperature. The sections were counterstained with hematoxilin, dehydrated through graded series of alcohols and mounted. A piece of human small intestine was used as a positive control and a section without primary antibody as a negative control. To identify endothelial cells, sections were incubated for 45 minutes with polyclonal anti-Factor VIII (1:2000, DAKO A 0082, Glostrup, Denmark) after blocking the endogenous peroxidase activity with $0.3 \% \mathrm{H}_{2} \mathrm{O}_{2}$ in methanol and predigestion with pepsin as described above. After incubation with biotinylated Sheep anti-rabbit IgG (1:100, Amersham, Life Science, England) for 30 minutes, the labelling protocol was continued as described above. Human colon served as a positive control and a section without primary antibody as a negative control.

The areas (CSA) of the tunica media and the tunica intima were assessed on the Lawson stained sections using a computerised morphometer (Quantimet 570, Leica, Cambridge, UK). The tunica intima was defined as the amount of tissue between the lumen and the internal elastic lamina. The tunica media was defined as the tissue between the internal and external elastic lamina. Because of the eccentric distribution of intimal thickening, thickness of tunica media and intima was assessed at 4 locations in the vessel area. In the anastomosis, location 1 was the roof, location 2 the floor of the anastomosis and location 3 and 4 the connections. In the artery and vein, location 1 was at the site where artery and vein faced each other, location 2 the opposite side and 3 and 4 in between those 2 locations (fig 4.1). The intima-media ratio in thickness $\left(I_{t h} / M_{t h}\right)$ was calculated at the four different sites, and a ratio of the intimal and medial area was calculated $\left(\mathrm{I}_{\mathrm{a}} / \mathrm{M}_{\mathrm{a}}=\right.$ intimal area / medial area). In the factor VIII stained slides, the degree of endothelial coverage was measured as the percentage of lumenoutline that was covered with endothelium.

Statistical analysis of the bridge-grafts was performed using the Student's ttest. In the direct AV fistulas different parameters were compared using ANOVA. Pearson's correlation coefficients were calculated for intimal area with time of follow-up and endothelial cell coverage with thrombus area. A pvalue $<0.05$ was considered statistically significant.

\section{Results}

In the 2 PTFE graft AV fistulas, the vein and artery cranial from the arteriovenous fistula were considered to be normal. The area between the internal elastic lamina and the lumen only contained a single layer of endothelial cells. The veins had a thin media with concentric fibres of elastin with $\alpha$-actin-positive vascular smooth muscle cells and a dense extracellular matrix between them. The arteries had a thicker media than the vein with 
more elastin and $\alpha$-actin-positive cells.

\section{PTFE Graft AV fistulas}

In the pilot study with the PTFE graft AV fistulas, the first goat (A) died 10 days postoperatively, with patent grafts, due to sepsis. The second goat (B) developed fistula occlusion on one side after 4 weeks and on the other side after 7 weeks. Morphometry showed a larger intimal area in goat $B$ compared to goat $A$ at all locations $(p=0.079)$. The intima was largest in the anastomosis $\left(A=0.5 \mathrm{~mm}^{2}, B=5.7 \mathrm{~mm}^{2}\right)$ and in the efferent vein $(A=0$ $\mathrm{mm}^{2}, B=1.3 \mathrm{~mm}^{2}$ ). In goat $B$, the venous anastomoses were almost entirely occupied by intimal hyperplasia. The residual lumen was filled with thrombus (fig 4.2). Both grafts were thrombosed over their entire length, probably because of reduced flow caused by severe stenosis at the venous anastomosis.

\section{Direct $A V$ fistulas}

The results of the 13 direct $A V$ fistulas are summarised in table 4.1. All of the $\operatorname{direct} A V$ fistulas were patent at the time of harvesting. The amount of intimal area was positively correlated with the duration of fistula existence $(r=0.30$; Confidence interval for $r=0.06-0.51 ; p=0.016)$. The intimal area was significantly smaller in the artery $\left(0.22 \mathrm{~mm}^{2}\right)$ than in the vein $\left(3.04 \mathrm{~mm}^{2}\right.$, $p=0.01)$. No significant difference was found between artery and anastomosis $\left(2.94 \mathrm{~mm}^{2}, p=0.10\right)$. The intimal-medial area ratio was significantly smaller in the artery $(0.03)$ than in the vein $(0.31, p<0.001)$, but was not different from la/Ma in the anastomosis $(0.17, p=0.23)$, indicating that intimal hyperplasia mainly occurred in the vein. The artery was usually not affected. The intima/media ratio in thickness was calculated for all 4 locations. $I_{\mathrm{th}} / \mathrm{M}_{\mathrm{th}}$ in the roof of the anastomosis (location 1) was comparable to $I_{\text {th }} / M_{\text {th }}$ in the artery $(0.03$ vs. $0.05, p=1.00)$ and was significantly smaller than in the vein $(0.64, p=0.02)$. At location 2 , the floor of the anastomosis,

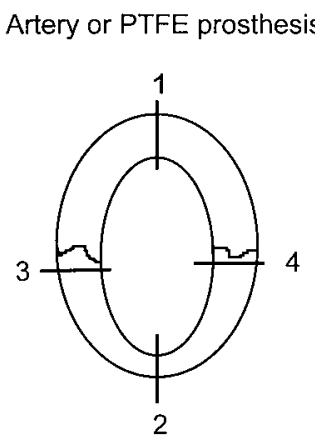

vein

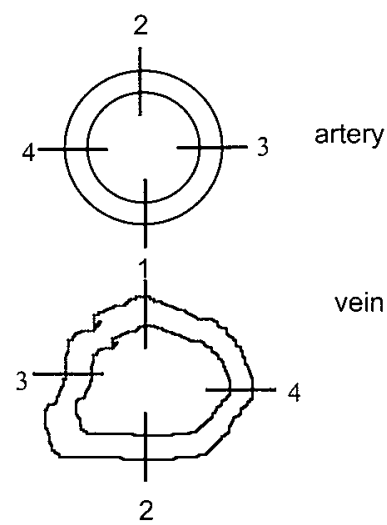

2

Figure 4.1 Location of measuring sites 1, 2, 3, 4 in the anastomotic and arterial and vein sections. 
no significant difference was found between the artery, anastomosis and vein. In the anastomosis, significantly more intimal hyperplasia developed at the suture line $\left(\mathrm{I}_{\mathrm{th}} / \mathrm{M}_{\mathrm{th}} 3=0.87, \mathrm{I}_{\mathrm{th}} / \mathrm{M}_{\mathrm{th}} 4=0.92\right)$ compared to the locations in the vein $\left(I_{t h} / M_{t h} 3=0.59, I_{t h} / M_{t h} 4=0.58\right)$ and in the artery $\left(I_{t h} / M_{t h} 3=0.05\right.$, $\left.\mathrm{I}_{\mathrm{th}} / \mathrm{M}_{\mathrm{th}} 4=0.04\right)$. The percentage of lumen, covered with endothelial cells was smaller in the anastomosis $(70 \%)$ than in the artery $(98 \% . p<0.001)$ and in the vein $(97 \%, p<0.001)$. In the anastomosis, intimal hyperplastic lesions at the sutureline were usually not covered with endothelium.

Often, fibrin deposition was seen on these locations. In the vein, the hyperplastic lesions of the intima were covered with endothelium. If EC coverage was absent, often a deposition of thrombus was seen. The area of thrombus was inversely correlated with the EC coverage $(r=-0.73$, $p<0.001)$. Thrombus area was largest in the anastomosis $\left(8.58 \mathrm{~mm}^{2}\right)$, whereas no difference in thrombus area between artery $\left(0.13 \mathrm{~mm}^{2}\right)$ and vein $\left(0.05 \mathrm{~mm}^{2}\right)$ could be demonstrated.

Smooth muscle cell $\alpha$-actin was abundantly present in the hyperplastic intimal lesions as well as in the media. Desmin distribution was patchy and only visible in small parts of the intimal hyperplastic lesions. Marked fragmentation of the elastic fibres, disrupting the structure of the media, was seen in all samples with intimal hyperplasia. This fragmentation was not seen in the vessels obtained cranial from the bridge grafts. Usually, no continuation of the internal and external elastic laminas was found (fig 4.3).

Table 4.1 Results of the direct AV fistulas. Values are mean $\pm S E M . N=$ number of tissue blocks; ana $=$ anastomosis; $\mathrm{I}_{\mathrm{a}} / \mathrm{M}_{\mathrm{a}}=$ intimal area $/$ medial area; $\% \mathrm{EC}=\%$ of lumen covered with endothelium; I = intimal; $\mathrm{l}_{\mathrm{th}} / \mathrm{M}_{\mathrm{th}} 1,2,3,4=$ intimal medial thickness at location 1,2,3,4.

\begin{tabular}{lllllll}
\hline & Artery & $\begin{array}{l}\text { Anasto- } \\
\text { mosis }\end{array}$ & Vein & $\begin{array}{l}\text { P-value } \\
\text { Artery } \\
\text { vs. Ana }\end{array}$ & $\begin{array}{l}\text { P-value } \\
\text { Artery } \\
\text { vs. vein }\end{array}$ & $\begin{array}{l}\text { P-value } \\
\text { Vein } \\
\text { vs. Ana }\end{array}$ \\
\hline $\mathrm{N}$ & 29 & 12 & 30 & & & \\
$\begin{array}{l}\text { Intimal area } \\
{\left[\mathrm{mm}^{2}\right]}\end{array}$ & $0.22 \pm 0.07$ & $2.94 \pm 1.41$ & $3.04 \pm 0.85$ & 0.10 & 0.01 & 1.00 \\
$\mathrm{l}_{\mathrm{a}} / \mathrm{M}_{\mathrm{a}}$ & $0.03 \pm 0.01$ & $0.17 \pm 0.07$ & $0.31 \pm 0.06$ & 0.23 & $<0.001$ & 0.31 \\
$\mathrm{I}_{\mathrm{th}} / \mathrm{M}_{\mathrm{th}} 1$ & $0.05 \pm 0.02$ & $0.03 \pm 0.02$ & $0.64 \pm 0.17$ & 1.00 & 0.002 & 0.02 \\
$\mathrm{I}_{\mathrm{th}} / \mathrm{M}_{\mathrm{th}} 2$ & $0.25 \pm 0.18$ & $0.60 \pm 0.24$ & $0.68 \pm 0.22$ & 1.00 & 0.38 & 1.00 \\
$\mathrm{I}_{\mathrm{th}} / \mathrm{M}_{\mathrm{th}} 3$ & $0.05 \pm 0.02$ & $0.87 \pm 0.39$ & $0.59 \pm 0.17$ & 0.02 & 0.05 & 0.94 \\
$\mathrm{l}_{\mathrm{th}} / \mathrm{M}_{\mathrm{th}} 4$ & $0.04 \pm 0.02$ & $0.91 \pm 0.48$ & $0.58 \pm 0.16$ & 0.01 & 0.06 & 0.74 \\
$\%$ EC & $98 \pm 1 \%$ & $70 \pm 5 \%$ & $97 \pm 1 \%$ & $<0.001$ & 1.00 & $<0.001$ \\
$T_{\text {Thrombus area }}$ & $0.13 \pm 0.13$ & $8.58 \pm 3.51$ & $0.05 \pm 0.00$ & $<0.001$ & 1.00 & $<0.001$ \\
{$\left[\mathrm{~mm}^{2}\right]$} & & & & & & \\
\hline
\end{tabular}


a

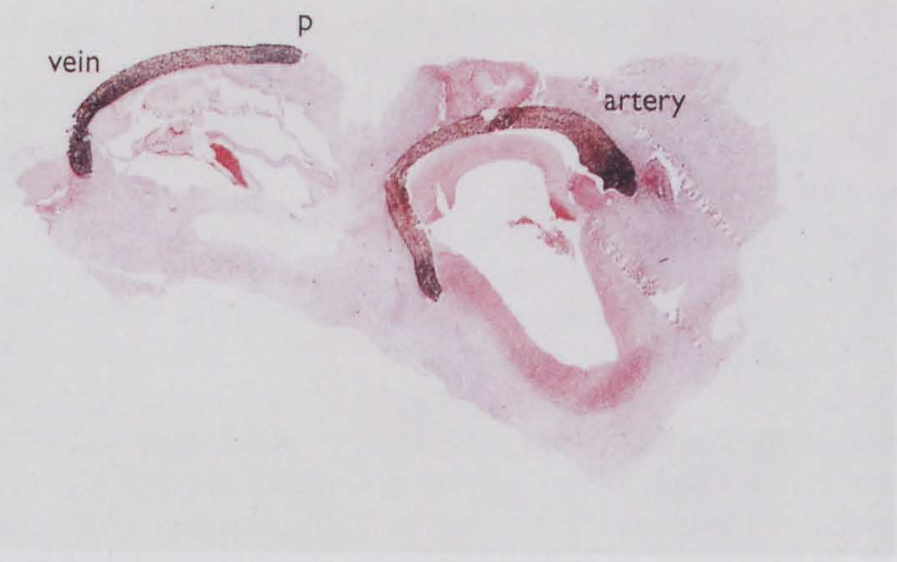

b

Figure 4.2

Prosthetic graft arteriovenous fistula, hematoxilin-eosin stained, magnification $5 x$. $l=$ =intima, $p=$ prosthesis, $t=$ thrombus.
a) arterial and venous anastomosis of the PTFE graft AV fistula explanted after 10 days
b) after 7 weeks with a thrombotic occlusion. 

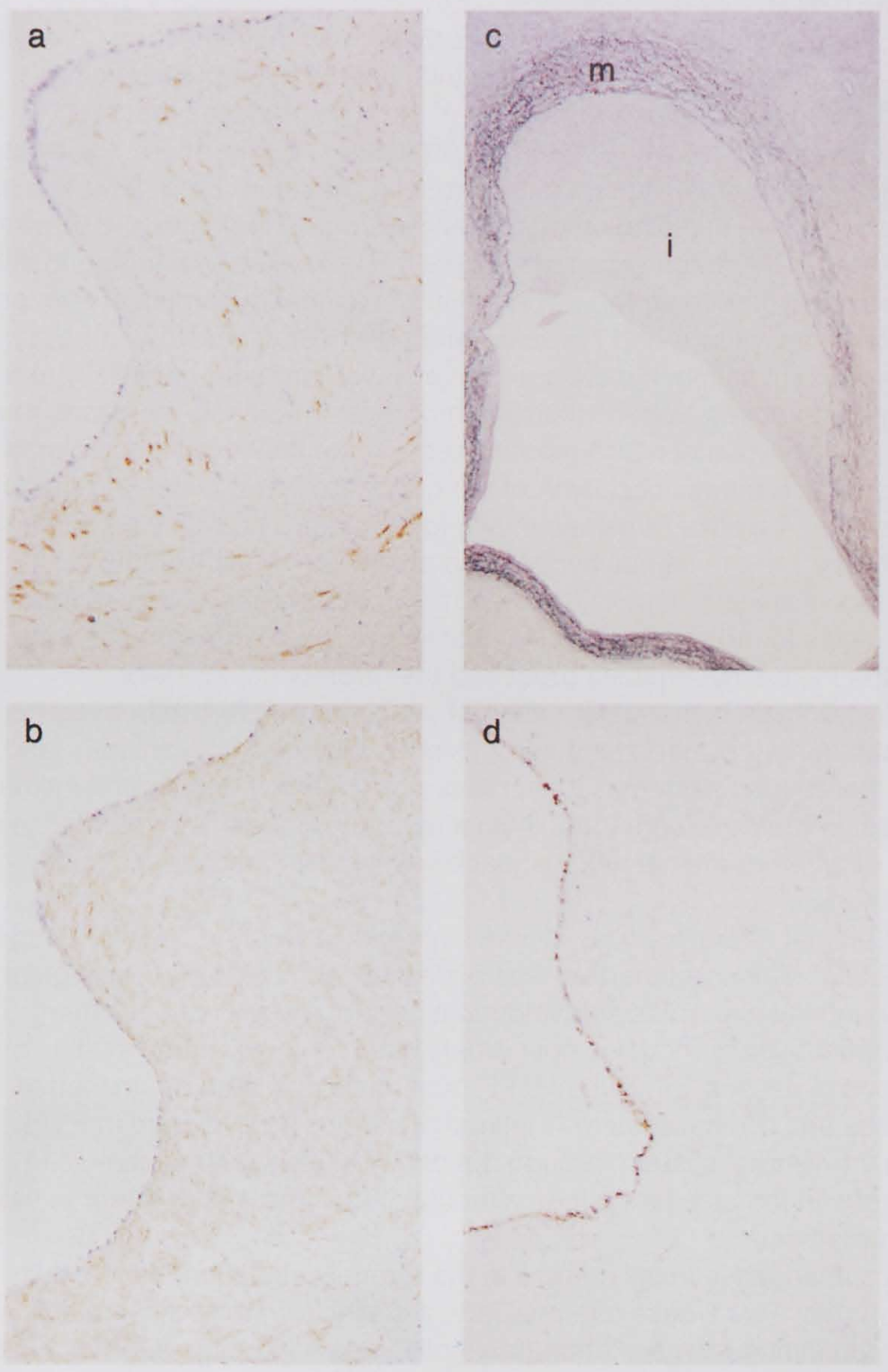

Figure 4.3 Direct arteriovenous fistula

a) desmin stained, magnification 200x. Note the patchy distribution, only present in the intima.

b) actin stained, magnification 200x. Actin positive cells are present in the media and the intima.

c) Lawson stained for elastic fibres, magnification 10x. The elastic fibres are fragmented, with no continuation of the internal and external elastic laminas. I=intima, $\mathrm{m}=$ media.

d) FVIII stained for endothelium, magnification 200x. Endothelium covers the hyperplastic intimal lesion. 


\section{Discussion}

In the present study we found that goats developed intimal hyperplasia after creation of a direct or PTFE graft AV fistula. Intimal hyperplasia mainly occurred at the anastomosis and in the efferent vein at sites that are comparable to the sites of $\mathrm{IH}$ in human AV fistulas. Furthermore, the area and thickness of intimal hyperplasia increased with time. Fragmentation of the elastic fibres at the location of intimal hyperplasia indicates vessel wall damage, either due to surgical handling or the increased pressure and shear stress, possibly preceding the development of intimal hyperplasia. Two graft fistulas occluded after 4 and 7 weeks, with no signs of infection. In both grafts, prominent intimal hyperplastic lesions were present especially at the venous anastomoses, with concurrent thrombosis. Stenosis increases the anastomotic resistance, which jeopardises volume flow. Reduced volume flow leads to thrombotic occlusion of the grafts. However, since the graft that occluded after 4 weeks remained in situ for another 3 weeks, we could not establish whether the intimal hyperplasia preceded or followed the thrombotic occlusion. Since in the graft that occluded after 7 weeks fresh thrombus was found on a marked intimal lesion, we assume that in both fistulas the intimal hyperplasia preceded the thrombotic occlusion. Intimal hyperplasia is the major cause of vascular graft failure between 2 and 24 months. A better understanding of its pathobiology will eventually lead to rational therapeutic strategies to increase graft patency and control intimal hyperplasia. The development of intimal hyperplasia has been studied in a number of different animal models; each with its own advantages and disadvantages.

The first animal model to study intimal hyperplasia was the New Zealand white rabbit ${ }^{13}$. The carotid artery was bypassed with the ipsilateral jugular vein, and intimal hyperplasia developed within four weeks after grafting. This rabbit arterial bypass model is now widely used for intervention studies on autologous bypasses ${ }^{14-18}$. But a PTFE prosthesis may also be implanted into the venous and arterial system ${ }^{19}$. Intimal hyperplasia developed in PTFE grafts in the venous system through a mostly identical mechanism as in PTFE grafts in the arterial system, although it occurred much faster in the venous prosthesis ${ }^{20}$.

Histologic changes in veins, placed in the arterial circulation, have been studied in rats. Two weeks after surgery, a distinct organised neointima was present containing many inflammatory cells, a clearly visible internal elastic lamina, cellular debris, and immature collagen ${ }^{21}$.

Femoropopliteal bypasses with a reversed femoral vein inforced with Dacron were created in sheep to study the effect of compliance on the development of intimal hyperplasia ${ }^{22}$. Eight months after surgery, intimal hyperplasia was present, but did not compromise the flow.

PTFE prostheses implanted into the venous circulation of pigs developed a thin neointima throughout the length of the graft after 2 weeks ${ }^{23}$. In dogs, the carotid artery as well as the femoral artery have been used to study the effect of flow and graft geometry on intimal hyperplasia ${ }^{7 ; 8 ; 24-26}$. Intimal hyperplasia occurred under intact endothelium in patches throughout 
the graft and at the anastomoses ${ }^{26}$. The intimal hyperplasia never compromised the vessel lumen ${ }^{25}$.

Intimal hyperplasia in arteriovenous fistulas has been extensively investigated by Fillinger et al. ${ }^{9 ;} 10$ using PTFE prostheses between the femoral artery and the femoral vein of dogs. Intimal hyperplasia developed at the venous anastomosis of unbanded (normal flow) but not in banded (low flow) grafts. Excessive high Reynolds number, a measure for flow behaviour, was associated with the development of intimal hyperplasia. In a study on graft geometry, intimal hyperplasia was significantly less in 4 to $7 \mathrm{~mm}$ tapered grafts compared to untapered $6 \mathrm{~mm}$ grafts and 7 to $4 \mathrm{~mm}$ tapered grafts.

The effect of flow was also studied in PTFE aortoiliac bypasses of baboons $^{27-30}$. VSMC proliferation occurred at the growing edges and at the anastomoses. At the anastomosis, the proliferation was under a continuous layer of endothelial cells ${ }^{31}$. The intimal lesions produced no more than a $13 \%$ reduction in luminal diameter and were not flow limiting ${ }^{28}$.

A major drawback of baboons as an animal model is that they are very expensive and require special homing facilities. Dogs and pigs are less expensive but they do need individual homing, which means that only few experiments can be performed at the same time. Moreover, although they do develop intimal hyperplasia, no truly stenotic lesions have been described. Also, dissection of the vessels in the groin of dogs and pigs requires cleavage of the longer adductor muscle, which is joined in the groin of animals and the groin carries the risk of compression of the graft when the animal is in a supine position. Although dissection of the groin is quite possible, the surgical preparation of the vessels in the neck of the goat is less traumatising and more easily accomplished, and there is no risk of compression of the graft in any pose of the animal.

In the neck of $20 \mathrm{~kg}$ goats, the arterial diameter resembles that of the human elbow vessels, being $3-5 \mathrm{~mm}$. The venous diameter is slightly larger and varies between 5 and $9 \mathrm{~mm}$, compared to $4-8 \mathrm{~mm}$ in human elbow veins. This similarity in vessel diameter implies similarity in hemodynamic properties of the graft fistulas created in humans and in the neck of goats. Moreover, goats can be homed in groups. This reduces the daily costs of animal care and decreases the limitation of number of animals studied within the same time period or over a longer period of time due to restricted homing facilities.

In this study we showed that goats are able to develop intimal hyperplasia after the creation of direct and bridge-graft AV fistulas. The intimal hyperplasia develops mainly in the anastomosis and in the efferent vein. There was a small increase in intimal area from 10 days to 7 weeks in the PTFE graft AV fistulas, although it failed to reach statistical significance $(p=0.079)$. A significant correlation of intimal area with the duration of fistula function was found in the direct AV fistulas. However, the association of intimal area with time in this study, reflected in a small value of $r$, is not very strong.

The hyperplastic lesions contained VSMC that contained actin, and desmin. 
At the anastomotic suture lines, the hyperplastic lesions were not covered with endothelium and often a deposition of fibrin or thrombus formation was seen. However, the venous hyperplastic lesions were covered with endothelium. This coincides with the findings of Hofstra et al. ${ }^{32}$ in human AV fistulas. They measured a lesser degree of EC coverage of the lumen of stenotic segments than in the adjacent normal vessel segments $(48 \%$ vs. $98 \%$ EC coverage). However, a positive correlation was found between the $E C$ coverage of the lumen and subendothelial intimal proliferation $(r=0.85$; $p<0.001$ ).

Also, the site and the composition of the intimal hyperplasia were comparable to those seen in human AV fistulas. In the graft AV fistulas, occlusion occurred after 4 and 7 weeks due to thrombosis. Severe stenoses were found at the venous anastomosis of these grafts, probably limiting the flow thus causing thrombosis. Fistula occlusion in humans is also mainly caused by thrombosis due to low flow, caused by a stenosis in the outflow trajectum $^{33}$.

To study the effect of graft geometry and flow on intimal hyperplasia in prosthetic arteriovenous fistulas, we were interested to find a cheap and easy to handle animal model. To mimic the human situation as closely as possible, we wanted to use $6 \mathrm{~mm}$ PTFE prosthesis to create an AV fistula. Therefore the diameter of the artery should be between 3 and $6 \mathrm{~mm}$, and the diameter of the vein between 4 and $8 \mathrm{~mm}$. Since we wanted to use PTFE prostheses, which are thrombogenic, a flow of at least $500 \mathrm{ml} / \mathrm{min}$ must be generated through the $6 \mathrm{~mm}$ prosthesis (calculated Reynolds number of 440). Also we needed large vessels with a diameter of 3 to $5 \mathrm{~mm}$ to connect the prosthesis with. The rat and rabbit were therefore unsuitable because of their small size.

Here we showed that the goat can be used as a model to study the development of intimal hyperplasia in arteriovenous fistulas. Goats are not only inexpensive and can be homed together, but also the relatively long neck of the goat is easily accessible for surgical dissection of vessels and the creation of $A V$ fistulas. Therefore this model can be useful to study the effects of flow variation and graft geometry on the development of intimal hyperplasia in PTFE graft AV fistulas.

Acknowledgements: We would like to thank F.J. van der Veen and J. Habets for generously providing us with the samples of direct AV fistulas of their goats.

\section{Reference List}

1. Schwartz RS, Murphy JG, Edwards WD, Camrud AR, Vlietstra RE, Holmes DR. Restenosis after balloon angioplasty. A practical proliferative model in porcine arteries. Circ. 1990;82:2190-2200.

2. Schmidt SP, Workman JR, Evancho MM, et al. A canine model of intimal hyperplasia in autogenous vein grafting: a preliminary report. J.Invest. Surg. 1990;3:357-364.

3. Neville RF, Padberg FT, Jr., DeFouw D, Hernandez J, Duran W, Hobson RW2. The arterial wall response to intimal injury in an experimental model.

Ann.Vasc.Surg. 1992;6:50-54.

4. Bassiouny HS, White $S$, Glagov $S$, 
Choi E, Giddens DP, Zarins CK.

Anastomotic intimal hyperplasia: mechanical injury or flow induced. J.Vasc. Surg. 1992;15:708-716.

5. Fingerle J, Tina YP, Clowes AW, Reidy MA. Intimal lesion formation in rat carotid arteries after endothelial denudation in absence of medial injury. Arteriosclerosis 1990;10:1082-1087.

6. Calligaro $K D$, Ascer $E$, Torres $M$, Veith FJ. The effect of adjunctive arteriovenous fistula on prosthetic graft patency: a controlled study in a canine model. J. Cardiovasc. Surg. 1990;31:646-650.

7. Suggs WD, Henriques $\mathrm{HF}$, DePalma RG. Vein cuff interposition prevents juxtaanastomotic neointimal hyperplasia. Ann. Surg. 1988;207:717-723.

8. Sottiurai VS. Biogenesis and etiology of distal anastomotic intimal hyperplasia. Int.Angiol. 1990;9:59-69.

9. Fillinger MF, Reinitz ER, Schwartz RA, et al. Graft geometry and venous intimal-medial hyperplasia in arteriovenous loop grafts. J.Vasc. Surg. 1990;11:556-566.

10. Fillinger MF, Reinitz ER, Schwartz RA, Resetarits DE, Paskanik AM, Bredenberg CE. Beneficial effects of banding on venous intimalmedial hyperplasia in arteriovenous loop grafts. Am.J. Surg. 1989;158:87-94.

11. Schwartz SM. Why animal experiments do not predict outcome in human beings. Special communication. J.Vasc. Surg. 1995;22:85-86.

12. Bolotin $G$, Schreuder JJ, Kaulbach $H$, Lorusso $R$, Habets $J$, van der Veen FH. The Maastricht experience with the carotid jugular AV shunt model. In: Concerted action on heart assist and replacement. Salmons, S. 1995. 15-23.

13. Murday AJ, Gershlick AH, Syndercombe-Court YD, et al. Intimal hyperplasia in arterial autogenous vein grafts: a new animal model. Cardiovasc. Res.
1983;17:446-451.

14. Gershlick AH, Syndercombe-Court YD, Murday AJ, Lewis CT, Mills PG. Platelet function is altered by autogenous vein grafts in the early postoperative months.

Cardiovasc.Res. 1984;18:119-125.

15. Fulton GJ, Davies MG, Koch WJ, Dalen $H$, Svendsen E, Hagen PO. Antisense oligonucleotide to protooncogene c-myb inhibits the formation of intimal hyperplasia in experimental vein grafts J. Vasc. Surg. 1997;25:453-463.

16. Davies MG, Dalen $H$, Barber L, Svendsen E, Hagen PO. Lazaroid therapy (methylaminochroman: U83836E) reduces vein graft intimal hyperplasia. J.Surg.Res. 1996;63:128-136.

17. Chen C, Li J, Mattar SG, et al. Boundary layer infusion of basic fibroblast growth factor accelerates intimal hyperplasia in endarterectomized canine artery. J.Surg.Res. 1997; 69:300-306.

18. Toes GJ, Barnathan ES, Liu H, et al. Inhibition of vein graft intimal and medial thickening by periadventitial application of a sulfated carbohydrate polymer. J.Vasc. Surg. 1996;23:650-656.

19. Friedman EW, Hamilton AJ. Polytetrafluoroethylene grafts in the peripheral circulation of rabbits. Am.J.Surg. 1983;146:355-359.

20. Watase $\mathrm{M}$, Kambayashi J, Itoh $\mathrm{T}$, et al. Ultrastructural analysis of pseudo-intimal hyperplasia of polytetrafluoroethylene prostheses implanted into the venous and arterial systems. Eur.J.Vasc. Surg. 1992;6:371-380.

21. Hoch JR, Stark VK, Hullett DA, Turnipseed WD. Vein graft intimal hyperplasia; leukocytes and cytokine gene expression. Surgery 1994;116:463-471.

22. Trubel $W$, Schima $H$, Moritz $A$, et al. Compliance mismatch and formation of distal anastomotic intimal hyperplasia in externally stiffened and lumen-adapted venous grafts. Eur.J.Vasc. Endovasc.Surg. 1995;10:415-423.

23. Soyer $T$, Lempinen $M$, Cooper $P$, 
Norton L, Elseman B. A new venous prosthesis. Surgery 1972;72:864-872.

24. Norberto JJ, Sidawy AN, Trad KS, et al. The protective effect of vein cuffed anastomoses is not mechanical in origin. J.Vasc. Surg. 1995;21:558-566.

25. Rittgers SE, Karayannacos PE, Guy JF, et al. Velocity distribution and intimal proliferation in autologous vein grafts in dogs. Circ.Res. 1978;42:792-801.

26. Faulkner SL, Fisher RD, Conkle DM, Page DL, Bender-HW J. Effect of blood flow rate on subendothelial proliferation in venous autografts used as arterial substitutes. Circulation 1975;52:1163-1172.

27. Kohler TR, Kirkman TR, Kraiss LW, Zierler BK, Clowes AW. Increased blood flow inhibits neointimal hyperplasia in endothelialized vascular grafts. Circ. Res. 1991;69:1557-1565.

28. Geary RL, Kohler TR, Vergel S, Kirkman TR, Clowes AW. Time course of flow-induced smooth muscle cell proliferation and intimal thickening in endothelialized baboon vascular grafts. Circ.Res. 1993; 74:14-23.

29. Reidy MA, Chao SS, Kirkman TR, Clowes AW. Endothelial regeneration: IV. Chronic nondenudating injury in baboon vascular grafts. Am.J.Pathol. 1986;123:432-439.

30. Hanson SR, Powell JS, Dodson T, et al. Effects of angiotensin converting enzyme inhibition with cilazapril on intimal hyperplasia in injured arteries and vascular grafts in the baboon. Hypertension 1991;18[suppI II]:II-70-II-76.

31. Clowes AW, Gown AM, Hanson SR, Reidy MA. Mechanisms of arterial graft failure. 1. Role of cellular proliferation in early healing of PTFE prostheses. Am.J.Pathol. 1985;118:43-54.

32. Hofstra L, Tordoir JHM, Kitslaar PJEHM, Hoeks APG, Daemen MJAP. Enhanced cellular proliferation in intact stenotic lesions derived from human arteriovenous fistulas and peripheral bypass grafts. Does it correlate with flow parameters? Circulation 1996;94:1283-1290.

33. Tordoir J, Herman J, Kwan TS, Diderich PM. Long-term follow-up of the polytetrafluoroethylene (PTFE)prosthesis as an arteriovenous fistula for haemodialysis. Eur.J.Vasc.Surg. 1988;2:3-7. 


\section{Anastomotic geometry in PTFE arteriovenous fistulas: hemodynamic studies in the goat}

M.S. Lemson ${ }^{1,4}$, J.H.M Tordoir ${ }^{1,4}$, R. Ezzahiri ${ }^{1}$, M.J.A.P. Daemen ${ }^{2,4}$, A.P.G. Hoeks ${ }^{3,4}$.

Departments of ${ }^{1}$ Surgery and ${ }^{2}$ Pathology, University Hospital Maastricht; ${ }^{3}$ Department of Biophysics, University Maastricht and ${ }^{4}$ Cardiovascular Research Institute Maastricht (CARIM), The Netherlands. 


\section{Abstract}

Introduction. Intimal hyperplasia $(\mathrm{IH})$ compromises the success of all vascular interventions. It is thought to be caused by either low or high wall shear stress, although compliance mismatch may also play a role. Prosthetic arteriovenous fistulas for hemodialysis have an unphysiologically high volume flow probably resulting in a very high shear stress. Interposition of a venous cuff increases the local anastomotic diameter and may reduce shear stress. Also, reduction of volume flow in the graft fistula might reduce shear stress. In the present study, we assessed the effects of a venous cuff and / or reduced flow on hemodynamic parameters and on the development of intimal hyperplasia in graft AV fistulas created in goats.

Materials \& methods. Graft AV fistulas were created bilaterally in the neck of goats. In 12 goats (group A) a normal graft fistula was compared to a graft with a cuffed anastomosis. In group $B(n=8)$ normal grafts were compared with low flow grafts. In group $C(n=8)$ both grafts had cuffed anastomoses, while one side had a reduced volume flow.

Results. In none of the groups a difference between the control side and the intervention side could be demonstrated in patency or development of intimal hyperplasia. Considering only the graft fistulas that were patent 6 weeks after implantation, the area of intimal hyperplasia was not associated with hemodynamic parameters like volume flow, wall shear rate and relative distension. Considering all grafts, the patency was significantly related to volume flow, pressure in the efferent vein and relative pressure decrease at the venous anastomosis.

Conclusions. In the present study, neither low flow nor a venous cuff at the venous anastomosis of PTFE graft fistulas, or a combination of these improved the patency, nor did they decrease the development of intimal hyperplasia as compared to graft fistulas with normal flow and standard anastomosis. 


\section{Introduction}

Intimal hyperplasia $(\mathrm{IH})$ is a major complication in all vascular interventions ${ }^{1-5}$. Intimal thickening of the vessel wall leads to a critical stenosis, compromising volume flow ${ }^{6}$ and eventually causing failure of the vascular intervention.

The causes of $\mathrm{IH}$ are still unclear. Compliance mismatch at the anastomosis causes flow disturbances ${ }^{7}$ and excessive stretching ${ }^{8}$, stimulating the vascular smooth muscle cells to migrate and proliferate. Also, high ${ }^{9-11}$ and low ${ }^{12-15}$ shear stress can cause migration and proliferation of smooth muscle cells, a process mediated by messengers derived from the endothelial cells and thrombocytes.

In peripheral bypass surgery, the use of a venous cuff at the distal anastomosis is claimed to improve patency rates ${ }^{16}$. Theoretically, the cuff should lead to a better transition of elastic properties because the vein is used in a transverse direction ${ }^{17 ; 18}$. Also, the locally increased luminal diameter should lead to a local decrease of velocity and peak shear rate. The improved hemodynamics at the graft-vein junction should lead to less $\mathrm{IH}$. We hypothesised that cuff implantation decreases shear stress in the efferent vein and leads to a lower compliance mismatch and therefore should decrease the development of intimal hyperplasia.

The arteriovenous fistula is a high flow system, in which high shear rates probably predominate. Reduction of the volume flow through the fistula would result in a lower shear stress in the fistula, since the diameter of the prosthesis is constant. We hypothesised that flow reduction leads to a more physiologic shear stress and to less intimal hyperplasia.

To test these hypotheses, we conducted in vivo measurements of hemodynamic parameters and post mortem measurements of intimal area in PTFE graft fistulas in the neck of goats. To study the effect of a venous cuff, PTFE graft fistulas with and without a venous cuff at the venous anastomosis were studied. To assess the effect of local hemodynamic conditions, low flow graft fistulas were compared to normal flow graft fistulas. Also, a synergistic effect of low flow and a venous cuff was studied in a model with bilateral cuffed anastomoses and unilateral low flow.

\section{Materials and Methods}

In 28 Dutch landrace milkgoats weighing approximately $20 \mathrm{~kg}$, polytetrafluoro-ethylene (PTFE; Gore-Tex ${ }^{\circledast}$, W.L. Gore \& Associates, Flagstaff, Arizona, USA) arteriovenous (AV) grafts were created on both sides of the neck between the common carotid artery and the jugular vein. The goats were divided into 3 groups. In group A $(n=12)$, the PTFE graft was directly connected to the jugular vein in the neck (control). On the contralateral side, a venous cuff was created between the PTFE graft and the vein (intervention). In group B $(n=8)$, the PTFE grafts on both sides were directly connected to the jugular vein; on one side 
(intervention) a tapering was made in the prosthesis near the arterial anastomosis to reduce the flow to $50 \%$ of the contralateral (control) side. In group $C(n=8)$, both PTFE grafts were connected to the jugular vein with implantation of a venous cuff. On one side (intervention), the flow was reduced to $50 \%$ of the contralateral (control) side. The vein segment to create the venous cuff was derived from the groin femoral vein. Intervention side, intervention group and sequence of implantation were randomly assigned.

Daily transcutaneous continuous-wave Doppler measurements were performed to establish the patency of the grafts. At two weeks, Duplex examination and vessel wall Doppler tracking ${ }^{19}$ was performed of the venous part of the graft, the venous anastomosis and the efferent vein. At six weeks, or earlier if both fistulas were occluded, the animals were sacrificed after explantation of the fistula complex. The Ethical Committee on Animal Experiments of the Maastricht University approved the design of the study. The animals were treated according to the Dutch Law on Animal Experimentation (WOD) and The European Directive for the Protection of Vertebrate Animals used for Experimental and other Scientific Purposes (86/609/EU).

\section{Operative procedures}

After one week of conditioning on the fields of the laboratory, the goats were anaesthetised with sodiumthiopental $3 \mathrm{mg} / \mathrm{kg}$ (Nesdonal ${ }^{\circledR}$, RhônePoulenc Rorer, Amstelveen, The Netherlands) and intubated endotracheally. Inhalation anaesthesia was continued with $\mathrm{N}_{2} \mathrm{O}_{2} \mathrm{O}_{2}$ (1:2) and Halothane $(0.4 \%)$. The femoral artery was cannulated for continuous systemic pressure monitoring and the femoral vein was used for i.v. administration of fluids. One dose of ceftiofur $250 \mathrm{mg}$ (UpJohn, Ede, The Netherlands) was given intravenously for antibiotic prophylactics.

\section{Direct (standard) anastomosis}

Through a longitudinal incision the common carotid artery and the jugular vein were dissected. After measuring the diameters of the vessels with a coronary probe, a thinwalled stretch PTFE prosthesis (Gore-Tex ${ }^{\circledR}$, W.L. Gore \& Associates, Flagstaff, Arizona, USA) of $15 \mathrm{~cm}$ length, an internal diameter of $6 \mathrm{~mm}$ and a wall thickness of $0.4 \mathrm{~mm}$, was tunnelled in a subcutaneous loop. The artery was clamped, an arteriotomy of 5-7 mm was made and the graft was anastomosed end-toside to the artery with polypropylene monofilament $6 \times 0$ (Prolene ${ }^{\circledR}$, Ethicon, Johnson \& Johnson Medical BV, Amersfoort, The Netherlands). Next, the jugular vein was clamped, a venotomy of $1.5-2 \mathrm{~cm}$ was made and the PTFE prosthesis was anastomosed to the vein, also with polypropylene $6 \times 0$ (Prolene ${ }^{\circledR}$ ).

\section{Cuffed anastomosis}

The dissection of the vessels and tunnelling of the PTFE prosthesis was 
performed as described above. The venous cuff was created according to the technique initially described by Tyrrell and Wolfe ${ }^{20}$ (fig 5.1). A vein segment of $6 \mathrm{~cm}$ was derived from the femoral vein of the goat and was opened lengthwise and trimmed to $5 \mathrm{~mm}$ width. A $1.5 \mathrm{~cm}$ long incision was made in the jugular vein, and the short side of the vein segment was anastomosed to the proximal part of the venotomy (fig $5.1 a$ and b). Next, the long side of the vein segment was anastomosed to the venotomy (fig 5.1c). The excess vein was trimmed. The proximal edge of the vein segment was then anastomosed to the longitudinal edge to form a cuff (fig 5.1d). To enlarge the cuff opening, the heel of the cuff was partially opened by scissors (fig 5.1e). After vein cuff completion, the prosthesis was anastomosed to the cuff (fig 5.1f). Arterial and venous anastomoses were performed with running polypropylene 6X0 (Prolene ${ }^{\circledR}$ ) sutures.

\section{Tapered fistulas}

To obtain a flow reduction of $50 \%$ as compared to the contralateral side, one prosthesis was tapered before implantation. A semicircular suture line reduced the internal diameter to $3 \mathrm{~mm}$ which was measured with a coronary probe. The prosthesis was implanted as described.

\section{Peroperative measurements}

After creation of the fistulas and 15 minutes of stabilisation, a Doppler ultrasound transit time flow probe (Transonic Systems Inc., Ithaca, New York) was applied around the jugular vein to measure fistula flow. Then a pressure cannula was introduced through a small venous branch and moved up through the prosthesis into the carotid artery. Intraluminal pressure was measured at $1 \mathrm{~cm}$ intervals throughout the prosthesis and anastomoses by pulling back the cannula. The same procedure was conducted contralaterally.

The relative blood pressure in the carotid artery, the graft and the jugular vein was calculated by dividing the local pressure by the current systemic pressure to correct for a difference in systemic blood pressure between goats.

\section{Follow-up measurements \\ Duplex examination}

At 2 weeks Duplex measurements were performed. After anaesthetising the goat as described previously, Duplex examination was performed using a B-mode Ultramark 4 echo-system (Advanced Technology Laboratories, Bothell, USA). Using Doppler ultrasound, the velocity waveform was assessed in the venous part of the loop, in the venous anastomosis and $2 \mathrm{~cm}$ in the efferent vein. From the waveform, peak systolic velocity (PSV) and mean velocity (Vmean) over a cardiac cycle were derived.

By means of M-mode ultrasound Vessel Wall Doppler Tracking $(\mathrm{VWDT})^{21}$, the diameter and its pulsatile change of the PTFE graft and 


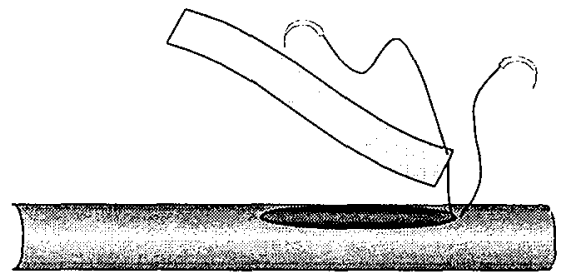

Fig 5.1a The corner of a $60 \times 5 \mathrm{~mm}$ vein segment is anastomosed to the apex of the venotomy.

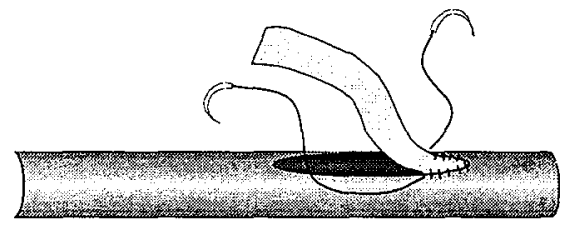

Fig 5.1c The long side of the vein segment is anastomosed to the venotomy.

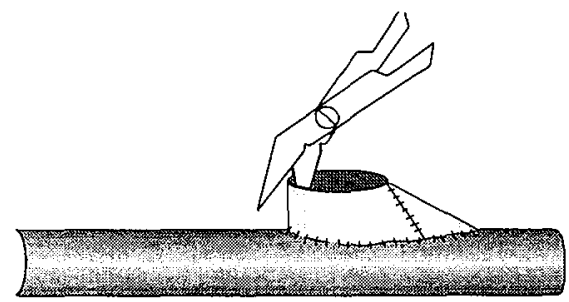

Fig 5.1e The heel of the cuff is partially opened to enlarge the cuff opening.

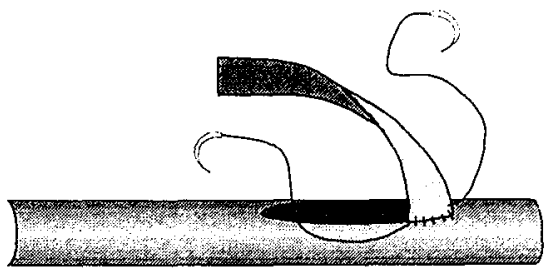

Fig 5.1b The short side of the vein segment is anastomosed to the venotomy.

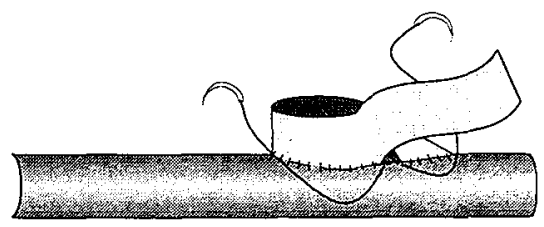

Fig 5.1d The vein is trimmed and anastomosed to its longitudinal edge.

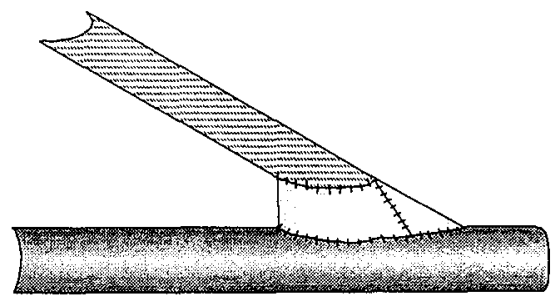

Fig 5.1f The prosthesis is connected to the cuff.

Figure 5.1 Technique of creating St Mary's booth (modified from Tyrrell and Wolfe ${ }^{20}$ ). 
the vein were recorded. Then a pressure cannula was applied percutaneously through the PTFE graft and pressure was measured in the venous part of the loop, in the venous anastomosis and $2 \mathrm{~cm}$ in the efferent vein.

From end-diastolic diameter (D), cyclic diameter change $(\Delta \mathrm{D})$ and mean velocity (Vmean), relative distension ( $R D, \%)$ and mean wall shear rate (WSR, $\mathrm{s}^{-1}$ ) were calculated, using the following equations:

$R D=\Delta D / D * 100 \%$

WSR $=2^{*} n^{*} V$ mean/diameter

with $n$ describing the assumed shape of the velocity distribution $(n=2$ for parabolic flow). This approximation of WSR is only applicable for symmetric laminar flow. Relative distension, or strain, is the percentage diameter increase during the cardiac cycle.

\section{Explantation and histopathological examination}

A detailed description of the explantation and histopathological examination used, has been described in chapter 4 . Cross-sectional areas (CSA) of the tunica media and tunica intima were assessed on Lawson stained sections of the graft, the venous anastomosis and the efferent vein using a computerised morphometry system. Also, intima and media thickness was measured at previously determined sites and intima-media ratios in thickness (I/M) were calculated for each location.

\section{Analysis}

Patency between control side and intervention side of the different groups was calculated using life table analysis and compared with the logrank test. Differences in vessel diameter, mean arterial blood pressure, anastomotic pressure decline and volume flow were tested using the Student's t-test for paired measurements. Results are given as mean and standard error of the mean (SEM). RD, WSR, I/M ratios and intimal area were tested using the Wilcoxon signed rank test for paired measurements. Results are given as medians and interquartile range (IQ).

In the overall group, Pearson's correlation coefficient was used to demonstrate a correlation between initial vessel diameter, volume flow, patency, intimal area, relative pressure decline at the anastomoses and relative pressure in the graft and efferent vein. Also, a backward linear regression analysis was performed to state the individual effect of the parameters. Parameters were alternately excluded if $p>0.05$ and included if $p<0.10$. A $p$-value $<0.05$ was considered statistically significant.

\section{Results}

PTFE graft AV fistula characteristics and results of morphometrical analysis are presented in table 5.1. Systemic blood pressure before and after fistula implantation are displayed in table 5.2 and hemodynamic parameters are shown in table 5.3. 
Table 5.1

Fistula characteristics and results of morphometric measurements, differentiated for each group. $S=$ standard anastomosis and normal flow, $\downarrow_{Q}=$ low flow, $\varnothing=$ diameter, $Q=$ flow, Intima = intimal area, measured in grafts that reached the endpoint of 6 weeks, except for group B, where all grafts were considered. $\varnothing$ and $Q$ presented as mean (standard error of the mean), patency and intimal area as median (interquartile range). ${ }^{*}=p<0.05 ;{ }^{* *}=p<0.001$ intervention side vs. control side.

\begin{tabular}{|c|c|c|c|c|c|c|}
\hline & $\begin{array}{l}\text { Group A } \\
S\end{array}$ & Cuff & $\begin{array}{l}\text { Group B } \\
S\end{array}$ & $\downarrow Q$ & $\begin{array}{l}\text { Group C } \\
\text { Cuff }\end{array}$ & cuff $+\downarrow Q$ \\
\hline$\varnothing$ artery $[\mathrm{mm}]$ & $\begin{array}{c}3.3 \\
(0.1)\end{array}$ & $\begin{array}{c}3.3 \\
(0.1)\end{array}$ & $\begin{array}{c}3.8 \\
(0.2)\end{array}$ & $\begin{array}{c}3.7 \\
(0.2)\end{array}$ & $\begin{array}{c}3.5 \\
(0.2)\end{array}$ & $\begin{array}{c}3.5 \\
(0.2)\end{array}$ \\
\hline$\varnothing$ vein $[\mathrm{mm}]$ & $\begin{array}{c}6.7 \\
(0.3)\end{array}$ & $\begin{array}{c}7.1 \\
(0.2)\end{array}$ & $\begin{array}{c}7.6 \\
(0.4)\end{array}$ & $\begin{array}{c}7.4 \\
(0.3)\end{array}$ & $\begin{array}{c}7.4 \\
(0.4)\end{array}$ & $\begin{array}{c}7.4 \\
(0.4)\end{array}$ \\
\hline $\mathrm{Q}[\mathrm{ml} / \mathrm{min}]$ & $\begin{array}{c}1026 \\
(98)\end{array}$ & $\begin{array}{l}1165 \\
(124)\end{array}$ & $\begin{array}{l}1080 \\
(106)\end{array}$ & $\begin{array}{l}613^{\star *} \\
(67)\end{array}$ & $\begin{array}{l}1710 \\
(225)\end{array}$ & $\begin{array}{l}684^{\star \star} \\
(130)\end{array}$ \\
\hline $\begin{array}{l}\text { Patency } \\
\text { [days] }\end{array}$ & $\begin{array}{c}28.5 \\
(12.5-42.0)\end{array}$ & $\begin{array}{c}34.0 \\
(14.5-42.0)\end{array}$ & $\begin{array}{c}14.0 \\
(12.5-27.5)\end{array}$ & $\begin{array}{c}13.0 \\
(8.3-38.5)\end{array}$ & $\begin{array}{c}41.4 \\
(37.8-42.0)\end{array}$ & $\begin{array}{c}38.5 \\
(16.8-42.0)\end{array}$ \\
\hline $\begin{array}{l}\text { Intima }<1 \mathrm{~cm} \\
\text { vein }\left[\mathrm{mm}^{2}\right]\end{array}$ & $\begin{array}{c}0.45 \\
(0.21-1.25)\end{array}$ & $\begin{array}{c}1.21^{*} \\
(0.41-3.83)\end{array}$ & $\begin{array}{c}0.25 \\
(0.00-2.20)\end{array}$ & $\begin{array}{c}0.00 \\
(0.00-3.06)\end{array}$ & $\begin{array}{c}0.00 \\
(0.00-0.01)\end{array}$ & $\begin{array}{c}0.24 \\
(0.00-2.06)\end{array}$ \\
\hline $\begin{array}{l}\text { Intima }>1 \mathrm{~cm} \\
\text { vein }\left[\mathrm{mm}^{2}\right]\end{array}$ & $\begin{array}{c}0.45 \\
(0.00-2,47)\end{array}$ & $\begin{array}{c}0.79 \\
(0.16-3.00)\end{array}$ & $\begin{array}{c}0.31 \\
(0.00-1.15)\end{array}$ & $\begin{array}{c}0.00 \\
(0.00-1.60)\end{array}$ & $\begin{array}{c}0.01 \\
(0.00-1.08)\end{array}$ & $\begin{array}{c}0.00 \\
(0.00-1.02)\end{array}$ \\
\hline $\begin{array}{l}\text { Intima } \\
\text { anastomosis } \\
{\left[\mathrm{mm}^{2}\right]}\end{array}$ & $\begin{array}{c}2.51 \\
(0.80-5.34)\end{array}$ & $\begin{array}{c}2.57 \\
(1.43-3.48)\end{array}$ & $\begin{array}{c}0.19 \\
(0.00-2.00)\end{array}$ & $\begin{array}{c}0.26 \\
(0.00-1.71)\end{array}$ & $\begin{array}{c}0.63 \\
(0.03-8.45)\end{array}$ & $\begin{array}{c}0.00 \\
(0.00-1.81)\end{array}$ \\
\hline
\end{tabular}

\section{Group $A$}

In group $A(n=12)$, mean arterial diameter at implantation was $3.3 \mathrm{~mm}$ on the control side and $3.3 \mathrm{~mm}(p=0.82)$ on the cuffed side. For the venous diameter the values were $6.7 \mathrm{~mm}$ vs. $7.1 \mathrm{~mm}(p=0.14)$. The mean volume flow in the grafts was $1026 \mathrm{ml} / \mathrm{min}$ on the control side and $1165 \mathrm{ml} / \mathrm{min}(p=0.21)$ on the cuffed side (table 5.1). The systemic mean arterial blood pressure decreased from $117 \mathrm{mmHg}$ before to $84 \mathrm{mmHg}$ $(p<0.001)$ after implantation of both graft fistulas (table 5.2).

Of the 12 goats, 2 goats had bilateral occluded grafts at 24 and 28 days and were sacrificed. Four goats died (1 sepsis, 1 neurologic complication, 1 arrhythmia, and 1 unknown cause) 5 to 16 days after implantation and 6 goats reached the endpoint of 6 weeks. Four grafts without cuff occluded at 12, 13, 17 and 42 days; four grafts with cuff occluded $24,28,40$ and 42 days after implantation. No significant difference in endpoint patency was found between normal anastomoses (patency at 42 days $57 \%$ ) and cuffed anastomoses (patency at 42 days $42 \% ; p=0.59$ ). Relative pressure decrease at the arterial anastomosis, measured at implantation, was 0.45 on the control side and 0.39 $(p=0.38)$ on the cuff side. At the venous anastomosis, the relative pressure decrease was 0.11 on the control side and $0.13(p=0.69)$ on the cuff side (table 5.3). No difference was found in relative distension measured 2 weeks after implantation (median $\mathrm{RD}=2.7 \%$ on control side 


\begin{tabular}{lcccc}
\hline Group & $\mathrm{N}$ & Before implantation & After implantation & p-value \\
\hline A & 12 & $117(6) \mathrm{mmHg}$ & $84(4) \mathrm{mmHg}$ & $<0.001$ \\
B & 8 & $108(10) \mathrm{mmHg}$ & $109(4) \mathrm{mmHg}$ & 0.94 \\
C & 8 & $114(3) \mathrm{mmHg}$ & $90(4) \mathrm{mmHg}$ & $<0.001$ \\
\hline
\end{tabular}

Table 5.3

Hemodynamic parameters, differentiated for each group. $S=$ standard anastomosis and normal flow, $\downarrow_{Q}=$ low flow, $\Delta p$ artery and vein=relative pressure decrease at the arterial and venous anastomosis, both measured at the time of implantation and presented as mean (standard error of the mean). $\mathrm{RD}=$ relative distension and WSR $=$ wall shear rate, both measured 2 weeks after implantation and presented as median (interquartile range). ${ }^{*}=p<0.05$ intervention side vs. control side.

\begin{tabular}{|c|c|c|c|c|c|c|}
\hline & $\begin{array}{l}\text { Group A } \\
S\end{array}$ & Cuff & $\begin{array}{l}\text { Group B } \\
S\end{array}$ & $\downarrow \downarrow$ & $\begin{array}{l}\text { Group C } \\
\text { Cuff }\end{array}$ & cuff $+\downarrow Q$ \\
\hline$\Delta p$ artery & $\begin{array}{c}0.45 \\
(0.05)\end{array}$ & $\begin{array}{c}0.39 \\
(0.05)\end{array}$ & $\begin{array}{c}0.29 \\
(0.08)\end{array}$ & $\begin{array}{c}0.28 \\
(0.08)\end{array}$ & $\begin{array}{c}0.35 \\
(0.05)\end{array}$ & $\begin{array}{c}0.30 \\
(0.04)\end{array}$ \\
\hline$\Delta p$ vein & $\begin{array}{c}0.11 \\
(0.02)\end{array}$ & $\begin{array}{c}0.13 \\
(0.02)\end{array}$ & $\begin{array}{c}0.12 \\
(0.04)\end{array}$ & $\begin{array}{c}0.08 \\
(0.02)\end{array}$ & $\begin{array}{c}0.20 \\
(0.03)\end{array}$ & $\begin{array}{c}0.11^{*} \\
(0.03)\end{array}$ \\
\hline $\mathrm{RD}[\%]$ & $\begin{array}{c}2.7 \\
(1.4-3.0)\end{array}$ & $\begin{array}{c}2.0 \\
(1.4-1.9)\end{array}$ & - & - & $\begin{array}{c}1.4 \\
(1.2-2.4)\end{array}$ & $\begin{array}{c}4.8^{*} \\
(1.8-17.8)\end{array}$ \\
\hline WSR graft [s-1] & $\begin{array}{l}1698 \\
(1554-1710)\end{array}$ & $\begin{array}{l}1250 \\
(879-1360)\end{array}$ & - & - & $\begin{array}{l}1105 \\
(533-1469)\end{array}$ & $\begin{array}{c}762 \\
(561-1323)\end{array}$ \\
\hline WSR vein [s-1] & $\begin{array}{l}529 \\
(512-1143)\end{array}$ & $\begin{array}{l}588 \\
(427-749)\end{array}$ & - & - & $\begin{array}{l}808 \\
(267-1139)\end{array}$ & $\begin{array}{l}454 \\
(438-1051)\end{array}$ \\
\hline
\end{tabular}

and median $\mathrm{RD}=2.0 \%$ at the cuff side; $\mathrm{p}=0.66$ ), nor in wall shear rate measured 2 weeks after implantation (WSR graft 1698/s on the control side and $1250 / \mathrm{s}$ on the cuff side; $p=0.18$; WSR vein $529 / \mathrm{s}$ on the normal side and $588 / \mathrm{s}$ on the cuff side; $p=0.66$ ). The $1 / \mathrm{M}$ and intimal area were only measured in 5 goats that had patent grafts $>40$ days on both sides. $\mathrm{I} / \mathrm{M}$, measured at 4 locations, was comparable between the control and cuff side in the graft, the anastomosis and the efferent vein. Intimal area was larger in the efferent vein $<1 \mathrm{~cm}$ from the anastomosis on the cuff side (median $0.45 \mathrm{~mm}^{2}$ on the control side and median $1.21 \mathrm{~mm}^{2}$ on the intervention side; $p=0.04$ ), but no difference in intimal area was found in the efferent vein $>1 \mathrm{~cm}$ from the anastomosis or in the anastomosis (table 5.1). 
Group B

In group $B(n=8)$, mean arterial diameter at implantation was $3.8 \mathrm{~mm}$ on the control side and $3.7 \mathrm{~mm}(p=0.60)$ on the low flow side. For the venous diameter the values were $7.6 \mathrm{~mm}$ vs. $7.4 \mathrm{~mm}(p=0.50)$. The mean volume flow in the grafts was $1080 \mathrm{ml} / \mathrm{min}$ on the control side and $613 \mathrm{ml} / \mathrm{min}(\mathrm{p}<0.001)$ on the low flow side (table 5.1$)$. The systemic mean arterial blood pressure before implantation of the fistulas was 108 $\mathrm{mmHg}$ and after implantation of both graft fistulas this was $109 \mathrm{mmHg}$ $(p=0.94$, table 5.2).

Of the 8 goats in group B, 5 had bilateral occlusion after 12, 14, 14, 26 and 28 days and were sacrificed. One goat died of unknown causes 4 days after implantation with both grafts patent. Two goats reached the endpoint and were sacrificed after 6 weeks. Five low flow grafts occluded $7,12,12,14$ and 28 days after implantation and 6 grafts with normal flow occluded 12, 14, 14, 14, 26 and 28 days after implantation. No significant difference in endpoint patency was observed between the normal flow and low flow grafts (patency rate normal side at 42 days $14 \%$, at the low flow side $29 \%, p=0.74$ ).

Relative pressure decrease at the arterial anastomosis was 0.29 on the control side and $0.28(p=0.93)$ on the low flow side. At the venous anastomosis, the relative pressure decrease was 0.12 on the control side and $0.08(p=0.42)$ on the low flow side (table 5.3). Due to the many early occlusions, no analysis of the few measurements of 2 weeks were performed and no comparisons of relative distension and wall shear rate were made. Intimal area and I/M ratios were calculated for all fistulas, including the occlusions. No difference was found between low flow and high flow side.

\section{Group C}

In group $C(n=8)$, mean arterial diameter at implantation was $3.5 \mathrm{~mm}$ and the venous diameter was $7.4 \mathrm{~mm}$ on both sides. The mean volume flow in the grafts was $1710 \mathrm{ml} / \mathrm{min}$ on the control side and $684 \mathrm{ml} / \mathrm{min}$ $(p=0.001)$ on the low flow side (table 5.1). The systemic mean arterial blood pressure decreased from $114 \mathrm{mmHg}$ before to $90 \mathrm{mmHg}$ $(p<0.001)$ after implantation of both graft fistulas (table 5.2). All goats reached the endpoint of 6 weeks. Six of the 8 grafts with low flow occluded $10,15,22,37,40$ and 40 days after implantation. Three of the control grafts occluded 32, 40 and 42 days after implantation. No significant difference in endpoint patency was observed between the normal flow and low flow grafts (patency rate normal side at 42 days $44 \%$, at the low flow side $25 \%, p=0.069$ ).

Relative pressure decrease at the arterial anastomosis was 0.35 on the control side and $0.30(p=0.43)$ on the low flow side. At the venous anastomosis, the relative pressure decrease was 0.20 on the control side and $0.11(p=0.05)$ on the low flow side. Median relative distension at 2 weeks was $1.4 \%$ on the control side and $4.8 \%$ on the low flow side $(p=0.043)$. WSR in the graft and in the efferent vein were comparable 
(graft WSR 1105/s on the control side and 762/s on the low flow side, $p=0.89$; vein WSR $808 / \mathrm{s}$ on the control side and $454 / \mathrm{s}$ on the low flow side $(p=1.00$, table 5.3$)$.

Of the 8 grafts that were patent for $>40$ days, no difference in intimal area or in I/M was found between the control group and the low flow group (table 5.1).

\section{All grafts}

In a backward linear regression analysis concerning only the fistulas that reached the endpoint of 6 weeks, no correlation was found between the development of intimal hyperplasia and the following parameters: initial vein diameter, pressure decrease at the venous anastomosis, graft volume flow, wall shear rate, relative distension and mean pressure in the graft.

Also, a backward linear regression analysis was performed on all grafts to assess the influence of the hemodynamic parameters on the duration of patency. This showed that patency was significantly related to lower mean pressure in the efferent vein (standardised slope $\beta=-1.04, p=0.003$ ) and higher graft volume flow $(\beta=1.13, p=0.010)$ at the time of implantation. Patency tended to increase with a lower relative pressure decrease at the venous anastomosis $(\beta=-0.63, p=0.061)$.

\section{Discussion}

In the present study, neither low flow nor a venous cuff at the venous anastomosis of PTFE graft fistulas, or a combination of these, improved the patency of fistulas. In the cuffed grafts, larger intimal areas developed in the efferent vein near the anastomosis as compared to the control side. However, no difference in endpoint patency rates was found. In the anastomosis and in the efferent vein more than $1 \mathrm{~cm}$ from the anastomosis, no difference was found in the development of intimal hyperplasia as compared to graft fistulas with normal flow and standard anastomoses. Large inter-animal variability in intimal hyperplasia occurred. It seemed that, like in humans with arteriovenous fistulas, some goats were "responders" and developed intimal hyperplasia, and others were non-responders and did not develop intimal hyperplasia after 6 weeks. In the overall analysis, no effect of hemodynamic parameters was found on the development of intimal hyperplasia at 6 weeks in patent grafts. However, considering all grafts, a longer patency was associated with a high volume flow, low pressure decrease at the venous anastomosis and with a low pressure in the graft.

The systemic hemodynamic influence of the graft fistulas was apparent in group $A$ and $C$, where a significant decrease in mean arterial pressure was found after implantation of both grafts. In group B no significant mean arterial pressure decrease was found. This is probably because the average flow of both fistulas together was about $500 \mathrm{ml}$ less than in group $A$ and $C$, posing a lesser cardiac load. Despite a lower mean arterial pressure decrease, group $B$ had the highest incidence of graft 
failure.

In group $C$, flow reduction and a venous cuff on one side and a venous cuff on the contralateral side was performed. Surprisingly, the volume flow on the side without flow reduction was much higher (mean 1710 $\mathrm{ml} / \mathrm{min}$ ) than in the other normal flow fistulas (means of 1026,1165 and $1080 \mathrm{ml} / \mathrm{min}$ ). The difference with group A can be partially explained from the difference in initial vessel diameters. However, this does not account for all of the difference. The cerebral circulation has a very strong autoregulatory mechanism. Creating arteriovenous fistulas in the neck reduces cerebral flow by shunting the blood directly into the vein. This probably induces adaptive mechanisms to ensure cerebral circulation. A large difference in volume flows between left and right carotid artery might create a difference in left and right cerebral circulatory resistance, resulting in an even larger flow difference. This only occurs in the fistulas that have cuffs on both sides (group C).

Possibly, the cuff does have some effect on anastomotic resistance that we could not demonstrate with our measurements.

Graft failure due to intimal hyperplasia is a multifactorial problem. Apart from repetitive endothelial cell injury, hemodynamic factors play a role. In vascular access, an interposition graft between artery and vein leads to a large pressure gradient and flow increase in the efferent vein. Due to the unphysiologically high flow, turbulence occurs at the anastomosis. This turbulence might play a role in inducing intimal hyperplasia. The dispersed flow direction may lift the endothelium, presenting subendothelium to blood components ${ }^{22}$. Exposition of venous endothelium to arterial flow conditions with severe stretching and high tangential stress damages the endothelial cells ${ }^{23 ;} 24$. This induces adherence and activation of thrombocytes, which release proliferation and migration stimulating factors. Changes in shear stress can induce activation of shear responsive elements in the promotors of certain genes involved in $\mathrm{IH}^{25}$. Cyclic stretching of VSMC induces proliferation and synthesis of collagen and matrix ${ }^{26}$.

In the past, two major hypotheses on the development of intimal hyperplasia opposed each other: low shear stress and high shear stress. Low shear stress was thought to stimulate the endothelium to reduce vessel diameter to keep shear stress within normal limits. When low shear stress existed for a prolonged time, remodelling of the vessel wall would occur to produce a permanent smaller diameter, hereby restoring wall shear stress to a normal level ${ }^{27}$. This hypothesis does not apply to the situation in this study where, because of the arteriovenous graft, a high rather than a low shear rate is observed. In the grafts with flow reduction WSR was not significantly lower than in grafts without flow reduction, and the WSR was approximately twice as high as in the normal vasculature.

Because of the high flow velocities and turbulence, direct measurement of the wall shear stress was not possible in the arteriovenous graft fistulas. Therefore, an approximation of the WSR was used. The largest 
influence of the cuff is expected in the anastomosis. Since the condition for approximation, being symmetrical laminar flow, was not met in the anastomosis, the WSR could not be calculated. Even in the efferent vein, calculated WSR is a mere approximation, since flow disturbances are expected downstream from the anastomosis. We found high wall shear rates in grafts (762-1698/s) and in the efferent vein (445$808 / \mathrm{s}$ ), but no difference was found between the cuffed and normal anastomoses. Although we are unable to prove that the cuff reduces local WSR, we can state that the cuff does not lead to a reduced WSR in the efferent vein. Between low flow and high flow grafts without a cuff (group B), neither a difference in duration of patency was found, nor differences in intimal area or intimal-medial thickness. However, in group $\mathrm{C}$, high flow fistulas with a cuff performed better than low flow fistulas with a cuff. Despite the significant difference in flow, no significant difference in WSR was found.

Turbulence occurs in regions of pressure decrease. In the anastomosis and efferent vein a pressure decrease was observed and, therefore, turbulence should be present. The cuff is only a small structure of about $5 \mathrm{~mm}$ high and $1.5 \mathrm{~cm}$ wide. The hemodynamic effects will therefore only be apparent within a short distance. This distance is probably not long enough to decrease intimal hyperplasia. Moreover, in our hypothesis we assumed that changing the geometry of the distal anastomosis or altering fistula volume flow would automatically have its effect on the arteriovenous fistula as a whole. However, since animal models are dynamic systems, compensation in another part of the system might occur, that undoes the effects of the cuff or flow reduction. We did not observe these compensatory mechanisms with our measurements that were concentrated around the venous anastomosis. In the overall analysis, high flow was associated with better patency. This is in contrast with the findings of Fillinger et $a^{10}$. In PTFE AV loop fistulas created between the femoral artery and the femoral vein of dogs, they found that intimal-medial thickness was $50 \%$ less in the banded (low flow, $460 \mathrm{ml} / \mathrm{min}$ ) than in the unbanded (high flow, 1094 $\mathrm{ml} / \mathrm{min}$ ) side. No measurements of WSR were performed, but they calculated Reynolds number ( \pm 1000 in unbanded and \pm 400 in banded fistulas), which had the best correlation with the development of intimal hyperplasia. In the present study, low flow fistulas without a venous cuff had lower patency rates in the first 4 weeks than grafts with a venous cuff and low flow. Although these fistulas were created in different animals, it is a striking finding. Possibly, graft fistulas with a normal flow do not benefit from the hemodynamic properties of a venous cuff, but fistulas with a low flow do. In an in vitro model using a cuff, a unidirectional coherent vortex developed during most of the cardiac cycle. This vortex had a high velocity with greater shear stress exertion on the vessel wall than laminar flow ${ }^{28}$. In a low flow system, where low shear stress may be the cause of intimal hyperplasia ${ }^{12-14 ; 29}$, this increase of shear stress by the venous cuff may have a beneficial effect. Recent studies, however, 
have shown that not the absolute shear stress, but a large spatial and temporal gradient of shear stress is more important in inducing intimal hyperplasia ${ }^{30-32}$.

The use of a venous cuff at the venous anastomosis of graft fistulas increases the anastomotic diameter. In in-vitro experiments, anastomoses with a venous cuff had a higher median roundness $(92 \%)$ than a direct anastomosis $(81 \%)$, indicating a lower resistance than in the direct anastomosis ${ }^{17}$. Theoretically, this would lead to a decrease in the pressure drop at the connection with the efferent vein, causing less stretching and stress on the venous endothelium. However, we could not find a lower pressure decrease at the venous anastomosis in cuffed grafts than in normal grafts. Also, no difference in relative distension (RD) in the efferent vein was found between the paired normal and cuffed anastomoses, or in the overall group in a non-paired analysis. More studies doubt the mechanical effect of venous cuffs. In bilateral PTFE carotid artery bypasses in dogs with cuffed anastomoses, limitation of the expandability of the vein cuff by a PTFE jacket around it, resulted in an equal distribution of intimal hyperplasia $(\mathrm{IH})$ between the jacketed and the normal cuffed side ${ }^{33}$.

In a large animal study, that compared arterial bypasses of different types of graft material, a venous patch at the venous anastomosis was found to improve patency rates of the PTFE grafts. In thin-walled PTFE grafts, the patency was adversely affected by the venous patch. The anastomosis between the more compliant thin-walled PTFE graft and the native artery might be adversely affected by the double row of sutures of the venous patch. Intimal hyperplasia occurred both in bypasses with and without a patched anastomosis and at the same locations ${ }^{34}$. Another study of prosthetic arterial bypasses in dogs concluded that a vein cuff at the anastomosis distributed the kinetic energy more widely from the non-compliant graft to the compliant native vessel, resulting in less mechanical injury ${ }^{35}$. The cuff might create a more gradual transition of compliance between the prosthesis and the native vessel ${ }^{17 ; 18}$. However, at highly elevated blood pressures the vein becomes almost rigid ${ }^{36}$ and the gain of this effect is expected to be low. Moreover, computer simulation models of anastomotic flow indicate that compliance mismatch is not a causal factor in the development of $\mathrm{IH}^{37}$.

Intimal hyperplasia remains one of the major obstacles to long-term graft patency. It appears to be the response of the vascular smooth muscle cells to a combination of physical, cellular and humoral factors accompanied by dysfunctional endothelial cell regulation ${ }^{38 ;}$. In the present study, we found that patency of prosthetic arteriovenous fistulas improved with high flow in the fistula, a low pressure decrease at the venous anastomosis and with a low pressure in the efferent vein. In graft fistulas with a venous cuff at the venous anastomosis, a larger intimal area was found in the efferent vein, however, this did not result in a lower patency rate. We could not demonstrate a beneficial effect of a 
venous cuff at the venous anastomosis of PTFE AV fistulas on patency and the development of intimal hyperplasia.

\section{Reference List}

1. Dilley R, McGeachie J, Prendergast $F$. A review of the histologic changes in vein-to-artery grafts, with particular reference to intimal hyperplasia. Arch.Surg. 1988;123:691-696.

2. Liu M, Roubin R, King II S. Restenosis after coronary angioplasty. Potential biologic determinants and role of intimal hyperplasia. Circulation 1989;79:1347-1387.

3. Garratt KN, Edwards WD, Vlietstra RE, Kaufmann UP, Holmes DR. Coronary morphology after percutaneous directional coronary atherectomy in humans: autopsy analysis of three patients. J.Am.Coll.Cardiol. 1990;16:14321436.

4. Johnson DE, Hinohara T, Selmon MR, Braden LJ, Simpson JB. Primary peripheral arterial stenoses and restenoses excised by transluminal atherectomy: a histopathologic study. J.Am.Coll. Cardiol. 1990;15:419-425.

5. Guillou P, Leveson S, Kester R. The complications of arteriovenous grafts for vascular access. Br.J.Surg. 1980;67:517-521.

6. Swedberg SH, Brown BG, Sigley R, Wight TN, Gordon D, Nicholls SC. Intimal fibromuscular hyperplasia at the venous anastomosis of PTFE grafts in hemodialysis patients. Clinical, immunocytochemical, light and electron microscopic assessment. Circulation 1989;80:1726-1736.

7. Wang LC, Guo GX, Tu R, Hwang $\mathrm{NH}$. Graft compliance and anastomotic flow patterns. ASAIO.Trans. 1990;36:90-94.

8. Sumpio BE, Banes AJ, Levin LG, Johnson $G$. Mechanical stress stimulates aortic endothelial cells to proliferate. J.Vasc.Surg. 1987;6:252256.

9. Sterpetti AV, Cucina A, Santoro L, Cardillo B, Cavallaro A. Modulation of arterial smooth muscle cell growth by haemodynamic forces.

Eur.J.Vasc. Surg. 1992;6:16-20.

10. Fillinger MF, Reinitz ER, Schwartz RA, Resetarits DE, Paskanik AM, Bredenberg CE. Beneficial effects of banding on venous intimal-medial hyperplasia in arteriovenous loop grafts. Am.J.Surg. 1989;158:87-94.

11. Schwartz LB, O'Donohoe MK, Purut CM, Mikat EM, Hagen PO, McCann R. Myointimal thickening in experimental vein grafts is dependent on wall tension. J.Vasc.Surg. 1992;15:176-186.

12. Kohler TR, Kirkman TR, Kraiss LW, Zierler BK, Clowes AW. Increased blood flow inhibits neointimal hyperplasia in endothelialized vascular grafts. Circ. Res. 1991;69:1557-1565.

13. Calligaro KD, Ascer $E$, Torres $M$, Veith FJ. The effect of adjunctive arteriovenous fistula on prosthetic graft patency: a controlled study in a canine model. J.Cardiovasc. Surg. 1990;31:646-650.

14. Faulkner SL, Fisher RD, Conkle DM, Page DL, Bender-HW J. Effect of blood flow rate on subendothelial proliferation in venous autografts used as arterial substitutes. Circulation 1975;52:I163-I172.

15. Geary RL, Kohler TR, Vergel S, Kirkman TR, Clowes AW. Time course of flow-induced smooth muscle cell proliferation and intimal thickening in endothelialized baboon vascular grafts. Circ. Res. 1993;74:14-23.

16. Miller JH, Foreman RK, Ferguson L, Faris I. Interposition vein cuff for anastomosis of prosthesis to small artery. Aust.N.Z.J.Surg. 1984;54:283285.

17. Tyrrell MR, Chester JF, Vipond MN, Clarke GH, Taylor RS, Wolfe J. Experimental evidence to support the use of interposition vein collars/patches in distal PTFE anastomoses. Eur.J.Vasc. Surg. 
1990;4:95-101.

18. Tyrrell MR, Clarke GH, Wolfe J. Consideration of the mechanical properties at the distal anastomosis of PTFE grafts may improve patency rates. J.Cardiovasc. Surg. 1989;30:91-91.

19. Hofstra L, Ermers EJM, Langeveldt APM, Hoeks APG, Kitslaar PJEHM. Vessel wall doppler tracking: a new technique to assess vessel wall compliance. J.Vasc. Tech. 1993;17:65-68.

20. Tyrrell MR, Wolfe J. New prosthetic venous collar anastomotic technique: combining the best of other procedures. Br.J.Surg. 1991;78:1016-1017.

21. Sherman RA, Levy SS. Assessment of a two-needle technique for the measurement of recirculation during hemodialysis. Am.J.Kidney Dis. 1991;18:80-83.

22. Sottiurai VS, Sue SL, Feinberg EL, Bringaze WL, Tran AT, Batson RC. Distal anastomotic intimal hyperplasia: biogenesis and etiology. Eur.J.Vasc. Surg. 1988;2:245-256.

23. Cox JL, Chiasson DA, Gotlieb Al. Stranger in a strange land: the pathogenesis of saphenous vein graft stenosis with emphasis on structural and functional differences between veins and arteries.

Prog.Cardiovasc.Dis. 1991;35:45-68.

24. Davies MG, Klyachkin ML, Dalen $H$, Massey MF, Svendsen E, Hagen $P O$. The integrity of experimental vein graft endothelium - Implications on the etiology of early graft failure. Eur.J.Vasc.Surg. 1993;7:156-165.

25. Gimbron-MA J, Nagle T, Topper JN. Biomechanical activation: an emerging paradigm in endothelial adhesion biology. J.Clin.Invest. 1997:99:1809-1813.

26. Sumpio B. Enhanced collagen production by smooth muscle cells during repetitive mechanical stretching. Arch.Surg. 1988;123:1233-1236.

27. Clowes AW, Reidy MA, Clowes MM. Mechanisms of stenosis after arterial injury. Lab.Invest. 1983; 49:208-215.

28. da Silva AF, Carpenter T, How TV,
Harris PL. Stable vortices within vein cuffs inhibit anastomotic myointimal hyperplasia? Eur.J.Vasc.Endovasc. Surg. 1997;14:157-163.

29. Mattsson EJ, Kohler TR, Vergel SM, Clowes AW. Increased blood flow induces regression of intimal hyperplasia. Arterioscler.Thromb. Vasc. Biol. 1997;17:2245-2249.

30. Steinman $D A$, Vinh $B$, Ethier $C R$, Ojha M, Cobbold RS, Johnston KW. A numerical simulation of flow in a two-dimensional end-to-side anastomosis model. J.Biomech.Eng. 1993;115:112-118.

31. Ojha M, Cobbold RS, Johnston KW. Hemodynamics of a side-to-end proximal arterial anastomosis model. J.Vasc.Surg. 1993;17:646655.

32. Henry FS, Collins MW, Hughes PE How TV. Numerical investigation of steady flow in proximal and distal end-to-side anastomoses.

J.Biomech.Eng. 1996;118:302-310.

33. Norberto JJ, Sidawy AN, Trad KS, et al. The protective effect of vein cuffed anastomoses is not mechanical in origin. J.Vasc.Surg. 1995;21:558-566.

34. Sottiurai VS, Jones $R$, Nakamura YA, Boustany C, Sue SL, Batson RC. The role of vein patch in distal anastomotic intimal hyperplasia: an histologic characterization. Int.Angiol. 1994;13:96-102.

35. Suggs WD, Henriques HF, DePalma RG. Vein cuff interposition prevents juxta-anastomotic neointimal hyperplasia. Ann.Surg. 1988;207:717723.

36. Dobrin PB, Littooy FN, Golan J, Blakeman B, Fareed J. Mechanical and histologic changes in canine vein grafts. J.Surg.Res. 1988;44:259-265.

37. Sottiurai VS. Biogenesis and etiology of distal anastomotic intimal hyperplasia. Int.Angiol. 1990;9:59-69.

38. Clowes AW. Intimal hyperplasia and graft failure. Cardiovasc.Pathol. 1993;2 (Suppl):179S-186S.

39. Chervu A, Moore WS. An overview of intimal hyperplasia. Surg. Gynecol. Obstet. 1990;171:433-447. 


\section{Effects of a venous cuff at the venous anastomosis of PTFE grafts for
hemodialysis vascular access}

M.S. Lemson ${ }^{1,8}$, R.J. van Det $^{2}$, R.J.Th.J. Welten ${ }^{3}$, H.Burger ${ }^{4}$, R.J.A. Estourgie $^{5}$, H.J.G. Stroeken ${ }^{6}$, K.M.L. Leunissen ${ }^{7,8}$, J.H.M. Tordoir ${ }^{1,8}$. Departments of Surgery: ${ }^{1}$ University Hospital Maastricht, ${ }^{2}$ Medisch Spectrum Twente Enschede, ${ }^{3}$ De Wever Hospital Heerlen, ${ }^{4}$ Albert Schweitzer Hospital

Dordrecht, ${ }^{5}$ St Laurentius Hospital Roermond, ${ }^{6}$ Maasland Hospital

Sittard. ${ }^{7}$ Department of Nephrology, University Hospital Maastricht,

${ }^{8}$ Cardiovascular Research Institute Maastricht (CARIM), The Netherlands. 


\section{Abstract}

Introduction \& Methods: The most frequent complication of

polytetrafluoroethylene (PTFE) graft arteriovenous (AV) fistulas for hemodialysis is thrombotic occlusion due to stenosis caused by intimal hyperplasia. This complication is also known for peripheral bypasses. Since the use of a venous cuff at the distal anastomosis improves the patency of prosthetic femorodistal bypasses we considered that it might also improve the patency of PTFE graft AV fistulas. Therefore, a randomised multicenter trial was carried out to study the effect of a venous cuff at the venous anastomosis of PTFE graft AV fistulas on the development of stenoses and the patency rates.

Results: Of the 120 included patients, 59 were randomised for a venous cuff. The incidence of thrombotic occlusion was lower in the cuff group $(0.68 / p y)$ than in the no cuff group $(0.88 / p y, p=0.0007)$. The primary and secondary patency rates were similar. The cuff group tended to have less stenoses at the venous and arterial anastomoses at Duplex examination. The number of graft failure was higher in patients with an initial anastomosing vein diameter smaller than $4 \mathrm{~mm}(7 / 18=39 \%)$ than with a vein diameter of $4 \mathrm{~mm}$ or larger $(16 / 88=18 \%, p=0.052)$. Loca oedema, skin atrophy and obesity yielded a higher risk on graft failure (23\% vs. $11 \%)$. Conclusion: A venous cuff at the venous anastomosis of PTFE graft AV fistulas for hemodialysis reduced the incidence of thrombotic occlusions by reduction of stenosis at the venous anastomosis. However, this did not result in a better patency rate. Therefore the venous cuff should not be used routinely. Considering all patients, initial vein diameter and local problems (oedema, obesity or skin atrophy) appear to be the most important risk factors for graft failure. 


\section{Introduction}

Although a Brescia-Cimino (BC) fistula is still the method of first choice as vascular access for hemodialysis, polytetrafluoroethylene (PTFE) grafts are increasingly used as secondary access because of failure of $B C$ fistulas or the impossibility to create a BC fistula. This is due to the increase in age and number of the hemodialysis population ${ }^{1 ; 2}$. Older patients have more comorbidities like diabetes mellitus and cardiac disease and are more likely to have peripheral vascular problems.

The incidence of thrombotic occlusion of PTFE arteriovenous (AV) grafts is high and leads to graft failure of about $30 \%$ within the first year after implantation. Eighty percent of the thrombotic complications is caused by stenosis, developing at the venous anastomosis or in the efferent vein ${ }^{3-5}$. This stenosis consists of intimal hyperplasia $(\mathrm{IH})$, an accumulation of medial smooth muscle cells in the intima that proliferate and deposit an extracellular matrix. This thickening of the vessel wall leads to critical stenosis, jeopardising graft flow $w^{6}$. Much research has been conducted to reveal the causes of intimal hyperplasia. Hemodynamic factors like compliance mismatch ${ }^{7,8}$, high ${ }^{9-11}$ and low ${ }^{12-15}$ shear stress trigger the release of cellular and humoral factors from the endothelial cells and blood components. They induce vascular smooth muscle cell proliferation, migration and matrix deposition, resulting in intimal hyperplasia.

Implantation of a venous patch or cuff at the distal anastomosis of prosthetic femorodistal bypasses leads to a decrease in graft thrombosis and an increased patency rate ${ }^{16-19}$. The cuff might improve flow hemodynamics at the graft-native vessel junction and could lead to less $\mathrm{IH}$. We hypothesised that these cuffs could also have a beneficial effect on the thrombosis and patency rate of PTFE graft fistulas.

Therefore a prospective randomised study was performed, comparing the incidence of stenoses, the number of complications and patency rates in patients receiving PTFE graft AV fistulas with or without a venous cuff implantation at the venous anastomosis.

\section{Patients and Methods}

Patients

A prospective randomised trial was conducted between October 1994 and June 1998 in six hemodialysis centres. Patients who were considered for secondary access surgery were included and all patients entered the study once. Patients were randomised for a PTFE graft AV fistula with or without a venous cuff usin computerised randomisation. Patient characteristics and the use of drugs were registered. The study was approved by the Ethics Committee of the hospitals concerned and informed consent was obtained from each patient.

\section{Operative procedure}

Thin-walled stretch PTFE grafts (Gore-Tex ${ }^{\circledR}$, W.L. Gore \& associates. Flagstaff, USA), with an internal diameter of $6 \mathrm{~mm}$ and a wall thickness of 
$0.4 \mathrm{~mm}$, were positioned in a subcutaneous loop in the forearm between the brachial artery and a suitable elbow vein, after measuring the diameter of the vessels with coronary probes, which were calibrated with $0.5 \mathrm{~mm}$ increments. The vein segment was taken from the basilic vein in the forearm in 35 patients, from an upper arm vein in 4 patients and from the greater saphenous vein in the ankle in 16 patients. In four patients of the cuff group, no suitable vein could be found to use as a cuff. These patients were analysed in the cuff group according to the intention-to-treat principle, although we also performed an analysis without these patients, leaving 55 patients in the cuff group. The results of both analyses were comparable, therefore we only present the results of the whole group.

The venous cuff was created according to the technique initially described by Tyrrell and Wolfe ${ }^{20}$ (see also chapter 5 ). A vein segment of $6 \mathrm{~cm}$ was derived from the arm or ankle and was opened lengthwise and trimmed to $5 \mathrm{~mm}$ width. A $1.5 \mathrm{~cm}$ long incision was made in the elbow vein, and the short side of the vein segment was anastomosed to the proximal part of the venotomy. Subsequently, the long side of the vein segment was sutured circumferentially to both sides of the venotomy. Finally the abundant vein was trimmed and sutured to the long side of the vein segment to form a cuff. To enlarge the cuff opening, the heel of the cuff was partially opened by scissors. After vein cuff completion, the prosthesis was anastomosed to the cuff. Arterial and venous anastomoses were performed with running $7 \times 0$ polypropylene monofilament (Prolene ${ }^{\circledR}$, Ethicon, Johnson \& Johnson, Amersfoort, The Netherlands) sutures. Prophylactic antibiotic therapy was given during each procedure. Postoperatively coumarin was given to all patients in a dosage that was sufficient for an adequate anticoagulation $(\mathrm{INR}>2.5)$.

\section{Follow up}

Duplex examination was performed 3 months postoperatively. The patients were examined in the supine position with B-mode imaging and Doppler spectrum analysis of the brachial artery in the upper arm, the arterial anastomosis, the graft, the venous anastomosis and the efferent vein up to the subclavian vein. Peak Systolic Velocity (PSV), End Diastolic Velocity (EDV) and diameter were measured at defined sites and saved as videoprints. Significant stenoses with a diameter reduction of $50 \%(=75 \%$ area reduction) or more were diagnosed according to previously outlined criteria $^{21}$. Also volume flow was measured in the brachial artery and the PTFE prosthesis.

Fistulography of the PTFE graft AV fistulas was performed three months postoperatively. Contrast was injected through the dialysis needle into the graft. The graft, venous anastomosis and outflow tract were depicted, and visualisation of the arterial anastomosis and the brachial artery was obtained using a proximal occluding cuff ${ }^{22}$. The percentage of diameter reduction was calculated by dividing the diameter in the stenosis by the diameter of the adjacent normal vessel. Only stenoses with a diameter reduction of $50 \%$ or more were included for analysis. 
Complications were treated according to local customs of the hospital where the patient was treated. Early and late complications were registered and interventional and surgical revisions were noticed.

\section{Analysis}

Statistical analysis of the clinical patient variables was performed with the Chi-square test. The patency rates were calculated using Life-table analysis and compared with the logrank test. Primary patency rate was defined as the percentage of grafts that functioned well without any surgical or catheter intervention after implantation. Primary assisted patency was defined as the percentage of grafts that functioned well without graft occlusion $>24$ hours after surgery. In this definition, grafts needing intervention for postoperative bleeding or occlusion due to postoperative hypotension or technical failures occurring within 24 hours after graft implantation were considered patent. Also, grafts needing intervention for stenosis to prevent occlusion were considered patent. Interventions for other reasons were scored as an event. For calculation of the thrombosis-free patency, only thrombotic occlusions were scored as an event. Secondary patency was defined as the proportion of patent grafts still in use for hemodialysis, including those requiring elective intervention or intervention for graft failure. Patients with a patent graft who died, were transplanted or withdrawn from hemodialysis therapy alive were censored. Clinical risk factors were defined as a Body Mass Index (BMI)>30, significant pitting oedema and skin atropy on physical examination. Endpoints were reached in case of irreversible graft failure, death, transplantation or transfer to CAPD treatment.

The incidence rate was defined as the number of complications or interventions per patient-year (py) and analysed with Poisson regression analysis. Risk factors, end-points, Duplex parameters and fistulography findings in the two groups were compared using the Chi-square test and correlated with patency using Pearson's' correlation coefficient. Means were compared with the Student-t test. Differences between the groups were considered to be statistically significant when $p<0.05$.

\section{Results}

Patient characteristics and trial end-points

A total of 120 patients were enrolled in the study, with 61 patients randomised for no cuff and 59 for a cuff. Patient characteristics are summarised in table 6.1. More males entered the no cuff group (48\%) than the cuff group $(29 \%, p=0.034)$. Other risk factors like age, duration of kidney failure, previous vascular access, arterial and venous diameter and medical history were equally distributed. Patients with ischemic cardiac disease had a history of chest pain, myocardial infarction and/or coronary artery bypass grafting or percutaneous transluminal coronary angioplasty (PTCA). Patients with peripheral vascular disease suffered from intermittent claudication or were treated with peripheral bypass grafting or PTA. Patients with cerebrovascular disease suffered from transient ischemic attacks or cerebrovascular accidents. 
Table 6.1 Patient characteristics. $N=$ number of patients. Age, duration of kidney failure and vascular dimensions are presented as mean (standard error of the mean). All others are presented as $\mathrm{N}(\%)$

\begin{tabular}{|c|c|c|c|}
\hline & No cuff & Cuff & p-value \\
\hline N & 61 & 59 & \\
\hline Age [years] & $63(2)$ & $62(2)$ & 0.57 \\
\hline Male & $29(48 \%)$ & $17(29 \%)$ & 0.035 \\
\hline \multicolumn{4}{|l|}{ History of kidney disease } \\
\hline Duration of kidney failure [months] & $17(5)$ & $24(6)$ & 0.35 \\
\hline Previous kidney transplantation & $8(14 \%)$ & $7(12 \%)$ & 0.84 \\
\hline Previous accesses & $27(46 \%)$ & $33(57 \%)$ & 0.23 \\
\hline \multicolumn{4}{|l|}{ Causes of end stage renal disease } \\
\hline Glomerulosclerosis & $19(33 \%)$ & $19(34 \%)$ & 0.84 \\
\hline Diabetes Mellitus & $12(21 \%)$ & $6(11 \%)$ & 0.23 \\
\hline Hydronephrosis, lithiasis & $7(12 \%)$ & $8(15 \%)$ & 0.70 \\
\hline Polycystic kidney disease & $5(9 \%)$ & $8(15 \%)$ & 0.32 \\
\hline Pharmacological/contrast allergy & $5(9 \%)$ & $4(7 \%)$ & 0.79 \\
\hline Unknown & $2(3 \%)$ & $3(5 \%)$ & 0.60 \\
\hline Other & $9(15 \%)$ & $7(12 \%)$ & 0.67 \\
\hline \multicolumn{4}{|l|}{ Medical history } \\
\hline Smoking & $17(32 \%)$ & $14(27 \%)$ & 0.56 \\
\hline Diabetes Mellitus & $20(35 \%)$ & $12(21 \%)$ & 0.097 \\
\hline Hypertension & $36(62 \%)$ & $31(54 \%)$ & 0.35 \\
\hline Ischemic cardiac disease & $16(28 \%)$ & $18(31 \%)$ & 0.68 \\
\hline Peripheral vascular disease & $11(19 \%)$ & $12(21 \%)$ & 0.82 \\
\hline Cerebrovascular disease & $9(16 \%)$ & $11(19 \%)$ & 0.65 \\
\hline \multicolumn{4}{|l|}{ Vascular dimensions in the elbow } \\
\hline Artery [mm] & $3.9(0.13)$ & $4.2(0.14)$ & 0.25 \\
\hline Vein [mm] & $4.5(0.12)$ & $4.4(0.16)$ & 0.80 \\
\hline
\end{tabular}

Table 6.2 Final endpoints. Data presented as number of patients (\%)

\begin{tabular}{lrll}
\hline & No Cuff & Cuff & p-value \\
\hline Graft patent & $30(49 \%)$ & $29(49 \%)$ & 0.99 \\
Graft failure & $13(21 \%)$ & $12(20 \%)$ & 0.90 \\
CAPD & $0(0 \%)$ & $2(3 \%)$ & 0.15 \\
Kidney transplantation & $3(5 \%)$ & $6(10 \%)$ & 0.28 \\
Death & $15(25 \%)$ & $10(17 \%)$ & 0.30 \\
\hline
\end{tabular}


Forty patients (34\%) received a graft because of failure of the BC fistula, 23 $(17 \%)$ because of secondary access failure and $57(49 \%)$ because primary creation of a BC fistula was not possible. Total follow up was 84.0 patientyears (range 7 days -3.4 years, median 1.4 years) for the no cuff group and 77.5 patient-years (range 0 days -3.6 years, median 1.3 years) for the cuff group. Table 6.2 shows the endpoints. Forty-nine percent of the patients in each group reached the endpoint with a patent graft. Twenty-five patients died of complications of their kidney failure with a patent fistula and 10 patients received a kidney transplantation, one of which failed within one week and this patient remained in the study. Two patients turned to CAPD treatment with a patent graft.

\section{Patency rates, complications and interventions}

Life table analysis showed all patency rates to be comparable between the two groups. There was a primary patency of $69 \%$ at 6 months, $56 \%$ at 1 year, $42 \%$ at 18 months and $34 \%$ at 2 years for the no cuff group and $62 \%$, $43 \%, 30 \%$ and $19 \%$ respectively with cuff ( $p=0.097$, fig 6.1$)$. The primary assisted patency was $76 \%$ at 6 months, $62 \%$ at 1 year, $52 \%$ at 18 months and $43 \%$ at 2 years without a cuff and $71 \%, 60 \%, 53 \%$ and $41 \%$ respectively with cuff ( $p=0.53$, fig 6.2). The secondary patency was $86 \%$ at 6 months, $84 \%$ at 1 year, $79 \%$ at 18 months and $79 \%$ at 2 years without cuff and respectively $89 \%, 81 \%, 76 \%$ and $65 \%$ with cuff ( $p=0.42$, fig 6.3 ).

The effect of the cuff on thrombosis-free patency was assessed with exclusion of the 4 patients who had no suitable vein to create a cuff. The primary patency in the no cuff group was $60 \%$ at one year and $42 \%$ at 2 years. In the cuff group this was resp. 55 and $37 \%$ ( $p=0.49$, fig 6.4). In the overall group, thirty-five patients (57\%) without cuff underwent 94 interventions and in 36 patients (61\%) with cuff 92 interventions were performed. In five patients $(8 \%)$ in the no cuff group and in 4 patients of the cuff group $(7 \%, p=0.77)$, early occlusion was successfully treated with thrombectomy. Late complications were noticed in 33 patients (54\%) without cuff and 35 patients $(59 \%)$ with cuff $(p=0.56)$. By far the most frequent complication was thrombosis, occurring 74 times ( 0.88 per py) in 28 patients in the no cuff group and 53 times $(0.68$ per $p y, p=0.0007)$ in 22 patients in the cuff group. The main intervention for thrombosis was surgical thrombectomy with revision ( 0.43 per py without cuff and 0.36 per py with cuff) or without revision ( 0.43 per py without cuff and 0.34 per py with cuff). Occasionally, fibrinolysis was performed with PTA (0.02 per py without cuff) or without PTA (0.02 per py without cuff).

Stenosis was the second most frequent complication for which intervention was necessary: 12 times ( 0.14 per py) in 11 patients in the no cuff group and 17 times $(0.22$ per py, $p=0.77)$ in 12 patients in the cuff group. It was treated with PTA 9 times ( 0.11 per py) in 8 patients in the no cuff group and 13 times (0.17 per py) in 11 patients in the cuff group. In the other cases, surgical revision was carried out because of the extension of the stenosis. Infection was seen once ( 0.01 per py) in the no cuff group and 5 times ( 0.06 per py, $p=0.45$ ) in 5 patients in the cuff group. The operative procedure with a 


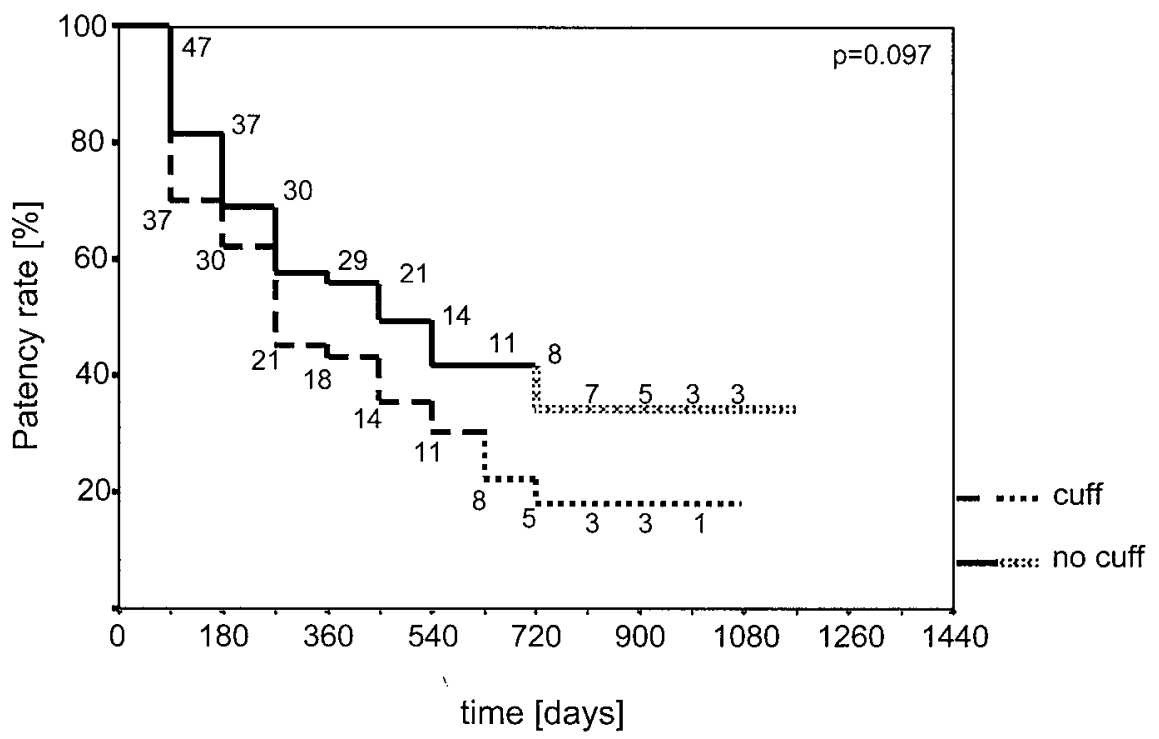

Figure 6.1 Primary patency rates. Numbers of patients is presented in the graph; when less than 8 patients entered the analysis, the graph is no longer statistically reliable.

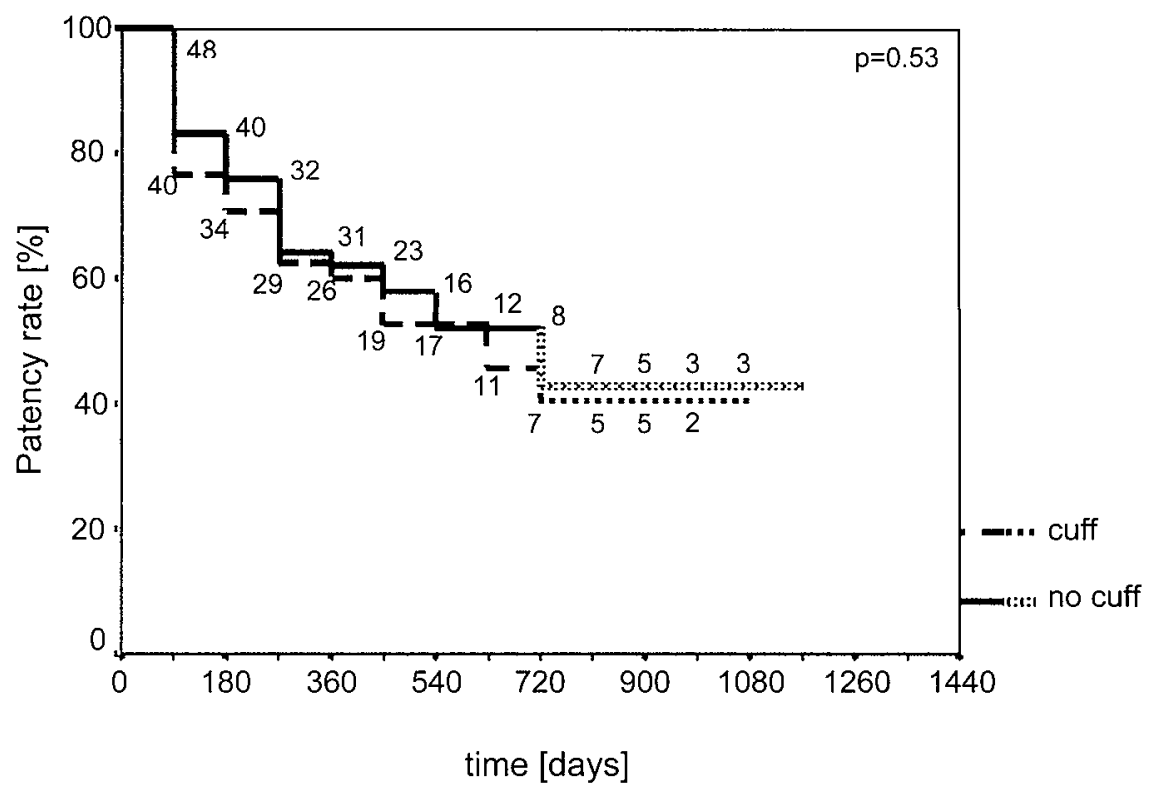

Figure 6.2 Primary assisted patency rates. Number of patients is presented in the graph; when less than 8 patients entered the analysis, the graph is no longer statistically reliable. 


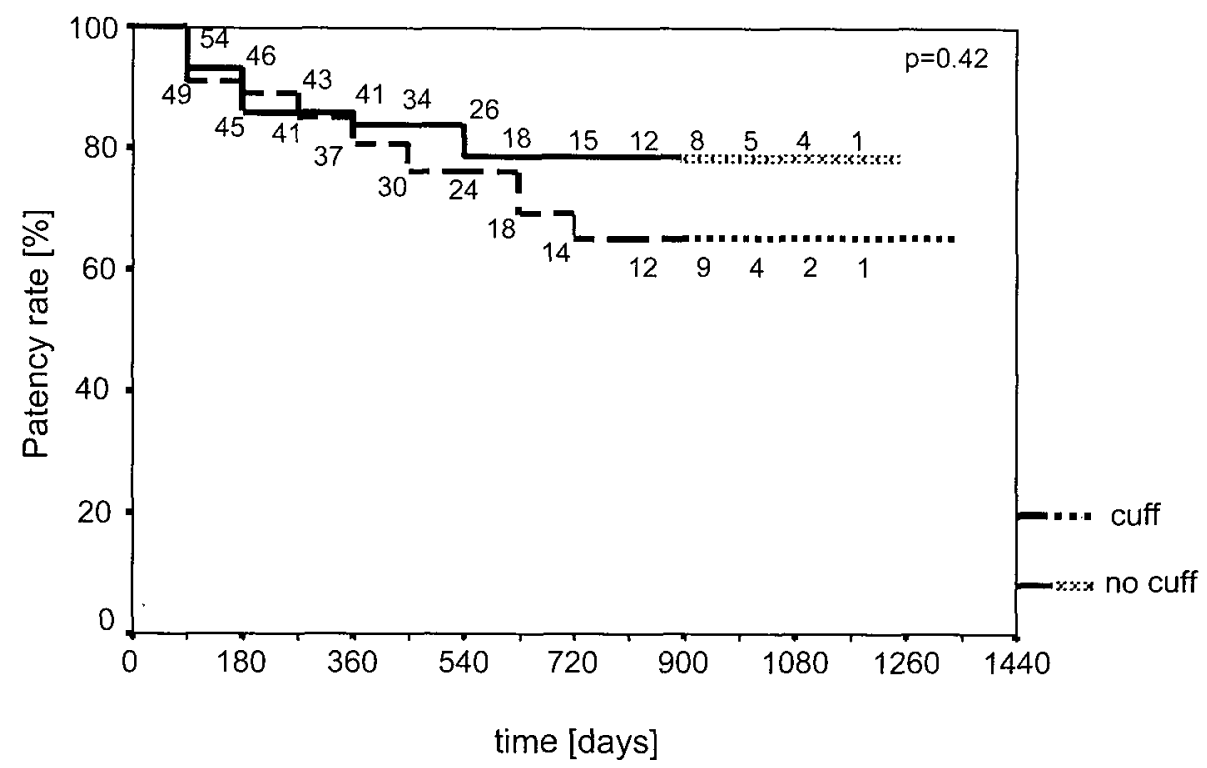

Figure 6.3 Secondary patency rates Number of patients is presented in the graph; when less than 8 patients entered the analysis, the graph is no longer statistically reliable.

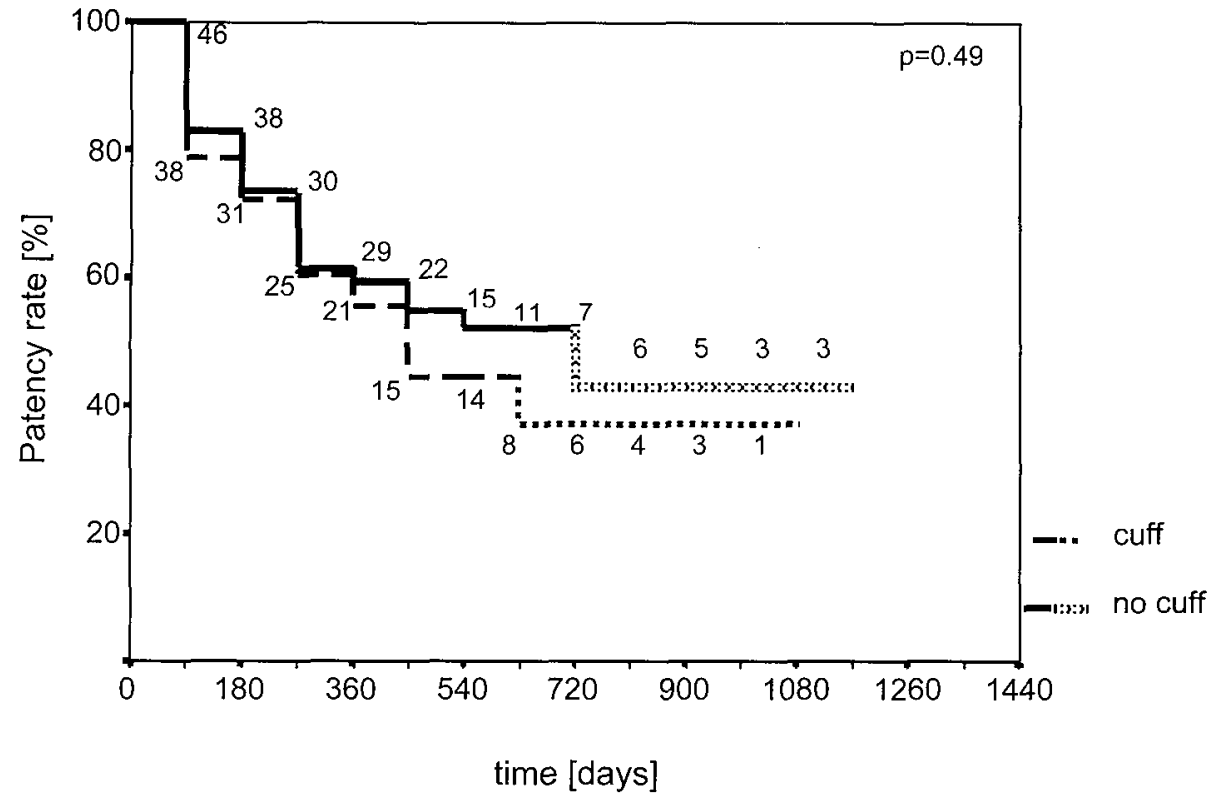

Figure 6.4 Thrombosis free patency rates. Number of patients is presented in the graph; when less than 8 patients entered the analysis, the graph is no longer statistically reliable. 
Table 6.3

Indications for interventions. Number of events and number of patients (pat) and the incidence (inc) per py are indicated. ${ }^{* *}=p<0.001$ cuff group vs. No cuff group.

\begin{tabular}{lcccccc}
\hline & \multicolumn{1}{c}{ No cuff } & & & Cuff \\
& Events & Pat & Inc [py] & Events & Pat & Inc [py] \\
\hline Thrombosis & 74 & 28 & 0.88 & 53 & 22 & $0.68^{* *}$ \\
Stenosis & 12 & 11 & 0.14 & 17 & 12 & 0.22 \\
Infection & 1 & 1 & 0.01 & 5 & 5 & 0.06 \\
Haemorrhage & 1 & 1 & 0.01 & 8 & 6 & 0.10 \\
Pseudoaneurysm & 2 & 2 & 0.02 & 3 & 3 & 0.04 \\
Ischemia & 0 & 0 & 0 & 3 & 2 & 0.04 \\
Venous hypertension & 1 & 1 & 0.01 & 0 & 0 & 0 \\
Seroma & 3 & 2 & 0.04 & 3 & 1 & 0.04 \\
\hline Total events or patients & 94 & $35^{\mathrm{a}}$ & 1.12 & 92 & $36^{\mathrm{a}}$ & 1.19 \\
\hline
\end{tabular}

a the total number of patients that suffered from complications is less than the sum because some patients had more than one complication.

venous cuff usually took about half an hour longer than a normal procedure, however, most infections occurred more than 2 months after surgery. This suggests that the infections are not due to peroperative contamination but are caused by repetitive puncture. In three patients of the cuff group, explantation of the graft was necessary $(0.04 \mathrm{per} p y)$. The other grafts were salvaged with partial excision and jump graft $(0.01$ per py in the no cuff group and 0.03 per py in the cuff group). Haemorrhage occurred once (0.01 per py) in the no cuff group after puncture and 8 times ( 0.10 per py) in 6 patients in the cuff group, 3 times after intervention and 5 times after puncture. All patients received coumarin postoperatively, and the haemorrhage was not located in the cuff area. Haemorrhage was treated with surgical closure of the bleeding site. Pseudoaneurysms were excised twice (0.02 per py) in 2 patients in the no cuff group and 3 times $(0.04$ per py; $p=0.97)$ in 3 patients in the cuff group. Three interventions ( 0.04 per py) were performed in two patients with ischemia of the hand. In one patient, banding was attempted to reduce the complaints, without success. In both patients, the graft was ligated. In one patient, the ischemic damage was irreversible, requiring arm amputation. Venous hypertension occurred in one patient ( 0.01 per py) in the no cuff group, and the graft was ligated. In each group, 3 interventions (0.04 per py) were undertaken for excessive oozing of the graft, causing severe oedema of the arm.

Three times fibrin glue (Tissuecol ${ }^{\circledR}$ ) was used to seal the graft, without success. All three grafts were explanted (table 6.3 and 6.4). 
Table 6.4 Interventions. Number of events, number of patients (pat) and the incidence (inc) per py are indicated.

\begin{tabular}{|c|c|c|c|c|c|c|}
\hline & $\begin{array}{l}\text { No cuff } \\
\text { Events }\end{array}$ & Pat & Inc [py] & $\begin{array}{l}\text { Cuff } \\
\text { Events }\end{array}$ & Pat & Inc [py] \\
\hline \multicolumn{7}{|l|}{ Thrombosis and stenosis } \\
\hline Thrombectomy & 36 & 21 & 0.43 & 28 & 18 & 0.36 \\
\hline Thrombectomy + revision & 36 & 17 & 0.43 & 26 & 15 & 0.34 \\
\hline Thrombectomy + revision + PTA & 1 & 1 & 0.01 & 3 & 3 & 0.04 \\
\hline Fibrinolysis & 2 & 2 & 0.02 & 0 & 0 & 0 \\
\hline Fibrinolysis + PTA & 2 & 2 & 0.02 & 0 & 0 & 0 \\
\hline PTA & 9 & 8 & 0.11 & 13 & 11 & 0.17 \\
\hline Total thrombosis + stenosis & 86 & & 1.02 & 70 & & 0.90 \\
\hline \multicolumn{7}{|l|}{ Infection } \\
\hline Revision & 1 & 1 & 0.01 & 2 & 2 & 0.03 \\
\hline Explantation & 0 & 0 & 0 & 3 & 3 & 0.04 \\
\hline \multicolumn{7}{|l|}{ Ischemia } \\
\hline Banding & 0 & 0 & 0 & 1 & 1 & 0.01 \\
\hline Ligation & 0 & 0 & 0 & 2 & 2 & 0.03 \\
\hline \multicolumn{7}{|l|}{ Seroma } \\
\hline Tissuecol & 1 & 1 & 0.01 & 2 & 1 & 0.01 \\
\hline Explantation & 2 & 2 & 0.02 & 1 & 1 & 0.01 \\
\hline Ligation of pseudoaneurysm & 2 & 2 & 0.02 & 3 & 3 & 0.04 \\
\hline Ligation of hemorrhage & 1 & 1 & 0.01 & 8 & 6 & 0.10 \\
\hline Ligation for venous hypertension & 1 & 1 & 0.01 & 0 & 0 & 0 \\
\hline Total events of patients & 94 & $35^{\mathrm{a}}$ & 1.12 & 92 & $36^{a}$ & 1.19 \\
\hline
\end{tabular}

a the total number of patients that underwent interventions is less than the sum because some patients had more than one intervention.

Table 6.5 Stenoses detected with Duplex examination. Number and locations of $>50 \%$ stenoses at three months $(n=59)$.

\begin{tabular}{lccl}
\hline & No cuff $(\mathrm{n}=29)$ & Cuff $(\mathrm{n}=30)$ & p-value \\
\hline Brachial artery & $2(4 \%)$ & $1(4 \%)$ & 0.51 \\
Arterial anastomosis & $14(29 \%)$ & $8(24 \%)$ & 0.097 \\
Arterial part of loop & $2(4 \%)$ & $2(6 \%)$ & 0.91 \\
Venous part of loop & $2(4 \%)$ & $2(6 \%)$ & 0.91 \\
Venous anastomosis & $14(29 \%)$ & $8(24 \%)$ & 0.097 \\
Efferent vein $<2 \mathrm{~cm}$ & $9(19 \%)$ & $11(32 \%)$ & 0.72 \\
Efferent vein $>2 \mathrm{~cm}$ & $5(11 \%)$ & $2(6 \%)$ & 0.23 \\
Total number of stenoses & 48 & 34 & 0.066 \\
Total number of patients & $21(72 \%)$ & $21(70 \%)$ & 0.66 \\
\hline
\end{tabular}




\begin{tabular}{lrrrrl}
\hline & \multicolumn{2}{l}{ No cuff (29) } & \multicolumn{2}{l}{ Cuff(30) } & p-value \\
\hline Flow brachial artery [ml/min] & 1707 & $(95)$ & 1520 & $(153)$ & 0.31 \\
Flow prosthesis [ml/min] & 1623 & $(117)$ & 1392 & $(146)$ & 0.23 \\
PSV brachial artery [m/s] & $2.14(0.24)$ & $1.71(0.10)$ & 0.098 \\
PSV venous anastomosis [m/s] & $4.19(0.90)$ & $3.83(1.27)$ & 0.82 \\
PSV efferent vein $<2 \mathrm{~cm}[\mathrm{~m} / \mathrm{s}]$ & $2.41(0.32)$ & $2.69(0.34)$ & 0.54 \\
PSV efferent vein $>5 \mathrm{~cm}[\mathrm{~m} / \mathrm{s}]$ & $1.56(0.26)$ & $1.35(0.17)$ & 0.49 \\
\hline
\end{tabular}

Results of Duplex scanning and fistulography at three months In 59 patients ( 30 without cuff and 29 with cuff) Duplex examination was performed 3 months postoperatively (table 6.5). A total of 48 stenoses were found in the no cuff group compared to 34 stenoses in the cuff group $(p=0.066)$. These stenoses occurred in 21 patients of both groups. There was no difference in the distribution of the stenoses, although the group without cuff tended to have more anastomotic stenoses than the group with cuff ( 14 vs. 8 at the arterial anastomosis, $p=0.097 ; 14$ vs. 8 at the venous anastomosis, $p=0.097$ ). Comparison of hemodynamic parameters, measured with Duplex examination, revealed no difference between the two groups (table 6.6). No significant correlation was found between the volume flow in the brachial artery or prosthesis and the primary and secondary patency.

At three months, a fistulography was done in 59 patients ( 30 without cuff and 29 with cuff). Less significant stenoses ( $>50 \%$ ) were revealed by fistulography than by Duplex scanning. Most stenoses were located in the venous anastomosis and the efferent vein. No significant differences were found in the distribution of the stenoses between the groups without and with cuff (table 6.7).

\section{Analysis of risk factors}

No correlation was found between the presence of risk factors listed in table 1 and the occurrence of graft failure. Additional analysis was performed on the occurrence of graft failure and the use of erythropoietin, acetylsalicylic acid and angiotensin converting enzyme (ACE) -inhibitors, which showed no correlation. In 102 patients, the presence of oedema, skin atrophy or obesity of the arm was scored. The presence of one of these problems tended to impose a higher risk on graft failure $(11 / 47=23 \%)$ than without local problems (graft failure $6 / 55=11 \% ; p=0.091$ ). Of the 106 veins in which the diameter was measured with coronary probes, $7(39 \%)$ of the 18 fistulas connected to a vein of $3.5 \mathrm{~mm}$ diameter or smaller occluded, whereas only $16(18 \%)$ of the 88 fistulas connected to a vein of $4 \mathrm{~mm}$ or larger occluded $(p=0.052)$. The diameters measured with Duplex ultrasound at 3 months were not correlated with fistula failure. 
Results of fistulograpy. Number and locations of $>50 \%$ stenoses at three months $(n=59)$.

\begin{tabular}{llll}
\hline & No cuff $(\mathrm{n}=30)$ & Cuff $(\mathrm{n}=29)$ & p-value \\
\hline Arterial anastomosis & 0 & 0 & 0.98 \\
Arterial part of loop & $1(3 \%)$ & $1(3 \%)$ & 0.98 \\
Venous part of loop & $1(3 \%)$ & $1(3 \%)$ & 0.98 \\
Venous anastomosis & $5(17 \%)$ & $3(10 \%)$ & 0.48 \\
Efferent vein $<2 \mathrm{~cm}$ & $4(13 \%)$ & $8(28 \%)$ & 0.17 \\
Efferent vein $>2 \mathrm{~cm}$ & $2(7 \%)$ & $6(21 \%)$ & 0.12 \\
Subclavian vein & $2(7 \%)$ & 0 & 0.16 \\
\hline
\end{tabular}

\section{Discussion}

In the present randomised study, the incidence of thrombotic occlusions was less in the group with a venous cuff at the venous anastomosis of polytetrafluoroethylene (PTFE) graft arteriovenous (AV) fistulas. This was probably due to a lower number of stenoses found with Duplex examination, although the total number of patients with stenoses was comparable. The decrease in thrombotic occlusions did not result in a better patency in the cuff group, because in the cuff group, less recurrent occlusions occurred, whereas the total number of patients suffering from thrombotic occlusions were the same as in the no cuff group. The 1-year patency rates are comparable to the results reported in the literature, varying from 40 to $57 \%$ for primary patency and 62 to $78 \%$ for secondary patency ${ }^{3 ; 23-29}$. The most frequent complication needing intervention was thrombosis, followed by interventions for stenosis causing impaired fistula function. The cuff group had more interventions for infections $(0.06$ per py vs. 0.01 per py in the non cuff group), but it is still well below the 0.21-0.37 per py, and the incidence of $11-34 \%$, reported by others $3 ; 24 ; 26-29$.

No correlation was found between risk factors like age, sex, smoking, diabetes, cardiovascular disease, cerebrovascular disease and the occurrence of fistula failure. Erythropoietin increases the $\mathrm{Hb}$ value and hematocrit and may result in a higher number of thromboses ${ }^{30}$. However, many studies, including the present study, could not confirm this ${ }^{31-35}$. Acetylsalicylic acid ${ }^{36-38}$ and ACE-inhibitors ${ }^{39-41}$ have both been indicated as possible inhibitors of intimal hyperplasia $(\mathrm{IH})$. In the present study, patients using these drugs did not have less graft failure.

Local thickness of the arm due to oedema or obesity hamper palpation of the graft. Apart from the problems this poses for graft puncture, it also decreases the possibility to detect stenoses or even occlusion by palpation of the graft. Atrophy of the skin increases the risk on wound healing problems. We found that patients with local problems had more graft failures. 
The importance of vessel diameter was already recognised for the development and patency of BC fistulas. Wong et al. found that BC fistulas created with vessels with a diameter of $<1.6 \mathrm{~mm}$, measured by preoperative Duplex examination, failed to mature ${ }^{42}$. Our study shows that the diameter of the efferent vein is an important factor for the patency of PTFE graft AV fistulas too. Of the fistulas with a diameter of $3.5 \mathrm{~mm}$ or less, $7 / 18(39 \%)$ failed, whereas only $16 / 88(18 \%)$ of the fistulas with a vein diameter of $4 \mathrm{~mm}$ or more failed. A smaller efferent vein poses a higher resistance to flow, and this could reduce the flow through the fistula. Moreover, a large transition of diameter at the anastomosis induces great flow disturbances. This would predispose a smaller vein to a greater hyperplastic reaction than a larger vein, compromising the flow even more.

PTFE is generally regarded as the material of choice for secondary access surgery, when a Brescia-Cimino (BC) fistula has failed or its construction is not possible ${ }^{43}$. However, PTFE graft AV fistulas have significantly more complications than BC fistulas ${ }^{24 ; 27 ; 28}$. Thrombotic occlusion in PTFE graft AV fistulas occurs with an incidence of 0.54 to 0.95 per $p^{2 ; 5 ; 24 ; 29}$, requiring intervention to re-establish patency or even implantation of a new graft. The key event in the occurrence of thrombotic complications in PTFE graft AV fistulas for hemodialysis is intimal hyperplasia $(\mathrm{IH})^{6}$. Stenoses due to $\mathrm{IH}$ also develop at the distal anastomosis of peripheral arterial bypasses and cause a decrease of patency. In an attempt to improve patency rates of peripheral bypasses, Siegman ${ }^{44}$ created a venous cuff between the prosthesis and the native vessel to facilitate the anastomosis. After Millers' publication of improved patency rates with the use of this venous cuff ${ }^{18}$, the cuffed anastomosis was internationally accepted. The improved patency rates of the Miller cuff were ascribed to the better transition of elastic properties and the insertion of venous endothelium, which might serve as a source for humoral factors preventing $\mathrm{H}^{45}$. Since then, several different types of cuffs and patches were developed, accompanied with reports of improved patencies in retrospective studies ${ }^{20 ; 46-48}$.

In an in vitro model, the hemodynamic changes induced by the venous cuff were examined to explain the beneficial effect of a venous cuff in the development of $\mathrm{IH}$. In the venous cuff, unidirectional vortices originated with relatively high velocities. This high velocity would exert a high shear stress on the vessel wall, inhibiting $1 \mathrm{H}^{49}$. However, in this model, flows were comparable to those in arterial bypasses and it is questionable whether the results can be extrapolated to the high flow system like the arteriovenous fistula. On the contrary, in previous studies, performed in our institute we could prove that initial high shear stress resulted in significantly more stenoses $^{50}$. Also, we showed a correlation between high shear stress, endothelial denudation of the vessel wall and intimal hyperplasia ${ }^{51}$. Moreover, a recent randomised trial showed that the Miller cuff had no effect on the patency of supragenual bypasses. In infragenual bypasses a better patency was obtained, but this was ascribed to facilitation of the anastomosing technique between a stiff prosthesis and a small calibre crural vessel, and not to mechanical or humoral effects of the cuff $f^{52}$. In the creation 
of PTFE AV loop grafts in the arm, the efferent vein in the elbow is usually easily accessible and has a diameter $>2 \mathrm{~mm}$. Therefore, PTFE graft AV fistulas may not benefit from this technical advantage of the cuff. Nevertheless, a recent presentation of the results of a non-randomised study of PTFE graft AV fistulas using a kind of Linton PTFE patch at the venous anastomosis, showed an improved patency rate ( $88 \%$ after 48 months) compared to 4-7 $\mathrm{mm}$ tapered grafts $(66 \% \text { after } 36 \text { months, } p=0.047)^{53}$. Also, a new type of PTFE prosthesis was designed with a cuffed or hooded venous end and used to create PTFE graft AV fistulas. Early reports are promising, with an improved 4 month secondary patency of $100 \%$ vs. $59 \%$ for the 4-7 $\mathrm{mm}$ tapered graft, although this study was not randomised either, and the patency of the tapered graft seems to be very low ${ }^{54}$.

In this prospective randomised study, we found that a venous cuff at the venous anastomosis of PTFE graft AV fistulas for hemodialysis reduces the incidence of thrombotic occlusions by reduction of stenosis at the venous anastomosis. However, this did not result in a better patency rate. Therefore the cuff should not be used routinely. Initial vein diameter and local risk factors (oedema, obesity or skin atrophy) appear to be the most important risk factors for graft failure.

Acknowledgements: we kindly thank F. Nieman for his statistical advice and calculations.

\section{Reference List}

1. Ramsteijn PG, Geerlings W, Krediet RT, Tjandra YI, de Charro FTh. Newsletter Registration Renal Replacement Therapy The Netherlands (Renine). Rotterdam, Stichting Renine. 1996;4:1-28.

2. Besarab A, Sullivan KL, Ross RP, Moritz MJ. Utility of intra-access pressure monitoring in detecting and correcting venous outlet stenosis prior to thrombosis. Kidney Int. 1995;47:1364-1373.

3. Tordoir J, Herman J, Kwan TS, Diderich PM. Long-term follow-up of the polytetrafluoroethylene (PTFE)prosthesis as an arteriovenous fistula for haemodialysis. Eur.J.Vasc.Surg. 1988;2:3-7.

4. Beathard GA. Mechanical versus pharmacomechanical thrombolysis for the treatment of thrombosed dialysis access grafts. Kidney Int. 1994;45:1401-1406.

5. Schwab SJ, Raymond JR, Saeed M, Newman GE, Dennis PA, Bollinger RR. Prevention of hemodialysis fistula thrombosis. Early detection of venous

stenoses. Kidney Int. 1989;36:707711.

6. Swedberg SH, Brown BG, Sigley R, Wight TN, Gordon D, Nicholls SC. Intimal fibromuscular hyperplasia at the venous anastomosis of PTFE grafts in hemodialysis patients. Clinical, immunocytochemical, light and electron microscopic assessment. Circulation 1989;80:1726-1736.

7. Wang LC, Guo GX, Tu R, Hwang $\mathrm{NH}$. Graft compliance and anastomotic flow patterns. ASAIO.Trans. 1990;36:90-94.

8. Sumpio BE, Banes AJ, Levin LG, Johnson $G$. Mechanical stress stimulates aortic endothelial cells to proliferate. J.Vasc. Surg. 1987;6:252-256.

9. Sterpetti AV, Cucina A, Santoro L, Cardillo B, Cavallaro A. Modulation of arterial smooth muscle cell growth by haemodynamic forces. Eur.J.Vasc. Surg. 1992;6:16-20.

10. Fillinger MF, Reinitz $E R$, Schwartz RA, Resetarits DE, Paskanik AM, Bredenberg CE. Beneficial effects of banding on venous intimal- 
medial hyperplasia in

arteriovenous loop grafts.

Am.J.Surg. 1989;158:87-94.

11. Schwartz LB, O'Donohoe MK,

Purut CM, Mikat EM, Hagen PO,

McCann R. Myointimal thickening

in experimental vein grafts is

dependent on wall tension.

J.Vasc. Surg. 1992;15:176-186.

12. Kohler TR, Kirkman TR, Kraiss

LW, Zierler BK, Clowes AW.

Increased blood flow inhibits

neointimal hyperplasia in

endothelialized vascular grafts.

Circ.Res. 1991;69:1557-1565.

13. Calligaro KD, Ascer $E$, Torres $M$, Veith FJ. The effect of adjunctive arteriovenous fistula on prosthetic graft patency: a controlled study in a canine model. J.Cardiovasc. Surg. 1990;31:646-650.

14. Faulkner SL, Fisher RD, Conkle DM, Page DL, Bender-HW J.

Effect of blood flow rate on subendothelial proliferation in venous autografts used as arterial substitutes. Circulation 1975;52:I163-I172.

15. Geary RL, Kohler TR, Vergel S, Kirkman TR, Clowes AW. Time course of flow-induced smooth muscle cell proliferation and intimal thickening in endothelialized baboon vascular grafts. Circ. Res. 1993;74:14-23

16. Tyrrell MR, Wolfe J. Vein collars make femorocrural grafts worthwhile. In: Greenhalgh R, Collier L, eds. The maintenance of arterial reconstruction. London: WB Saunders Co Ltd, 1991;45-55.

17. Wolfe J, Tyrrell MR. Justifying arterial reconstruction to crural vessels - even with a prosthetic graft. Br J Surg 1991;78:897-899.

18. Miller JH, Foreman RK, Ferguson

$L$, Faris I. Interposition vein cuff for anastomosis of prosthesis to small artery. Aust.N.Z.J.Surg. 1984;54:283-285.

19. Raptis S, Miller JH. Influence of a vein cuff on polytetrafluoroethylene grafts for primary femoropopliteal bypass. Br.J.Surg. 1995;82:487491.
20. Tyrrell MR, Wolfe J. New prosthetic venous collar anastomotic technique: combining the best of other procedures. Br.J.Surg. 1991;78:1016-1017.

21. Tordoir J, de Bruin HG, Hoeneveld $\mathrm{H}$, Eikelboom BC, Kitslaar P.

Duplex ultrasound scanning in the assessment of arteriovenous fistulas created for hemodialysis access: comparison with digital subtraction angiography. J.Vasc. Surg. 1989;10:122-128.

22. Staple TW. Retrograde venography of subcutaneous arteriovenous fistulascreated surgically for hemodialysis. Radiology 1973;106:223-224.

23. Tellis V, Kohlberg W, Bhat D, Driscoll B, Veith F. Expanded Polytetrafluoroethylene graft fistula for chronic hemodialysis.

Ann.Surg. 1979;189:101-105.

24. Aman LC, Levin NW, Smith DW. Hemodialysis access site morbidity. Proc.Dial. Transpl. Forum 1980;10:277-284.

25. Jenkins A, Buist $T$, Glover S. Medium-term follow-up of forty autogenous vein and forty polytetrafluoroethylene (Gore-Tex) grafts for vascular access. Surgery 1980;88:667-672.

26. Palder SB, Kirkman RL, Whittemore AD, Hakim RM, Lazarus JM, Tilney NL. Vascular access for hemodialysis. Patency rates and results of revisions. Ann.Surg. 1985;202:235-239.

27. Kherlakian GM, Roedersheimer LR, Arbaugh JJ, Newmark KJ, King LR. Comparison of autogenous fistula versus expanded polytetrafluoroethylene graft fistula for angioaccess in hemodialysis. Am.J.Surg. 1986;152:238-243.

28. Zibari GB, Rohr MS, Landreneau $M D$, et al. Complications from permanent hemodialysis vascular access. Surgery 1988;104:681686.

29. Bosman PJ, Blankestijn PJ, Graaf Yvd, Heintjes RJ, Koomans HA, Eikelboom BC. A comparison between PTFE and denatured 
homologous vein grafts for hemodialysis access: a prospective randomised multicentre trial. Eur.J.Vasc. Endovasc.Surg. 1998;16:126-132.

30. Dy G, Bloom E, ljelu G, Merritts $G$, Kramer M, Raja R. Effect of recombinant Human Erythropoietin on vascular access. Trans.ASAIO 1991;37:M274-M275.

31. Shand $B I$, Buttimore AL, Hurrell MA, et al. Hemorheology and fistula function in home hemodialysis patients following erythropoietin treatment: a prospective placebo- controlled study. Nephron 1993;64:53-57.

32. Culp K, Flanigan M, Taylor L, Rothstein M. Vascular access thrombosis in new hemodialysis patients. Am.J.Kidney Dis. 1995;26:341-346.

33. De Marchi S, Cecchin E, Falleti E, et al. Long-term effects of erythropoietin therapy on fistula stenosis and plasma concentrations of PDGF and MCP1 in hemodialysis patients. J.Am.Soc.Nephrol. 1997;8:11471156.

34. Goldwasser P, Avram MM, Collier JT, Michel MA, Gusik SA, Mittman N. Correlates of vascular access occlusion in hemodialysis.

Am.J.Kidney Dis. 1994;24:785794.

35. Jacquot $C$, Berthelot JM, Chiappini Judith $D$, et al. Treatment of anemia in chronic hemodialysis patients with recombinant human erythropoietin: long-term results in 15 patients. Nephrologie. 1990;11:11-16.

36. Dobrin PB, Littooy FN, Golan J, Blakeman B, Fareed J. Mechanical and histologic changes in canine vein grafts. J.Surg.Res. 1988;44:259-265.

37. Hirko MK, McShannic JR, Schmidt $S P$, et al. Pharmacologic modulation of intimal hyperplasia in canine vein interposition grafts. J.Vasc. Surg. 1993;17:877-887.

38. McCann R. Aspirin and dipyridamole decrease intimal hyperplasia in experimental vein grafts. Ann.Surg. 1980;191:238243.

39. Powell J, Clozel J, Müller R, et al. Inhibitors of angiotensin-converting enzyme prevent myointimal proliferation after vascular injury. Science 1989;245:186-188.

40. Bujan J, Bellon JM, Jurado $F$, et al. Inhibitor of angiotensin-converting enzyme modifies myointimal origin in an arterial autograft model. J.Cardiovasc. Pharmacol. 1996;28:285-293.

41. Park JS, Kim SN, Won JM, Koh YB, Kim IC. Synergistic inhibitory effect of angiotensin-converting enzyme inhibitor and heparin on intimal hyperplasia after rat aorta injury. Angiology. 1996;47:9-14.

42. Wong $V$, Ward R, Taylor J, Selvakumar S, How TV, Bakran A. Factors associated with early failure of arteriovenous fistulae for haemodialysis access. Eur.J.Vasc. Endovasc. Surg. 1996;12:207-213.

43. Eikelboom BC. Which material should be used in secondary haemodialysis access surgery. Eur.J.Vasc.Surg. 1988;2:1-2

44. Siegman FA. Use of a venous cuff for graft anastomosis. Surg. Gynecol.Obstet. 1979;148:930930.

45. Norberto JJ, Sidawy AN, Trad KS, et al. The protective effect of vein cuffed anastomoses is not mechanical in origin. J.Vasc. Surg. 1995;21:558-566.

46. Taylor RS, Loh A, McFarland RJ, Cox M, Chester JF. Improved technique for polytetrafluoroethylene bypass grafting: long-term results using anastomotic vein patches. Br.J.Surg. 1992;79:348-354.

47. Batson RC, Sottiurai VS, Craighead CC. Linton patch angioplasty: an adjunct to distal bypass with polytetrafluoroethylene grafts.

Ann.Surg. 1984;199:684-693.

48. Karacagil $S$, Narbani A, Almgren B, Bowald S, Bergqvist D. Modified vein cuff technique for distal polytetra-fluoroethylene graft 
anastomoses: how we do it.

Eur.J.Surg. 1995;161:47-48.

49. da Silva AF, Carpenter T, How TV, Harris PL. Stable vortices within vein cuffs inhibit anastomotic myointimal hyperplasia? Eur.J.Vasc.Endovasc.Surg. 1997;14:157-163.

50. Hofstra L, Bergmans DCJJ, Leunissen KML, et al. Anastomotic intimal hyperplasia in prosthetic arteriovenous fistulas for hemodialysis is associated with initial high flow velocity and not with mismatch in elastic properties. J.Am.Soc.Nephrol. 1995;6:16251633.

51. Hofstra $L$, Tordoir JHM, Kitslaar PJEHM, Hoeks APG, Daemen MJAP. Enhanced cellular proliferation in intact stenotic lesions derived from human arteriovenous fistulas and peripheral bypass grafts. Does it correlate with flow parameters? Circulation 1996;94:1283-1290.

52. Stonebridge PA, Howlett $R$, Prescott R, Ruckley CV. Randomised trial comparing polytetrafluoroethylene graft patency with and without a Miller cuff. Br.J.Surg. 1995;82:555-556.

53. Scholz $H$, Petzold K, Kruger $U$, Settmacher U, Petzold M, Zanow $J$. Four years experience with arteriovenous patchprosthesis as access for hemodialysis. In: Tordoir JHM. Proc. 3rd Int.congress on acces for dialysis, October 1997, Maastricht. 1997:61-62.

54. Escobar, FS. A preliminary study comparing a new "hooded" vs. conventional ePTFE graft in hemodialysis patients. Vascular access for hemodialysis VI. May 1998, Miami, Florida. 1998:26. 


\section{The effect of a venous cuff on the bloodflow}

hemodynamics of prosthetic
arteriovenous
fistulas for

M.S. Lemson ${ }^{1,4}$, J.H.M. Tordoir ${ }^{1,4}$, R. Ezzahiri ${ }^{1}$, K.M.L. Leunissen ${ }^{2,4}$, P.J.E.H.M. Kitslaar ${ }^{1,4}$, A.P.G. Hoeks ${ }^{3,4}$.

Departments of ${ }^{1}$ Surgery and ${ }^{2}$ Nephrology, University Hospital Maastricht, ${ }^{3}$ Department of Biophysics, Maastricht University and

${ }^{4}$ Cardiovascular Research Institute Maastricht (CARIM), The Netherlands. 


\section{Abstract}

Introduction. The patency of vascular interventions is jeopardised by intimal hyperplasia. Peripheral arterial bypasses benefit from a venous cuff at the distal anastomosis. We performed a randomised study to assess the effect of a venous cuff at the venous anastomosis of PTFE graft AV fistulas for hemodialysis on patency and hemodynamic parameters.

Patients and Methods. A total of 40 patients enrolled in the study, 20 of which randomised for a venous cuff. Follow up measurements were performed at 6 weeks and at 3,6 and 12 months postoperatively with Duplex measurements and vessel wall Doppler tracking. Relative distension (RD) and wall shear rate (WSR) were calculated.

Results. Patency rates of both groups were comparable ( 1 year primary patency no cuff $29 \%$, cuff $32 \%$; $p=0.82 ; 1$ year secondary patency no cuff $67 \%$, cuff $84 \%$; $p=0.44$ ). Volume flow, diameter of graft and efferent vein, RD and WSR were comparable for both groups. In failed grafts, the volume flow and WSR were significantly lower compared to patent grafts.

Conclusions. A venous cuff at the venous anastomosis of PTFE AV grafts did not improve patency rates, nor did it change WSR and RD near the venous anastomosis. Low flow and low WSR were associated with graft failure. 


\section{Introduction}

Polytetrafluoroethylene (PTFE) graft arteriovenous (AV) fistulas are increasingly used as secondary access for hemodialysis treatment when creation of an autologous fistula has failed or is not possible. A major drawback of these PTFE grafts is a high incidence of thrombotic occlusions. This is mainly caused by the development of intimal hyperplasia at the venous anastomosis and in the efferent vein.

Intimal hyperplasia occurs in all vascular interventions and is thought to be caused by a combination of humoral, cellular and hemodynamic factors. $A$ venous cuff at the distal anastomosis of peripheral arterial bypasses increases the patency rates of prosthetic femorocrural bypasses. It has been thought that interposition of venous endothelium or hemodynamic factors might cause the improvement in patency rate. We hypothesised that the interposition of a venous cuff at the venous anastomosis of PTFE graft AV fistulas would decrease local shear stress and provide a better compliance match between the stiff prosthesis and the vein. This would lead to better patency rates. Therefore hemodynamic measurements were performed in a subgroup of the multicenter trial population described in chapter 6 .

\section{Patients and Methods}

\section{Patients}

In a subgroup of 40 patients from the multicenter trial, additional measurements were obtained. For a detailed description of the surgical techniques see chapters 5 and 6 .

\section{Duplex examination}

At 6 weeks and 3, 6 and 12 months, Duplex measurements were performed using a B-mode Ultramark 4 echo-system (Advanced Technology Laboratories, Bothell, USA). Using Doppler ultrasound, the velocity waveform was assessed in the venous part of the loop, in the venous anastomosis and $2 \mathrm{~cm}$ in the efferent vein. From the waveform, peak systolic velocity (PSV) and mean velocity (Vmean) over a cardiac cycle were derived.

By means of M-mode ultrasound Vessel Wall Doppler Tracking (VWDT) ${ }^{1}$, the diameter and its pulsatile change of the PTFE graft and the vein were recorded. From end-diastolic diameter (D), cyclic diameter change $(\Delta D)$ and mean velocity (Vmean), relative distension (RD, \%) and mean wall shear rate (WSR, $\mathrm{s}^{-1}$ ) were calculated, using the following equations:

$$
\begin{aligned}
& R D=\Delta D / D^{*} 100 \% \\
& W S R=2^{*} n^{*} V \text { mean/diameter }
\end{aligned}
$$

with $n$ describing the assumed shape of the velocity distribution $(n=2$ for parabolic flow). The approximation of WSR is only applicable with symmetric laminar flow. Relative distension, or strain, is the percentage diameter increase from end diastole to peak systole. 
Analysis

Statistical analysis of the risk factors and endpoints of the two groups was performed using the Chi-square test. Means were compared using the Student t-test. Patency rates were compared using life table analysis. Primary patency rate was defined as the percentage of grafts that functioned well without any surgical or catheter intervention after implantation.

Secondary patency was defined as the proportion of patent grafts still in use for hemodialysis, including those requiring elective intervention or intervention for graft failure. Patients with a patent graft who died, were transplanted, or were withdrawn from hemodialysis therapy alive were censored.

Effects of venous diameter, volume flow, relative distension and wall shear rate on patency were assessed with regression analysis. Duplex measurements less than one month before an intervention were compared to measurements performed $>3$ months before, or after an intervention in the same patients. Means were compared with the Student t-test for paired samples. Differences between the groups were considered to be statistically significant if $p<0.05$.

\section{Results}

Patient characteristics, trial endpoints and patency rates

A total of 40 patients enrolled in the study with twenty patients randomised for a cuff. Patient characteristics are summarised in table 7.1. More males entered the no cuff group $(65 \%)$ than in the cuff group $(30 \% ; p=0.027)$. Other risk factors like age, duration of kidney failure, previous vascular access, arterial and venous diameter and medical history were equally distributed. Table 7.2 shows the endpoints. Forty-five percent of the no cuff group and $50 \%$ of the cuff group reached the endpoint with a patent graft. Four patients died of complications of their kidney failure with a patent fistula and six patients received a kidney transplantation, one of which failed within one week and this patient remained in the study.

Life table analysis showed all patency rates to be comparable between the two groups. There was a primary patency of $53 \%$ at 6 months and $29 \%$ at 1 year for the no cuff group and $48 \%$ at 6 months and $32 \%$ at 1 year with cuff $(p=0.824$, fig 7.1$)$. The secondary patency was $73 \%$ at 6 months and $67 \%$ at 1 year, 18 months and 2 years for patients without a cuff and respectively $90 \%$ and $84 \%$ with cuff ( $p=0.440$, fig 7.2 ). Total follow up was 25 patientyears for the no cuff group and 31.6 patient-years for the cuff group.

\section{Follow up measurements}

The mean volume flow in the grafts 6 weeks after implantation was 1528 $\mathrm{ml} / \mathrm{min}$ in the no cuff group and $1610 \mathrm{ml} / \mathrm{min}(p=0.694)$ in the cuff group (table 7.3). The relative distension measured 6 weeks after implantation was comparable between the groups in the graft (mean $\mathrm{RD}=1.2 \%$ in the no cuff group and $\mathrm{RD}=1.0 \%$ in the cuff group; $\mathrm{p}=0.62$ ), in the efferent vein $(R D=2.3 \%$ in the no cuff group, vs. $R D=2.2 \%$ in the cuff group; $p=0.87$ ) 
Table 7.1 Patient characteristics. $N=$ number of patients. Age, duration of kidney failure and vascular dimensions are presented as mean (standard error of the mean). All others are presented as $N(\%)$

\begin{tabular}{llll}
\hline & No cuff & Cuff & p-value \\
\hline $\mathrm{N}$ & 20 & 20 & \\
Age [years] & $59(4)$ & $61(2)$ & 0.64 \\
Male & $13(65 \%)$ & $6(30 \%)$ & 0.027 \\
History of kidney disease & & & \\
$\quad$ Duration of kidney failure [months] & $37(11)$ & $41(12)$ & 0.79 \\
$\quad$ Previous accesses & $12(60 \%)$ & $16(80 \%)$ & 0.17 \\
Causes of end-stage renal disease & & & \\
$\quad$ Glomerulosclerosis & $7(35 \%)$ & $5(26 \%)$ & 0.56 \\
$\quad$ Diabetes Mellitus & $2(10 \%)$ & $1(5 \%)$ & 0.58 \\
$\quad$ Hydronephrosis, lithiasis & $4(20 \%)$ & $6(32 \%)$ & 0.41 \\
$\quad$ Polycystic kidney disease & $1(5 \%)$ & $2(10 \%)$ & 0.52 \\
$\quad$ Other & $6(30 \%)$ & $6(30 \%)$ & 1.00 \\
Medical history & & & \\
$\quad$ Smoking & $6(30 \%)$ & $5(26 \%)$ & 0.80 \\
Diabetes Mellitus & $3(15 \%)$ & $5(25 \%)$ & 0.43 \\
Hypertension & $12(60 \%)$ & $9(45 \%)$ & 0.34 \\
Ischemic cardiac disease & $6(30 \%)$ & $5(25 \%)$ & 0.72 \\
Peripheral vascular disease & $1(5 \%)$ & $2(10 \%)$ & 0.55 \\
Cerebrovascular disease & $4(20 \%)$ & $4(20 \%)$ & 1.00 \\
Vascular dimensions in the elbow & $3.9(0.13)$ & $4.0(0.16)$ & 0.72 \\
$\quad$ Artery [mm] & $4.2(0.10)$ & $4.3(0.17)$ & 0.46 \\
$\quad$ Vein [mm] & & & \\
\hline
\end{tabular}

Table 7.2 Final endpoints. Data presented as number of patients (\%)

\begin{tabular}{llll}
\hline & No Cuff & Cuff & p-value \\
\hline Graft patent & $9(45 \%)$ & $10(50 \%)$ & 0.75 \\
Graft failure & $6(30 \%)$ & $5(25 \%)$ & 0.72 \\
Kidney transplantation & $3(15 \%)$ & $3(15 \%)$ & 1.00 \\
Death & $2(10 \%)$ & $2(10 \%)$ & 1.00 \\
\hline
\end{tabular}




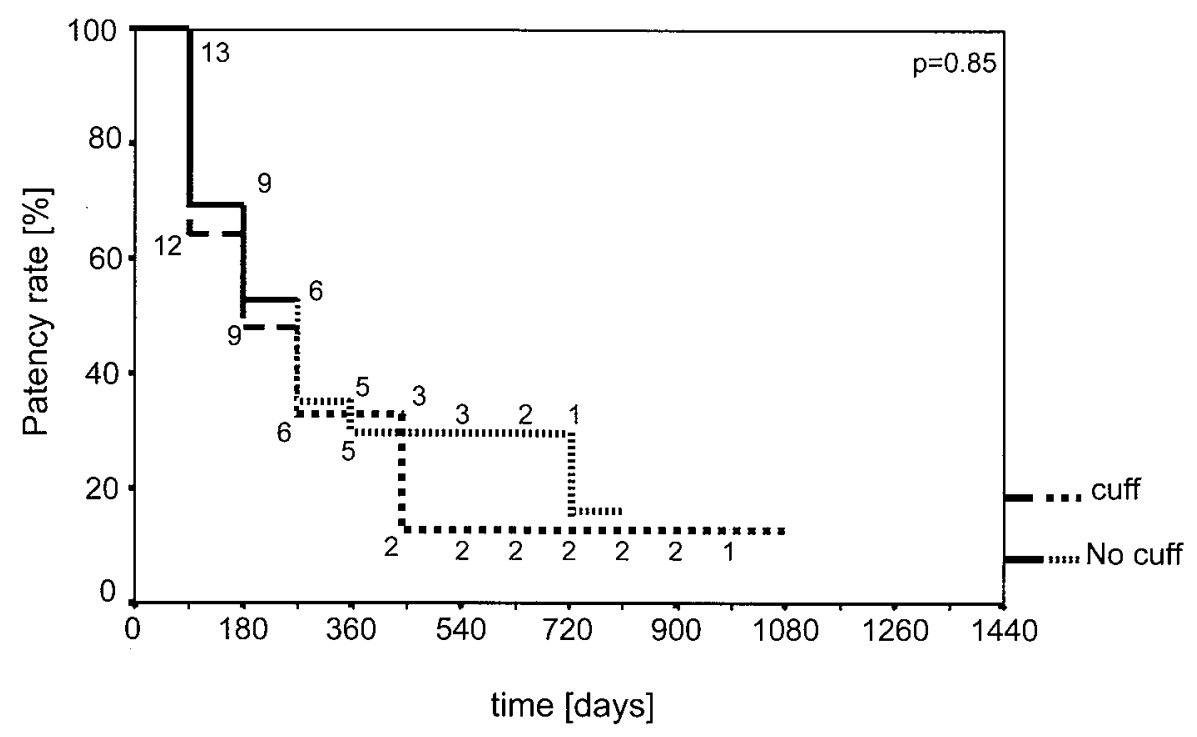

Figure 7.1 Primary patency. Number of patients is presented in the graph; when less than 8 patients entered the analysis, the graph is no longer statistically reliable.

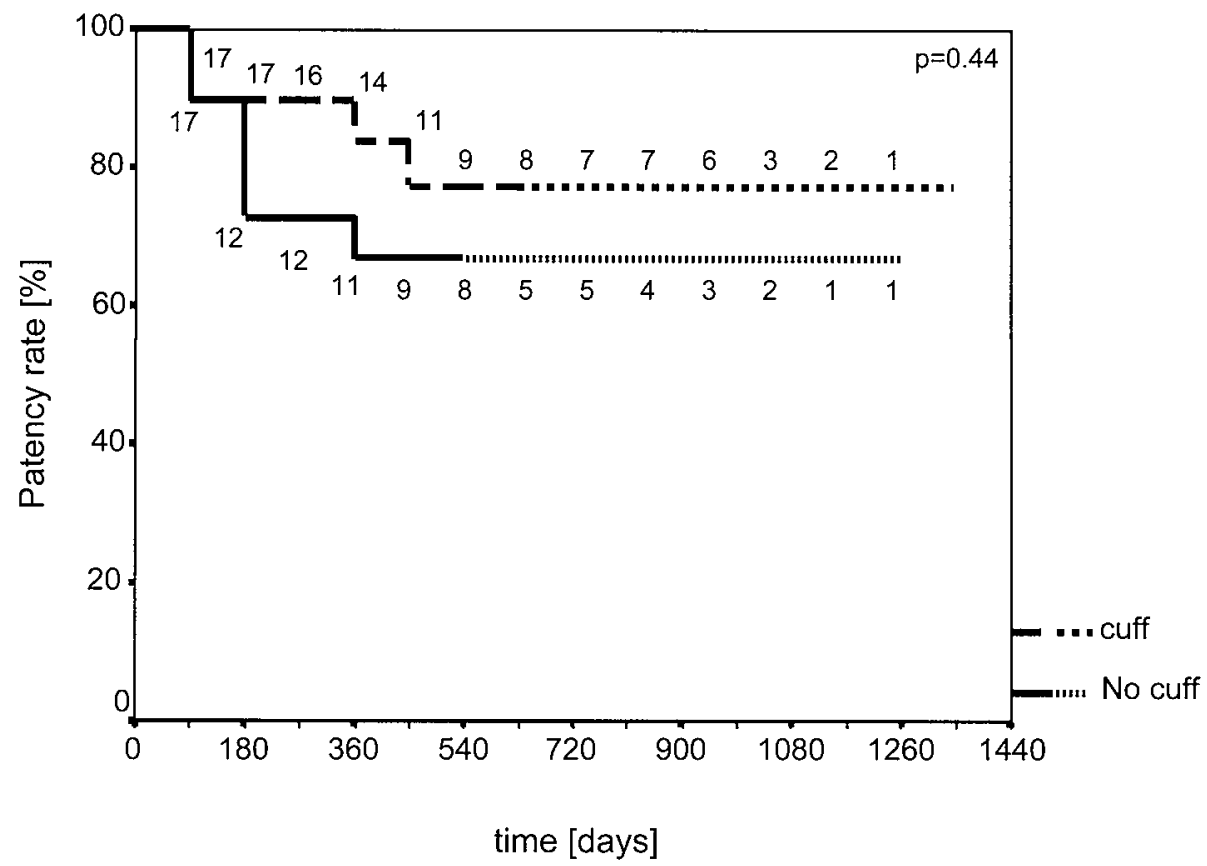

Figure 7.2 Secondary patency. Number of patients is presented in the graph; when less than 8 patients entered the analysis, the graph is no longer statistically reliable. 
Table 7.3 Hemodynamic measurements 6 weeks after implantation of the grafts. Qgraft $=$ volume flow in the graft, $D=$ diameter, $R D=$ relative distension, $W S R=$ wall shear rate, PSV ana = peak systolic velocity at the venous anastomosis. Data presented as means and standard error of the mean (SEM).

\begin{tabular}{lcccccc}
\hline & No cuff & \multicolumn{7}{c}{ Cuff } & p-value \\
\hline Qgraft [ml/min] & 1528 & $(147)$ & 1610 & $(147)$ & 0.69 \\
D graft [mm] & 5.6 & $(0.1)$ & 5.6 & $(0.1)$ & 0.88 \\
D vein [mm] & 6.9 & $(0.6)$ & 6.0 & $(0.7)$ & 0.39 \\
RD graft [\%] & 1.2 & $(0.2)$ & 1.0 & $(0.1)$ & 0.62 \\
RD vein [\%] & 2.3 & $(0.4)$ & 2.2 & $(0.5)$ & 0.87 \\
WSR graft [1/s] & 1329 & $(114)$ & 1137 & $(103)$ & 0.24 \\
WSR vein [1/s] & 687 & $(119)$ & 1705 & $(552)$ & 0.13 \\
PSV ana [m/s] & 2.80 & $(0.20)$ & 2.19 & $(0.19)$ & 0.10 \\
\hline
\end{tabular}

Table 7.4 Hemodynamic measurements just before intervention (intervention) and $>3$ months before or after intervention (control). Qgraft $=$ volume flow in the graft, $\mathrm{D}=$ diameter, $\mathrm{RD}=$ relative distension, $\mathrm{WSR}=$ wall shear rate, $\mathrm{PSV}$ ana $=$ peak systolic velocity at the venous anastomosis. Data presented as means and standard error of the mean (SEM).

\begin{tabular}{|c|c|c|c|}
\hline & Control & Intervention & p-value \\
\hline Qgraft [ml/min] & $1600 \quad(105)$ & $1225 \quad(140)$ & 0.004 \\
\hline D graft [mm] & $4.9 \quad(0.2)$ & $(0.2)$ & 0.84 \\
\hline $\mathrm{D}$ vein $[\mathrm{mm}]$ & $(0.3)$ & $(0.6)$ & 0.076 \\
\hline RD graft [\%] & $(0.3)$ & $(0.3)$ & 0.85 \\
\hline RD vein [\%] & $(1.0)$ & $(0.5)$ & 0.70 \\
\hline WSR graft [1/s] & $1095 \quad(97)$ & $681 \quad(80)$ & 0.007 \\
\hline WSR vein $[1 / s]$ & $1748 \quad(595)$ & 1430 & 0.55 \\
\hline PSV ana [m/s] & $(0.24)$ & $2.72 \quad(0.31)$ & 0.75 \\
\hline
\end{tabular}

and in the anastomosis $(R D=1.7 \%$ in the no cuff group vs. $R D=1.6 \%$ in the cuff group; $p=0.77$ ). Also, no difference in WSR was found in the graft (no cuff group mean WSR=1329/s, cuff group WSR=1137/s; $p=0.24$ ) or in the efferent vein (WSR=687/s vs. $W S R=1705 / \mathrm{s}, p=0.13$ ). No difference was found in diameter of the vein (no cuff vein $D=6.9 \mathrm{~mm}$, cuff vein $D=6.0 \mathrm{~mm}$; $p=0.39$ ) nor in diameter of the graft (both groups graft $D=5.6 \mathrm{~mm}, p=0.88$ ). Peak systolic velocity in the anastomosis tended to be lower in the cuff group (PSV $=2.19 \mathrm{~m} / \mathrm{s}$ ), than in the no cuff group (PSV $2.80 \mathrm{~m} / \mathrm{s}$ ), although this was not significant $(p=0.10)$. Regression analysis showed no influence of venous diameter, volume flow, relative distension and wall shear rate on primary patency. 
Comparing Duplex measurements $<1$ month before intervention with measurements more than 3 months before or after intervention in the same patient, graft flow was significantly lower just before intervention (mean $=1225 \mathrm{ml} / \mathrm{min}$ ) than with no intervention (mean=1600 $\mathrm{ml} / \mathrm{min}$, $p=0.004$ ). Also, WSR in the graft was lower (WSR=681/s vs. $W S R=1095 / \mathrm{s}$, $p=0.007$ ). As $W S R$ is proportional to flow and inversely proportional to diameter, higher flow with a constant diameter will lead to a higher WSR. The diameter of the graft was comparable in both groups $(D=4.9 \mathrm{~mm}$, $p=0.84)$. The diameter of the efferent vein tended to be smaller just before intervention ( $D=4.4 \mathrm{~mm}$, no intervention $D=5.6 \mathrm{~mm} ; p=0.076)$. No difference was found in RD in graft or efferent vein or in PSV in the anastomosis (table 7.4).

\section{Discussion}

In the present study, no differences in hemodynamic parameters and in patency were found between patients with or without venous cuff implantation at the venous anastomosis, neither a correlation was established between patency and hemodynamic parameters. However, just before graft failure, volume flow and wall shear rate in the graft were significantly lower than in non-failing fistulas.

Graft failure due to intimal hyperplasia is a multifactorial problem. Apart from repetitive endothelial cell injury, hemodynamic factors play a role. In vascular access, an interposition graft between artery and vein leads to a large pressure gradient and flow increase in the efferent vein. Due to the unphysiologically high flow, turbulence occurs at the anastomosis. This turbulence might play a role in inducing intimal hyperplasia. The dispersed flow direction may lift the endothelium, presenting subendothelium to blood components ${ }^{2}$. Exposition of venous endothelium to arterial flow conditions with severe stretching and high tangential stress damages the endothelial cells $s^{3 ; 4}$. This induces adherence and activation of thrombocytes, which release proliferation and migration stimulating factors. Changes in shear stress can induce activation of shear responsive elements in the promotors of certain genes involved in $\mathrm{IH}^{5}$. Cyclic stretching of VSMC induces proliferation and synthesis of collagen and matrix ${ }^{6}$. Stretching at the anastomosis can be caused by a compliance mismatch between graft and native vein. In PTFE bypasses implanted in carotid arteries of dogs, cuffed grafts developed less intimal hyperplasia than non-cuffed grafts ${ }^{7}$. The authors stated that inhibition of stenosis formation by the vein cuff might be caused by inhibition of proliferation of smooth muscle cells due to a wider distribution of kinetic energy (less compliance mismatch) or due to interposition of venous endothelium which offers a humoral protection. In rigid standard PTFE arterial bypass grafts, Doppler waveforms and patency were better and less intimal hyperplasia developed with a venous cuff than with a direct anastomosis, while in thin-walled PTFE grafts, the Doppler waveforms and patency were adversely affected by a cuff ${ }^{8}$. The anastomosis between the more compliant thin-walled PTFE graft and the native artery 
might be adversely affected by the double row of sutures of the venous patch. A randomised clinical trial did not find a beneficial effect of a venous cuff on the patency of PTFE femoropopliteal bypasses. In femorocrural bypasses a better patency was found in the cuff group, but this was attributed solely to the facilitation of anastomosing the graft to a small and difficult to reach artery ${ }^{9}$. In the present study, no difference in patency between the cuff group and the no cuff group was found. Thin-walled PTFE grafts were used, which might not benefit from the cuff. Moreover, the vessels in the elbow usually are easy to reach, and of acceptable calibre, so no technical benefit of the cuff can be expected. Also, no difference in relative distension was found, indicating no difference in compliance between the cuff group and the no cuff group.

More studies doubt the mechanical effect of venous cuffs. In bilateral PTFE carotid artery bypasses in dogs with cuffed anastomoses, limitation of the expandability of the vein cuff by a PTFE jacket around it, resulted in an equal distribution of intimal hyperplasia $(\mathrm{IH})$ between the jacketed and the normal cuffed side ${ }^{10}$. Also at highly elevated blood pressures the vein becomes almost rigid $^{11}$ and the effect of a cuff on the compliance is low. Moreover, computer simulation models of anastomotic flow indicate that compliance mismatch is not a causal factor in the development of $\mathrm{IH}^{12}$. This is confirmed by in vivo studies. Externally supported non-compliant Dacron grafts, used as a femoral artery transplant in dogs, did not develop more intimal hyperplasia than compliant autogenous carotid artery segments ${ }^{13}$. Also, in graft AV fistulas that developed stenoses a better initial match of elastic properties was found as compared to grafts that did not develop stenosis ${ }^{14}$. In the present study, direct measurement of the wall shear stress was not possible because of the high flow velocities and turbulence. Therefore, an approximation of the WSR was used. The largest influence of the cuff on WSR is expected in the anastomosis. However, the condition for approximation, being symmetrical laminar flow, was not met in the anastomosis, so the WSR could not be calculated at this location. Even in the efferent vein, calculated WSR is a mere approximation, since flow disturbances are expected downstream from the anastomosis. We found extremely high WSR in the graft and in the efferent vein, but no difference was found between the cuff group and the no cuff group. However, we did find that fistula failure was associated with a decrease in WSR. Since the diameter of the PTFE graft is fairly constant, a lower volume flow and velocity indicates a lower WSR. Although PSV tended to be lower in the cuff group, indicating a lower peak WSR with a constant diameter, no difference in patency was found.

In an in vitro model, the cuff induced a stable, unidirectional vortex in the anastomosis. This vortex had a high velocity with greater shear stress exertion on the vessel wall than laminar flow. The authors stated that the increased shear stress explained the beneficial effect of a cuff on anastomotic intimal hyperplasia ${ }^{15}$. Recent studies, however, have shown that not the absolute shear stress, but a large spatial and temporal gradient of shear stress is more important in inducing intimal hyperplasia ${ }^{16-18}$. 
In the present study, the diameter of the efferent vein was smaller just before failure, indicating the development of stenosis. This will lead to reduced graft volume flow, which was found in failing grafts as compared to non-failing grafts. It is well known that reduced flow predicts graft failure. The PTFE grafts are thrombogenic, and a volume flow below a critical point will lead to occlusion. A striking finding is that in peripheral bypasses, grafts remain patent with a volume flow around $100 \mathrm{ml} / \mathrm{min}$, whereas an arteriovenous graft with a volume flow below $600 \mathrm{ml} / \mathrm{min}$ has a high risk on occlusion ${ }^{19} 20$. This is partly explained because patients with end-stage renal disease have a predominantly thrombotic state, with activated coagulation markers and enhanced fibrinolysis in the systemic circulation. Moreover, in the arteriovenous (AV) fistulas the concentration of markers of coagulation, fibrinolysis and fibrinolysis inhibition are higher than in the systemic circulation, suggesting that $A V$ fistulas have an effect on the hemostasis ${ }^{21}$. In the high flow arteriovenous system, flow disturbances occur, inducing thrombocyte activation. Also, repetitive puncturing of the graft in hemodialysis treatment induces red cell injury and activation of thrombocytes ${ }^{22 ;} 23$ which could increase the risk on occlusion.

The present study indicates that a venous cuff at the venous anastomosis of PTFE graft AV fistulas does not improve patency, nor does it alter the WSR or RD around the venous anastomosis. Low flow and low WSR were associated with graft failure.

\section{Reference List}

1. Hofstra L, Ermers EJM, Langeveldt APM, Hoeks APG, Kitslaar

PJEHM. Vessel wall doppler tracking: a new technique to assess vessel wall compliance. J.Vasc. Tech. 1993;17:65-68.

2. Sottiurai VS, Sue SL, Feinberg EL, Bringaze WL, Tran AT, Batson RC. Distal anastomotic intimal hyperplasia: biogenesis and etiology. Eur.J.Vasc. Surg. 1988;2:245-256.

3. Cox JL, Chiasson DA, Gotlieb Al. Stranger in a strange land: the pathogenesis of saphenous vein graft stenosis with emphasis on structural and functional differences between veins and arteries. Prog.Cardiovasc.Dis. 1991;35:45-68.

4. Davies MG, Klyachkin ML, Dalen $H$, Massey MF, Svendsen E, Hagen PO. The integrity of experimental vein graft endothelium - Implications on the etiology of early graft failure. Eur.J.Vasc.Surg. 1993;7:156-165.

5. Gimbron-MA J, Nagle T, Topper JN. Biomechanical activation: an emerging paradigm in endothelial adhesion biology. J.Clin.Invest. 1997;99:1809-1813.

6. Sumpio B. Enhanced collagen production by smooth muscle cells during repetitive mechanical stretching. Arch.Surg. 1988;123:1233-1236.

7. Suggs WD, Henriques HF, DePalma RG. Vein cuff interposition prevents juxtaanastomotic neointimal hyperplasia. Ann. Surg. 1988;207:717-723.

8. Sottiurai VS, Jones $R$, Nakamura YA, Boustany C, Sue SL, Batson $\mathrm{RC}$. The role of vein patch in distal anastomotic intimal hyperplasia: an histologic characterization. Int.Angiol. 1994;13:96-102.

9. Stonebridge PA, Howlett $R$, Prescott R, Ruckley CV. Randomised trial comparing polytetrafluoroethylene graft patency with and without a Miller 
cuff. Br.J.Surg. 1995;82:555-556.

10. Norberto JJ, Sidawy AN, Trad KS, et al. The protective effect of vein cuffed anastomoses is not mechanical in origin. J.Vasc. Surg. 1995;21:558-566.

11. Dobrin PB, Littooy FN, Golan J, Blakeman B, Fareed J. Mechanical and histologic changes in canine vein grafts. J.Surg.Res. 1988;44:259-265.

12. Sottiurai VS. Biogenesis and etiology of distal anastomotic intimal hyperplasia. Int.Angiol. 1990;9:59-69.

13. Wu MH, Shi $Q$, Sauvage $L R$, et al. The direct effect of graft compliance mismatch per se on development of host arterial intimal hyperplasia at the anastomotic interface. Ann. Vasc. Surg. 1993;7:156-168.

14. Hofstra L, Bergmans DCJJ, Leunissen KML, et al. Anastomotic intimal hyperplasia in prosthetic arteriovenous fistulas for hemodialysis is associated with initial high flow velocity and not with mismatch in elastic properties. J.Am.Soc.Nephrol. 1995;6:16251633.

15. da Silva AF, Carpenter T, How TV, Harris PL. Stable vortices within vein cuffs inhibit anastomotic myointimal hyperplasia?

Eur.J.Vasc. Endovasc. Surg. 1997;14:157-163.

16. Steinman $D A$, Vinh $B$, Ethier $C R$, Ojha M, Cobbold RS, Johnston $\mathrm{KW}$. A numerical simulation of flow in a two-dimensional end-to-side anastomosis model. J.Biomech. Eng. 1993;115:112-118.

17. Ojha M, Cobbold RS, Johnston $\mathrm{KW}$. Hemodynamics of a side-toend proximal arterial anastomosis model. J.Vasc. Surg. 1993;17:646655.

18. Henry FS, Collins MW, Hughes PE, How TV. Numerical investigation of steady flow in proximal and distal end-to-side anastomoses. J.Biomech.Eng. 1996;118:302-310.

19. Shackleton CR, Taylor DC, Buckley AR, Rowley A,
Cooperberg PL, Fry PD. Predicting failure in polytetrafluoroethylene vascular access grafts for hemodialysis: a pilot study. Cañ.J.Surg. 1987;30:442-444.

20. Bosman PJ, Boereboom FTJ, Eikelboom BC, Koomans HA, Blankestijn PJ. Graft flow as a predictor of thrombosis in hemodialysis grafts. Kidney Int. 1998;54:1726-1730.

21. Erdem $Y$, Haznedaroglu IC, Celik I, et al. Coagulation, fibrinolysis and fibrinolysis inhibitors in haemodialysis patients: contribution of arteriovenous fistula. Nephrol.Dial. Transplant. 1996;11:1299-1305.

22. De Wachter $D$, Verdonck $P$, Verhoeven R, Hombrouckx R. Red cell injury assessed in a numeric model of a peripheral dialysis needle. ASAIO.J. 1996;42:M524M529.

23. De Wachter D, Verhoeven R, Verdonck P. Hemocompatibility of timedependent dialysis and fistula blood flow. 3rd int.congress on access for hemodialysis, 29-31 october 1997, Maastricht 1997;7374.(Abstract). 


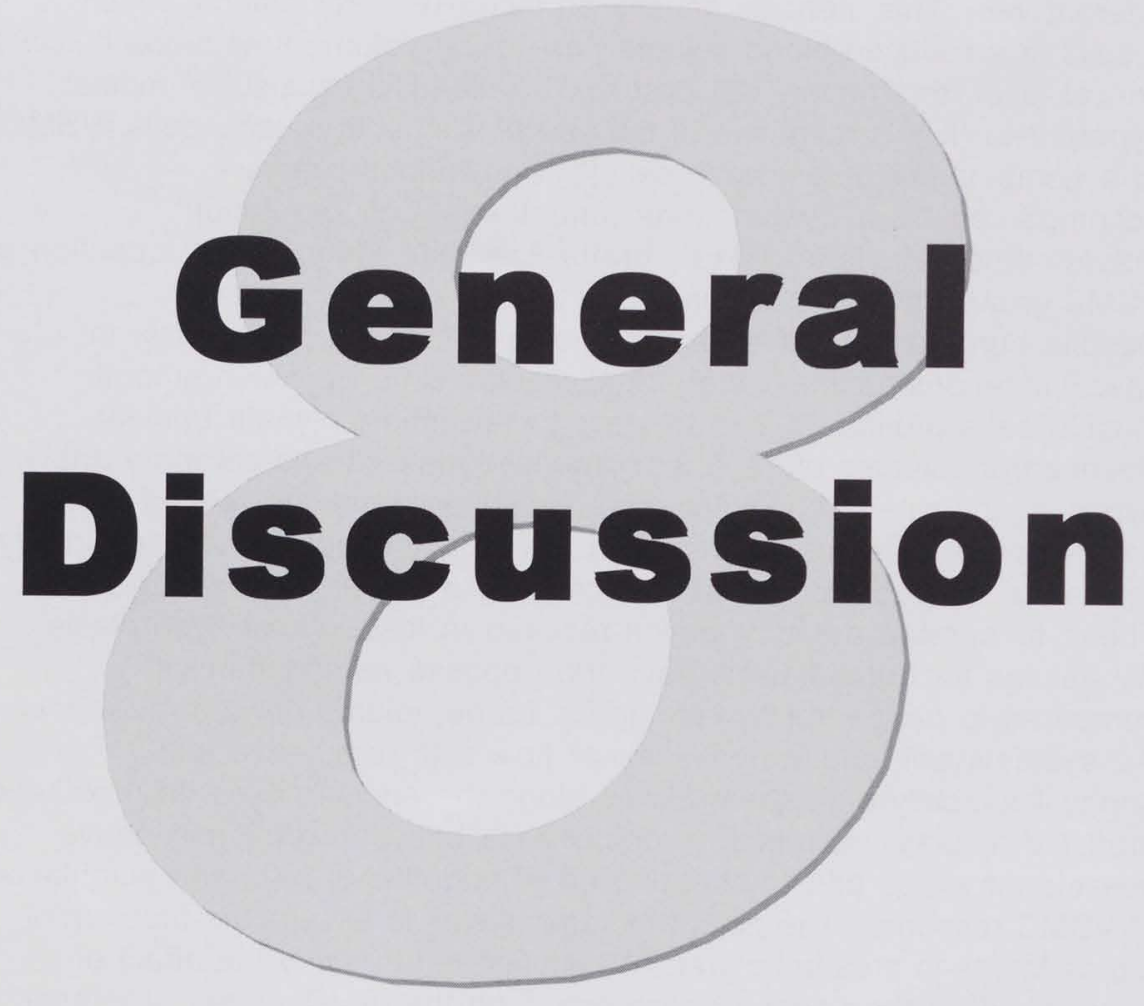




\section{Introduction}

The major problem of prosthetic graft arteriovenous (AV) fistulas is stenosis, usually occurring at the site of the venous anastomosis or in the efferent vein. This stenosis causes an increase in resistance, which results in a reduced blood volume flow. If the volume flow drops below a critical level, thrombosis will occur ${ }^{1}$. The stenosis consists of intimal hyperplasia $(\mathrm{IH})$, a response of the vascular smooth muscle cells (VSMC) to a combination of physical, cellular and humoral factors accompanied by a dysfunctional endothelial cell regulation ${ }^{2 ;} 3$. Polytetrafluoroethylene (PTFE) grafts itself can induce the production of VSMC growth factors in several ways ${ }^{2 ; 4 ; 5}$.

Despite numerous studies on the etiology of intimal hyperplasia in vascular reconstructions, the actual mechanisms by which smooth muscle cells proliferate and migrate to the intima remain unclear. Results from studies of peripheral arterial bypasses and coronary artery bypasses indicate that low flow and low shear stress are related to the development of initmal hyperplasia. Altering the anastomotic geometry with a cuff induced local vortices, creating a higher local shear stress. These favourable hemodynamics resulted in less intimal hyperplasia ${ }^{6}$. AV fistulas for hemodialysis have the opposite hemodynamics compared to peripheral bypass grafts. Large volume flows through the AV systems will induce non- laminar flow with turbulence and unphysiologically high shear stress along the anastomoses. In prosthetic graft AV fistulas, mismatch in compliance between graft and native vessels may also add to shearing off of endothelial cells and stimulation of VSMC response. The aim of this thesis was to assess the problem of stress forces in prosthetic graft AV fistulas and to study the effect of a venous cuff at the venous anastomosis on the development of intimal hyperplasia.

\section{Magnitude of intimal hyperplasia in AV fistulas}

PTFE graft AV fistulas have more than the double amount of complications than BC fistulas (0.72/vascular access for PTFE vs. $0.32 / v a s c u l a r$ access for $B C$ fistulas). Surgical intervention is mainly focussed on overcoming a stenosis, as is indicated from the treatment of choice for fistula failure (PTA, patch plasty and jump grafts) (chapter 2). The problems of intimal hyperplasia with PTFE graft AV fistulas are increasing. In the Netherlands, the hemodialysis population has increased from 2787 to 4128 (+48\%) from 1987 to 1996. And although the Brescia-Cimino (BC) fistula is still the vascular access of choice, there is an increasing need for alternative accesses. From 1987 to 1996, the number of PTFE graft AV fistulas increased with $8 \%$ at the expense of $\mathrm{BC}$ fistulas. This increase is partly due to ageing of the hemodialysis population. Firstly, the average age of the Dutch population as a whole is increasing, which has its repercussions on the hemodialysis population. Secondly, due to improved hemodialysis treatment, elderly 
people are also included into the hemodialysis program. Moreover, patients on hemodialysis treatment survive longer. The population on hemodialysis treatment over 65 years increased twice the amount of the younger population. Older patients are more likely to have vascular problems.

More effort in preoperative analysis may result in the creation of more native fistulas, as Sands has stated ${ }^{7}$. However, creating a BC fistula in a patient with inappropriate vessels might also result in an inadequate maturation of the fistula.

\section{Measures to influence intimal hyperplasia}

A new animal model was searched to study intimal hyperplasia in PTFE graft AV fistulas for hemodialysis, and this model was found in goats.

The vessels in the neck of goats are easy accessible and there is enough space for the positioning of a loop graft. Bilateral loop grafts are well tolerated, which makes intra-animal observations possible. The goats developed intimal hyperplasia at the same locations known from humans, being the suture line, the floor of the anastomosis and the efferent vein (chapter 4 ).

In the goat model as well as in humans, the effect of a venous cuff at the venous anastomosis on patency, shear stress, compliance and development of intimal hyperplasia was studied. In the goat model, the effect of low flow was also studied.

\section{Changing shear stress}

In the goat model, we attempted to reduce shear stress at the anastomosis by reducing the volume flow through the graft fistula. Although a significant reduction of volume flow was achieved, this did not lead to a reduced shear stress (chapter 5). This indicates that the relationship between volume flow and shear stress is not linear. The reduction of flow did not lead to a reduction in intimal hyperplasia. This is in contrast with the findings of Fillinger et al. ${ }^{8}$. They found that banding of a graft fistula reduced Reynolds number, a measure for turbulence, and this reduced the development of intimal hyperplasia. However, the volume flows achieved were much lower. For hemodialysis treatment a volume flow of more than $500 \mathrm{ml} / \mathrm{min}$ is required to meet with the demands of the artificial kidney. To be able to puncture the vessel adequately, a large vessel diameter is required. This results in a graft with a low resistance. The bottleneck of the arteriovenous graft complex is the anastomosis. In chapter 5 we showed that the largest pressure decrease is at the venous anastomosis. This pressure decrease indicates turbulence, which induces localised repetitive damage to the endothelium. This would then result in intimal hyperplasia. To overcome the problem of turbulence, a more gradual transition of resistance is necessary. This can only be achieved with a long graft with a small diameter, which is undesirable in hemodialysis vascular access. 
Changing graft geometry

A change of the geometry of the graft or the anastomosis alters the fluid hemodynamics around the anastomosis. The effect of graft diameter and geometry is demonstrated by Fillinger et al. in graft arteriovenous fistulas created between the iliac artery and femoral vein in dogs ${ }^{9}$. With a 4 to $7 \mathrm{~mm}$ tapered graft $(4 \mathrm{~mm}$ diameter at the arterial side and $7 \mathrm{~mm}$ diameter at the venous side), significantly less $\mathrm{IH}$ developed at the distal anastomosis as compared to $6 \mathrm{~mm}$ grafts. This was explained by less flow disturbance and turbulence at the distal anastomosis of the tapered graft. Since then, vascular surgeons in the USA mainly use tapered grafts to create vascular access for hemodialysis.

We examined the effect of a venous cuff in PTFE graft AV fistulas on the development of intimal hyperplasia. In goats, no decrease in intimal hyperplasia was found on the cuffed side as compared to the no-cuff side (chapter 5). In a clinical study, it appeared that the cuff decreased anastomotic stenoses but increased stenoses in the efferent vein. If thrombosis or stenosis occurs, the cuff group has fewer recurrences within the same patients, resulting in a lower incidence of thrombosis per patient year $(0.66$ vs. 0.88$)$. However, no difference in primary or secondary patency occurred (chapter 6).

Many other variations on the cuff theme have been studied. Recent presentation of the results of a non-randomised study of PTFE graft AV fistulas using a PTFE patch at the venous anastomosis, showed an improved patency rate $(88 \%$ after 48 montls $)$ compared to $4-7 \mathrm{~mm}$ tapered grafts $(66 \% \text { after } 36 \text { months, } p=0.047)^{10}$.

The long sutureline of the cuff was held responsible for the adverse effect of a venous cuff in thin-walled grafts. A graft design with an incorporated cuff would overcome this problem. A new type of PTFE prosthesis was designed with a cuffed or hooded venous end and used to create PTFE graft AV fistulas. Early reports are promising, with an improved 4 month secondary patency of $100 \%$ vs. $59 \%$ for the $4-7 \mathrm{~mm}$ tapered graft, although this study was not randomised either, and the patency of the tapered grafts seems to be very low ${ }^{11}$.

\section{Changing compliance}

Initially, the cuff was thought to reduce compliance mismatch between the prosthesis and the efferent vein. A vein patch is anisotropic and when used in a transverse direction, a better transition of compliance could be expected ${ }^{12}$. Since we could not measure local blood pressure to calculate the actual compliance, relative distension (RD) was used as a measure for compliance. No difference in RD between the cuff group and the no cuff group occurred in goats (chapter 5 ) or in humans (chapter 7). This is mainly explained by the fact that at high pressure, the vein becomes almost rigid ${ }^{13}$. Pressure at the venous anastomosis of AV fistula is probably too high to sustain any effect from a venous cuff interposition on compliance. 


\section{Limitations of the study}

In our hypothesis, we assumed that altering the hemodynamics on one side of an arteriovenous fistula complex would automatically lead to altered hemodynamics throughout the entire complex. However, in vivo experiments are performed in a dynamic system. Altering the hemodynamics on one location leads to compensatory mechanisms that reduce the effect of the change in other locations.

Also, the venous cuff is a small structure, changing the hemodynamics over only a short distance. The assessment of wall shear rate in the in vivo situation is difficult. A new ultrasonic system was developed at our institution to measure WSR in vivo ${ }^{14}$. However, in the high flow setting of the arteriovenous fistula, the range of the sampling frequency turned out to be too low. Therefore, we needed to use an approximation of the WSR, calculated from the mean bloodcell velocity and the vessel diameter. Although this is used in many studies, it has its limitations. Firstly, the mean bloodcell velocity over the cardiac cycle is calculated, so the pulsatility of the WSR is not taken into account. Recent simulation models have shown that the temporal and spatial gradient of the wall shear rate might be important in the development of intimal hyperplasia ${ }^{15-17}$. Secondly, the calculation of the mean velocity is made over the entire vessel diameter, and not only at the vessel wall. Also, meticulously localised measurements, for instance at the heel or the toe of the anastomosis, are not possible. As intimal hyperplasia develops mainly at these sites, local measurements of WSR would be interesting. Finally, the largest influence of the cuff on local hemodynamics is expected in the anastomosis. However, the condition for approximation, being symmetrical laminar flow, was not met in the anastomosis, so the WSR could not be calculated. Even in the efferent vein, calculated WSR was a mere approximation, since flow disturbances are expected downstream from the anastomosis.

\section{Clinical implications}

A venous cuff at the venous anastomosis of PTFE graft AV fistulas tends to reduce the development of stenosis at the anastomosis, but tends to increase stenosis formation in the efferent vein. This could have therapeutic advantages, since stenoses in the anastomosis are more difficult to treat with intervention procedures like PTA.

In the cuff and the no cuff group, the same amount of patients suffered from thrombotic occlusions. In the no cuff group, these patients had more recurrent occlusions than in the cuff group. So a venous cuff at the venous anastomosis of PTFE graft AV fistulas reduced the incidence of stenosis and thrombotic occlusions but this did not lead to an improved patency rate. Therefore, a venous cuff at the venous anastomosis of PTFE graft AV fistulas should not be used routinely. Graft fistulas connected to small veins $(<4 \mathrm{~mm})$ have a higher failure rate than those connected to large veins $(\geq 4 \mathrm{~mm})$. Preoperative Duplex 
examination can provide information on the best location and the best efferent vein for the creation of a PTFE graft AV fistula. This could improve the patency rates of graft fistulas.

Local problems increase the risk on failure of the graft fistulas. The decrease in patency of graft fistulas in patients with local oedema or obesity relates to difficulties in palpation of the graft. This will lead to more problems with puncturing of the graft. Repeated puncturing increases the risk on infection. Puncturing through the back wall of the graft leads to pseudoaneurysm formation. Also, if a graft cannot be palpated, adequate compression for hemostasis is difficult. Too strong compression may lead to occlusion, too weak compression may lead to pseudoaneurysm formation or bleeding. In obese patients, a more superficial location of the graft might reduce these problems. In patients with oedema, preoperative treatment of the oedema might improve patency rates.

Skin atrophy will easily lead to problems of wound healing, not only after surgery, but also after puncturing. This can increase the risk on infection of the graft. In patients with skin atrophy, the graft should be placed more deeply to prevent erosion of the overlying skin. Using a tunnelling device reduces the trauma to the surrounding tissue, which improves wound healing.

High flow was associated with better patency. Moreover, just before failure, graft flow was significantly lower compared to 3 months before failure in the same grafts. Early detection of pending fistula failure indicated by a decrease in flow would provide the option for elective intervention. Thus, a less invasive intervention might be performed, with a lower risk on complications. Also, secondary patency increases which is important, since the number of locations for bridge grafts is limited ${ }^{18}$. Therefore, a surveillance program with volume flow measurements should be performed. Not only the absolute flow, but probably also the individual decrease in flow is important to indicate the need for an intervention.

\section{Future perspectives}

Pharmacological control

A number of different substances with different targets have been used to decrease the development of intimal hyperplasia. Although some had promising results in animal studies ${ }^{13 ;} 19$, little or no positive effects have been obtained in clinical studies ${ }^{2}$. The molecular biology of the development of intimal hyperplasia is very complex. Because a number of different events finally leads to vascular smooth muscle cell proliferation, migration and deposition of a matrix, it is not likely that a single pharmacological agent can actually prevent intimal hyperplasia. It may be that a strategy designed to alter the vascular conduit or the covering cells rather than the administration of drugs will lead to a more satisfactory result. 
Improving biocompatibility

Increase in biocompatibility of the prosthesis could reduce activation of macrophages and thrombocytes, both probably involved in the development of intimal hyperplasia. This can be done by developing new types of prosthetic material or by coating currently used prostheses. In the seventies, polyurethane prostheses failed due to dissolving of the graft material. A new polymerisation technique has improved the performance of these grafts and the results of early studies are promising ${ }^{20 ; 21}$.

Also, bioprostheses have been reintroduced. The bovine mesenteric vein can be submitted to a conservation technique in which the elastic properties are maintained. This leads to a compliant prosthesis, with good results in non-randomised studies ${ }^{22 ; 23}$.

Endothelialisation of the luminal surface of prosthetic grafts is thought to decrease thrombogenicity of the graft and improve flow patterns. This would decrease thrombotic occlusion and the development of intimal hyperplasia. Although autologous endothelial cell seeding of PTFE grafts is technically feasible, it has not been successful in clinical studies.

\section{Decreasing surgical damage}

Surgical exposure decreases vessel wall compliance, probably due to arterial spasm. However, after simple exposure of the artery and wound closure, compliance has decreased to $50 \%$ of its initial value by 2 weeks. In some cases, partial reversal occurs after 4 weeks, but in others, the decreased compliance persists.

To diminish endothelial dysfunction, endothelial cell injury, endothelial denudation and smooth muscle cell injury, the "no touch" technique should be applied, where there is minimum manual and instrumental contact with the vessel ${ }^{24}$. However, no study has shown a difference in incidence of intimal hyperplasia according to technique. Using nonpenetrating staples to create the anastomosis could reduce surgical damage to the endothelium and improve patency rates ${ }^{25}$. A study on microvascular anastomosing techniques indicated that the skill of the surgeon was the most important factor determining the patency of the graft $^{26}$. This indicates that a vascular access should only be created by trained vascular surgeons.

\section{Influencing graft geometry}

A number of different geometries have been tried, thus far with little to no success. Based on the hypothesis that a high spatial or temporal gradient of wall shear stress might be responsible for the induction of $\mathrm{IH}$, numerical simulation models have calculated an optimal anastomotic design with minimal flow disturbance and low wall shear stress gradient. The optimal anastomosis has a 1.6-2:1 graft-to-vein diameter, a heel angle between $10^{\circ}$ and $15^{\circ}$ and at the toe a gradual transition in curvature and cross-sectional area ${ }^{27}$. However, there are no clinical data 
available on this design.

\section{Conclusion}

Intimal hyperplasia remains one of the major obstacles to long-term graft patency. It appears to be the response of the vascular smooth muscle cells to a combination of physical, cellular and humoral factors accompanied by dysfunctional endothelial regulation. It is now apparent that any form of endothelial trauma will produce a thickened neointima as part of the healing response. It has to be appreciated that neointimal hyperplasia occurs at different sites following different procedures, but will not always have the same sequelae. Given the multifactorial nature of the etiology of intimal hyperplasia it may be that a single intervention will not prove capable of controlling smooth muscle cell proliferation.

The present studies showed that a venous cuff at the venous anastomosis did not improve local hemodynamics. There seems to be a positive influence on anastomotic stenosis formation and a reduction in the incidence of thrombotic occlusions, however, this does not lead to improved patency rates.

\section{Reference List}

1. Bosman PJ, Boereboom FTJ, Eikelboom BC, Koomans HA, Blankestijn PJ. Graft flow as a predictor of thrombosis in hemodialysis grafts. Kidney Int. 1998;54:1726-1730.

2. Clowes AW. Intimal hyperplasia and graft failure. Cardiovasc. Pathol. 1993;2 (Suppl):179S-186S.

3. Chervu A, Moore WS. An overview of intimal hyperplasia. Surg. Gynecol.Obstet. 1990;171:433-447.

4. Ombrellaro MP, Stevens SL, Sciarrotta J, Freeman MB, Goldman $\mathrm{MH}$. Effect of endoluminal PTFE graft placement on cell proliferation, PDGF secretion, and intimal hyperplasia. J.Surg.Res. 1996;63:110-114.

5. Sumpio B. Enhanced collagen production by smooth muscle cells during repetitive mechanical stretching. Arch. Surg. 1988;123:1233-1236.

6. da Silva AF, Carpenter T, How TV, Harris PL. Stable vortices within vein cuffs inhibit anastomotic myointimal hyperplasia? Eur.J.Vasc.Endovasc. Surg. 1997;14:157-163.

7. Sands J, Miranda CL. Increasing numbers of $A V$ fistulas for

hemodialysis access. Clin. Nephrol. 1997;48:114-117.

8. Fillinger MF, Reinitz ER, Schwartz RA, Resetarits DE, Paskanik AM, Bredenberg CE. Beneficial effects of banding on venous intimal-medial hyperplasia in arteriovenous loop grafts. Am.J.Surg. 1989;158:87-94

9. Fillinger MF, Reinitz ER, Schwartz $R A$, et al. Graft geometry and venous intimal-medial hyperplasia in arteriovenous loop grafts. J.Vasc.Surg. 1990;11:556-566.

10. Scholz H, Petzold K, Kruger U, Settmacher U, Petzold M, Zanow J. Four years experience with arteriovenous patchprosthesis as access for hemodialysis. Tordoir JHM. Proc.3rd Int.congress on acces for dialysis Maastricht. 1997: 61-62.

11. Escobar, F. S. A preliminary study comparing a new "hooded" vs. conventional ePTFE graft in hemodialysis patients. In:Vascular access for hemodialysis VI, Miami, Florida. 1998:26.

12. Tyrrell MR, Chester JF, Vipond MN, Clarke GH, Taylor RS, Wolfe J.

Experimental evidence to support the use of interposition vein collars/patches in distal PTFE 
anastomoses. Eur.J.Vasc. Surg. 1990;4:95-101.

13. Dobrin PB, Littooy FN, Golan J, Blakeman B, Fareed J. Mechanical and histologic changes in canine vein grafts. J.Surg.Res. 1988;44:259-265.

14. Brands PJ, Hoeks APG, Hofstra L, Reneman RS. A non-invasive method to estimate wall shear rate using ultrasound. Ultrasound.Med. Biol. 1995;21:171-185.

15. Steinman $D A$, Vinh $B$, Ethier $C R$, Ojha M, Cobbold RS, Johnston KW. A numerical simulation of flow in a two-dimensional end-to-side anastomosis model. J.Biomech. Eng. 1993;115:112-118.

16. Ojha M, Cobbold RS, Johnston KW. Hemodynamics of a side-to-end proximal arterial anastomosis model. J.Vasc.Surg. 1993;17:646655.

17. Henry FS, Collins MW, Hughes PE, How TV. Numerical investigation of steady flow in proximal and distal end-to-side anastomoses. J.Biomech.Eng. 1996;118:302-310.

18. Sands J, Young S, Miranda C. The effect of Doppler flow screening studies and elective revisions on dialysis access failure. ASAIO.J. 1992;38:M524-M527

19. Davies MG, Dalen H, Kim JH, Barber L, Svendsen E, Hagen PO. Control of accelerated vein graft atheroma with the nitric oxide precursor: L-arginine. J.Surg.Res. 1995;59:35-42.

20. Allen RDM, Yuill E, Nankivell BJ, Francis DMA. Australian multicentre evaluation of a new polyurethane vascular access graft. Aust.N.Z. J.Surg. 1996;66:738-742.

21. Glickman $\mathrm{MH}$. Early results of a randomised trial between the Vectra graft and ePTFE for hemoaccess. Presented at Angioaccess for Hemodialysis: 2nd International Multidisciplinary Symposium. Tours, France, June 2, 1999. 1999;

22. Hancock Jaffe Laboratories. Technical report Procol vascular bioprosthesis. Invine, California. 1990.

23. Bourquelot PD. Procol Bioprosthetic vascular grafts for dialysis access.
Presented at Angioaccess for Hemodialysis: 2nd International Multidisciplinary Symposium. Tours, France, June 2, 1999. 1999:16-19.

24. Gottlob R. The preservation of the venous endothelium by a dissection without touching and by an atraumatic technique of vascular anastomosis. Min.Chir. 1977;32:693700.

25. Schild, AF. Use of a vascular staple device for creation of AV fistulas and bridge grafts for hemodialysis. In: Vascular access for Hemodialysis $V$. Henry, ML and Ferguson, RM. Percept Press, Tucson, Arizona. 1997:95-102.

26. Guity A, Young PH, Fischer WW. In search of the "perfect" anastomosis. Microsurgery. 1990;11:5-11.

27. Lei M, Archie JP, Kleinstreuer $C$. Computational design of a bypass graft that minimizes wall shear stress gradients in the region of the distal anastomosis. J.Vasc.Surg. 1997; 25:637-646. 


\section{Summary}

\section{Introduction (chapter 1)}

Patients with end-stage renal disease can be treated with hemodialysis.

To achieve this, access to the patient's circulation is necessary. The access of first choice is the autologous Brescia-Cimino (BC) fistula. Due to ageing of the dialysis population and prolongation of the dialysis therapy, more and more secondary accesses are used, mainly polytetrafluoroethylene (PTFE) grafts.

The most prevalent complication of arteriovenous (AV) fistulas is thrombosis due to stenosis. The stenosis is comprised of intimal hyperplasia.

Intimal hyperplasia is thought to be caused by either low or high shear stress, although compliance mismatch may also play a role. Reduction of volume flow through a vessel with a constant diameter, as is the case in graft fistulas, would reduce shear stress.

Intimal hyperplasia is also a problem for peripheral arterial bypass construction for the treatment of limb ischemia. Since the use of a venous cuff at the distal anastomosis improves the patency rate of femorodistal bypasses we postulated that it might also improve the patency rate of PTFE graft fistulas. A venous cuff increases the local anastomotic diameter and could therefore reduce the shear stress. Moreover, the cuff produces a better transition of elastic properties because the vein is used in a transverse direction.

We hypothesised that 1) flow reduction in PTFE graft fistulas reduces shear rate near the venous anastomosis and the development of intimal hyperplasia, 2) a venous cuff at the venous anastomosis of PTFE graft fistulas reduces the compliance mismatch and reduces the shear stress at the venous anastomosis, 3 ) a venous cuff at the venous anastomosis of PTFE graft fistulas reduces the development of intimal hyperplasia and improves the patency rates.

The aim of this thesis was to describe and analyse the practice of vascular access and its problems in the Netherlands and test the above mentioned hypothesis in animal studies and in a randomised clinical study.

\section{Vascular access in the Netherlands (Chapter 2)}

To establish the magnitude of the vascular access problems caused by intimal hyperplasia in PTFE graft fistulas, a survey was performed to assess the use of vascular accesses in the Netherlands. From 1987 to 1996 the number of patients depending on hemodialysis treatment increased with $48 \%$. The number of patients older than 65 years has increased disproportionally (with $92 \%$ ) to the total increase of hemodialysis patients. Arm vessels of elderly patients are often not suitable for the construction of a $\mathrm{BC}$ fistula. This was reflected in the increased use of PTFE graft fistulas in 1996 at the expense of BC 
fistulas, as compared to 1987 . These grafts needed twice as many interventions compared to the BC fistulas to remain patent. Therefore the number of complications, due to intimal hyperplastic stenoses, will grow, as the number of prosthetic graft implants will increase due to the rise in elderly patients in the dialysis program.

Routine surveillance to detect stenosis was rarely performed. When problems occurred, all centres performed angiography, $79 \%$ performed Duplex scanning, $79 \%$ performed recirculation measurements and $38 \%$ performed venous pressure curve measurements. For the treatment of stenosis, the use of percutaneous transluminal angioplasty has increased from $46 \%$ to $92 \%$ of the centres.

\section{Cell biology and hemodynamics of intimal hyperplasia (Chapter 3)}

Intimal hyperplasia $(\mathrm{IH})$ appears to be the response of the vascular smooth muscle cells (VSMC) to a combination of physical, cellular and humoral factors. Numerous studies have been conducted to reveal the causes of $\mathrm{lH}$. We now know that it occurs after different types of vascular damage, always involving endothelial cell (EC) dysfunction. Because of this, the normal inhibiting effect of EC on VSMC proliferation is lost.

Also, other types of cells like macrophages and thrombocytes are activated due to the vessel wall damage. These cells release migration and proliferation promoting factors, inducing migration of medial VSMC into the intimal proliferation of the VSMC in the intima and deposition of a matrix. Thus, the intima enlarges at the expense of the lumen, causing stenosis. When a PTFE graft fistula is implanted, the promotion of VSMC growth factors can be induced by foreign body response and thrombocyte activation caused by the prosthesis and compliance mismatch, turbulence and a high shear gradient occurring at the anastomosis.

\section{Validation of a new animal model (chapter 4)}

Present animal models to study intimal hyperplasia are usually expensive, need separate homing, and do not develop truly stenotic lesions within the time periods studied (up to 6 months). Therefore we developed and validated a new animal model to study intimal hyperplasia in arteriovenous (AV) fistulas. In the neck of $20 \mathrm{~kg}$ goats, the carotid artery diameter resembles that of the brachial artery in the human elbow. The jugular vein diameter is slightly larger than that of the elbow vein. This similarity in vessel diameters may imply similarity in hemodynamic properties of graft fistulas created in humans and in the neck of goats. Moreover, goats can be homed in groups. This reduces the daily costs of animal care and decreases the limitation of number of animals studied within the same time period or over a longer period of time due to restricted homing facilities.

Direct AV fistulas and PTFE graft fistulas created between the carotid 


\section{Summary}

artery and the jugular vein in goats were histologically examined and morphometric measurements were performed. In this study we showed that goats are able to develop intimal hyperplasia after the creation of direct and bridge graft $A V$ fistulas. The intimal hyperplasia develops mainly in the anastomosis and in the efferent vein. Intimal area increased with time, and the hyperplastic lesions contained VSMC with depositions of $\alpha$-actin, and desmin.

The site and the composition of the intimal hyperplasia were comparable to those seen in human AV fistulas. In the goat grafts, occlusion occurred due to thrombosis. Tight stenoses were found at the venous anastomosis of these grafts, probably limiting the flow thus causing thrombosis. Vascular access occlusion in humans is also mainly caused by thrombosis due to low flow, caused by a stenosis in the outflow traject.

\section{Hemodynamics of prosthetic grafts in the goat (chapter 5)}

To study the effect of graft geometry and flow on intimal hyperplasia in PTFE graft fistulas, a series of experiments was performed in the validated goat model.

Reduction of volume flow did not result in a reduction of WSR or a change in relative distension. The WSR was approximately twice as high as in the normal vasculature. No difference in development of $\mathrm{IH}$ was found between high and low flow fistulas.

A large pressure gradient at the anastomosis indicates a high anastomotic resistance, with the risk on turbulence and flow reduction. The use of a venous cuff at the venous anastomosis of graft fistulas increases the anastomotic diameter and reduces the anastomotic resistance. Theoretically, this would lead to a decrease in the pressure drop at the connection with the efferent vein, causing less stretching and stress on the venous endothelium. However, we could not find a lower pressure decrease at the venous anastomosis in cuffed grafts than in normal grafts. Also, no difference in relative distension (RD) in the efferent vein was found between the normal and cuffed anastomoses. Considering the graft fistulas that were patent 6 weeks after implantation, we found that the area of intimal hyperplasia was not associated with hemodynamic parameters like volume flow, wall shear rate and relative distension. Considering all grafts, a better patency was significantly related to higher wall shear rate, higher fistula volume flow and lower relative pressure decrease at the venous anastomosis.

We could not demonstrate a beneficial effect of a venous cuff at the venous anastomosis of PTFE AV fistulas on patency and the development of intimal hyperplasia in our goat model.

\section{A venous cuff in PTFE grafts in hemodialysis patients (chapter 6)}

A randomised multicenter trial was carried out in 120 patients to study 
the effect of a venous cuff at the venous anastomosis of PTFE AV grafts on the patency rates and the development of stenoses. Three months postoperatively, Duplex examination and fistulography was performed to detect stenosis. The incidence of thrombotic occlusions was less in the group with a venous cuff at the venous anastomosis of polytetrafluoroethylene (PTFE) arteriovenous (AV) grafts. This was probably due to a lower incidence of stenosis at the venous anastomosis, although this failed to reach statistical significance. However, the decrease in thrombotic occlusions did not result in a better patency rate in the cuff group because recurrent thrombotic occlusion occurred in the same patients. The 1-year patency rates were comparable to the results reported in the literature, varying from 40 to $57 \%$ for primary patency and 62 to $78 \%$ for secondary patency. The most frequent complication needing intervention was thrombosis, followed by interventions for stenosis causing impaired fistula function. The cuff group had more interventions for infections $(0.06$ per py vs. 0.01 per py in the no-cuff group), but it is still well below the 0.21-0.37 per py, and $11-34 \%$, reported by others.

Initial vein diameter and local problems (oedema, obesity or skin atrophy) appear to be the most important risk factors for graft failure.

\section{Hemodynamics of the venous cuff in PTFE grafts in patients (chapter 7)}

In a subgroup of the multicenter trial $(n=40)$, additional ultrasound measurements were performed to calculate relative distension (RD) and wall shear rate (WSR). Volume flow, diameter of graft and efferent vein, $\mathrm{RD}$ and WSR were comparable for both groups. Comparing hemodynamic measurements in failing grafts to non-failing grafts, volume flow and WSR were higher in non-failing than in failing grafts. We found high WSR in the graft and in the efferent vein, but these values were similar for the cuff group and the no-cuff group. Fistula failure was associated with a decrease in WSR. Since the diameter of the PTFE graft is fairly constant, a lower volume flow and velocity indicates a lower WSR. Although peak systolic velocity tended to be lower in the cuff group, indicating a lower peak WSR with a constant diameter, no difference in patency was found. No differences in relative distension were found, indicating no difference in compliance between the cuff group and the no-cuff group.

Just before failure, the diameter of the efferent vein was smaller, indicating the development of stenosis. This will lead to a reduced graft volume flow, which was indeed found in failing grafts as compared to non-failing grafts. It is well known that reduced flow predicts graft failure. The present study indicates that a venous cuff at the venous anastomosis of PTFE graft AV fistulas does not improve patency, nor does it alter the WSR or RD around the venous anastomosis. Low flow and low WSR were associated with graft failure. 


\section{Summary}

\section{General discussion (chapter 8)}

In this thesis we assessed the effect of a venous cuff at the venous anastomosis of PTFE graft AV fistulas. In animal studies as well as in a clinical trial, we found no reduction of WSR nor of RD when a venous cuff was used, compared to a standard anastomosis. In the animal studies, no reduction of development of intimal hyperplasia was seen. Although in the clinical study less thrombotic events occurred in the cuff group, this did not lead to an improved patency rate.

However, there are some limitations to the studies. An approximation of WSR was used, and it was calculated as a mean over the cardiac cycle and over the diameter. Therefore, fluctuations of WSR in time and locations were not taken into account. Also, it was not possible to calculate WSR and RD in the anastomosis, where the largest effect of the cuff is expected.

Since no effect of the venous cuff at the venous anastomosis of PTFE graft AV fistulas was found, it should not be used routinely. We did show that just before failure of a PTFE graft AV fistula, the flow is reduced. Routine surveillance of the fistulas may detect pending failure and lead to elective treatment of stenoses with better secondary patency rates. Intimal hyperplasia is a multifactorial problem and future research should be directed to (a combination of) pharmacological intervention of the hyperplastic response, improving the biocompatibility of the prosthesis, decreasing surgical damage, and influencing graft geometry. 


\section{Samenvatting}

\section{Introductie (hoofdstuk 1)}

Een van de behandelingsmethoden van patiënten met nierfalen is hemodialyse. Hiervoor is een toegang tot de bloedbaan nodig. De BresciaCimino (BC) arterioveneuze (AV) fistel is sinds zijn ontwikkeling in 1966 de toegang van keuze. Echter, door toename van oudere patiënten in het dialyse programma en de langere duur van hemodialyse behandeling zijn steeds vaker alternatieve toegangen tot de bloedbaan nodig. De meest gebruikte secundaire toegang tot de bloedbaan is de polytetrafluoroethylene (PTFE) prothetische AV fistel. De meest voorkomende complicatie van deze PTFE AV fistels is trombose ten gevolge van stenose door intima hyperplasie $(\mathrm{IH})$. Als mogelijke oorzaak van $\mathrm{IH}$ worden zowel hoge als lage schuifkracht op de vaatwand (shear stress) genoemd. Ook een verschil in rekbaarheid (compliantie) tussen prothese en vene kan een rol spelen. Wanneer de doorsnede van een vat constant blijft, zoals bij een prothese, zou vermindering van de volumeflow kunnen leiden tot een verlaging van de shear stress. IH treedt ook op bij perifere arteriële bypasses ter behandeling van ischemie. Een veneuze cuff op de distale anastomose verbetert de doorgankelijkheidsduur van deze femorodistale bypasses. Onze hypothese is dat een veneuze cuff op de veneuze anastomose van PTFE AV fistels ook een verbetering van de doorgankelijkheid geeft. Een veneuze cuff vergroot de diameter van de anastomose en zou daardoor de shear stress kunnen verlagen. Bovendien wordt de vene voor het aanleggen van de cuff in dwarse richting ingehecht, wat tot een meer geleidelijke overgang in compliantie leidt.

Onze hypotheses zijn: 1) flow vermindering in PTFE AV fistels vermindert de shear stress in de anastomose en daardoor is er minder ontwikkeling van intima hyperplasie, 2) een veneuze cuff op de veneuze anastomose van PTFE AV fistels vermindert het verschil in compliantie en vermindert de shear stress ter hoogte van de veneuze anastomose, 3) een veneuze cuff op de veneuze anastomose van PTFE AV fistels vermindert de ontwikkeling van intima hyperplasie en verbetert de doorgankelijkheidsduur.

Het doel van dit proefschrift was om het gebruik van de verschillende soorten toegang tot de bloedbaan in Nederland te beschrijven en de bovenstaande hypotheses te toetsen in een proefdierstudie en in een gerandomiseerde klinische studie.

\section{Toegang tot de bloedbaan in Nederland (hoofdstuk 2)}

Om de omvang van de problemen, veroorzaakt door IH in PTFE AV fistels, vast te kunnen stellen, werd een enquête gehouden om het type toegang tot de bloedbaan dat gebruikt wordt in Nederland, vast te leggen. De resultaten van de enquête werden vergeleken met die van een vergelijkbare studie, gehouden in 1987. Van 1987 tot 1996 is het aantal hemodialyse patiënten toegenomen met $48 \%$, terwijl het aantal patiënten ouder dan 65 jaar steeg met $92 \%$. Bloedvaten in de arm van oudere patiënten zijn vaak niet geschikt 


\section{Samenvatting}

om een $\mathrm{BC}$ fistel aan te leggen. Dit werd bevestigd door een daling in het gebruik van $B C$ fistels van $70 \%$ naar $62 \%$ van de totale toegangen tot de bloedbaan, en een toename van PTFE fistels van $13 \%$ naar $21 \%$. De PTFE fistels hadden twee maal zoveel interventies nodig om open te blijven dan de $B C$ fistels ( 0.32 vs. 0.72 per fistel per jaar). Met de toename van het aantal PTFE fistels zal ook de problematiek met intima hyperplasie toenemen.

Routine onderzoek om stenose vast te stellen werd zelden uitgevoerd. Wanneer er problemen met de fistels waren, werd door alle centra een angiogram verricht; $79 \%$ liet Duplex onderzoek doen; $79 \%$ deed recirculatie metingen en $38 \%$ bepaalde een veneuze drukcurve. De behandeling van stenoses met Percutane Transluminale Angioplasty (PTA) nam toe van $46 \%$ naar $92 \%$ van alle centra.

\section{Celbiologie en hemodynamica van intima hyperplasie (hoofdstuk 3)}

Intima hyperplasie $(\mathrm{IH})$ is een respons van de gladde spiercellen van de vaatwand (VSMC) op een combinatie van fysische, cellulaire en humorale factoren. Er zijn vele studies uitgevoerd om de oorzaken van IH vast te stellen. IH treedt op na verschillende vormen van schade aan de vaten, waarbij de endotheelcel (EC) functie wordt verstoord. Daardoor valt de normale remmende werking van de EC op de groei van VSMC weg. Ook worden andere celtypes, zoals macrofagen en trombocyten, geactiveerd door de schade aan de vaatwand. Deze cellen scheiden stoffen uit die de migratie en deling bevorderen, waardoor migratie van de VSMC van media naar intima, deling van de VSMC in de intima en produceren van een matrix door de VSMC wordt geïnduceerd. De intima verdikt ten koste van het lumen waardoor stenose ontstaat. Wanneer een PTFE AV fistel wordt geïmplanteerd, worden groeifactoren ook geïnduceerd door de vreemdlichaam reaktie van macrofagen en door trombocyten activatie door de prothese, en door compliantie verschil, turbulentie en hoge gradiënt in shear rate bij de anastomose.

\section{Validatie van een nieuw diermodel (hoofdstuk 4)}

De huidige beschikbare diermodellen om IH te onderzoeken zijn duur en geven geen flowbeperkende stenoses. Daarom ontwikkelden en valideerden we een nieuw diermodel om IH in arterioveneuze fistels te onderzoeken. Directe arterioveneuze fistels en PTFE AV fistels tussen de a. carotis communis en $v$. jugularis in geiten werden immunohistochemisch onderzocht en er werden morfometrische metingen uitgevoerd van intima en media. Het onderzoek toonde aan dat geiten IH ontwikkelen na aanleg van directe en PTFE AV fistels. De IH ontwikkelde voornamelijk in de anastomose en in de efferente vene. Intima oppervlak nam toe met de tijd en de laesies bevatten VSMC met deposities van $\alpha$-actine en desmine.

De locatie en samenstelling van IH waren vergelijkbaar aan die in humane AV fistels. In de PTFE AV fistels ontstond occlusie door trombose. Er 
werden ernstige stenoses aangetoond op de veneuze anastomose, die de flow beperkten en waarschijnlijk tot trombose hebben geleid. In de mens wordt occlusie van AV fistels veroorzaakt door trombose ten gevolge van lage flow, veroorzaakt door stenose in het uitstroom gebied. De afmeting van de a. carotis in de hals van een geit van $20 \mathrm{~kg}$ is vergelijkbaar met die van de a. brachialis in de elleboog van de mens. De v. jugularis is iets groter dan de elleboogsvene. Deze overeenkomst in vaatdiameter impliceert een vergelijkbaarheid in hemodynamische eigenschappen van PTFE AV fistels, aangelegd in de nek van een geit en in de arm van een mens. Bovendien kunnen geiten in groepen worden gehuisvest. Dit vermindert de dagelijkse kosten van verzorging en geeft minder beperkingen aan het aantal dieren dat tegelijk bestudeerd kan worden.

\section{Hemodynamiek in PTFE AV fistels in de geit (Hoofdstuk 5)}

Om het effect van de geometrie van de prothese en van volumeflow door de prothese op het ontwikkelen van $\mathrm{IH}$ te bestuderen, werd een aantal experimenten in het gevalideerde geitmodel uitgevoerd.

De shear rate in fistels was ongeveer tweemaal zo hoog dan in normale vaten. Vermindering van volumeflow leidde niet tot vermindering van de shear rate of van de relatieve distensie. Er werd geen verschil gevonden in ontwikkeling van $\mathrm{IH}$ tussen hoge en lage volumeflow fistels.

Een hoge drukgradiënt ter plaatse van de anastomose wijst op een hoge weerstand van de anastomose, met gevaar voor turbulentie en verminderde volumeflow. Het gebruik van een veneuze cuff op de veneuze anastomose van PTFE AV fistels vergroot de diameter van de anastomose en vermindert de weerstand. Dit zou theoretisch leiden tot een kleiner drukverval over de anastomose, met minder rek en shear stress op het veneuze endotheel. We vonden echter geen kleiner drukverval over de gecuffte anastomoses in vergelijking met de standaard anastomoses. Ook werd er geen verschil in relatieve distensie gevonden tussen de groepen.

In een analyse van de PTFE AV fistels die zes weken na implantatie nog open waren, werd geen relatie gevonden van $\mathrm{IH}$ met hemodynamische parameters zoals volume flow, shear rate en relatieve distensie. In een analyse van alle PTFE AV fistels was de doorgankelijkheid significant beter bij hogere shear rate, hogere volume flow en lager drukverval over de veneuze anastomose.

We konden in het geitmodel geen gunstig effect aantonen van de veneuze cuff ter hoogte van de veneuze anastomose van PTFE AV fistels op doorgankelijkheid en de ontwikkeling van $\mathrm{IH}$.

\section{Effect van een veneuze cuff in hemodialyse patiënten (Hoofdstuk 6)}

In 120 patiënten werd een multicenter studie uitgevoerd om het effect van een veneuze cuff ter hoogte van de veneuze anastomose van PTFE AV fistels op de doorgankelijkheid en de ontwikkeling van stenoses te bestuderen. Drie maanden postoperatief werden Duplex onderzoek en 
fistulografie verricht om stenoses vast te stellen. De incidentie van trombose was lager in de groep met een veneuze cuff. Dit werd waarschijnlijk veroorzaakt door een lagere incidentie van stenoses op de veneuze anastomose, hoewel dit verschil niet significant was. De vermindering van trombotische occlusies leidde echter niet tot een betere doorgankelijkheid in de cuff groep omdat herhaalde occlusie optrad in dezelfde patiënten . De doorgankelijkheid na 1 jaar waren vergelijkbaar met die uit de literatuur, variërend van $40 \%$ tot $57 \%$ voor primaire en van $62 \%$ tot $78 \%$ voor secundaire doorgankelijkheid. De meest voorkomende complicatie waarvoor een interventie werd verricht was trombose, gevolgd door stenose. In de cuff groep werden meer interventies verricht voor infecties $(0.06$ per py vs. 0.01 per py in de standaard groep), maar dit was nog altijd lager dan in de literatuur (0.21-0.37 per py en 11-34\%).

Initiële diameter van de vene en lokale problemen (oedeem, obesitas en huidatrofie) blijken de belangrijkste risicofactoren voor het falen van PTFE AV fistels.

\section{Hemodynamiek van een veneuze cuff in PTFE AV fistels in patiënten (hoofdstuk 7)}

In een subgroep van de multicenter trial $(n=40)$, werden extra ultrageluidsonderzoeken verricht om de relatieve distensie (RD) en de shear rate (WSR) te berekenen. Volume flow, diameter van de prothese en efferente vene, RD en WSR waren vergelijkbaar in beide groepen. Vlak voor het falen van de fistels waren volume flow en WSR lager dan in niet-falende protheses.

We vonden hoge WSR in de prothese en in de efferente vene, maar die was vergelijkbaar in beide groepen. Hoewel de piek systolische snelheid lager was in de cuff groep, samenhangend met een lagere piek WSR, werd er geen verschil in doorgankelijkheid gevonden. Er was geen verschil in RD, een maat voor compliantie, tussen de twee groepen.

Net voor falen was de diameter van de efferente vene kleiner, wijzend op stenosevorming. Dit leidt tot verminderde volume flow, wat inderdaad werd gevonden in de falende protheses in vergelijking met de goed functionerende protheses. Het is algemeen bekend dat verminderde flow een voorspellende waarde heeft voor falen van fistels.

Uit de huidige studie blijkt dat een veneuze cuff op de veneuze anastomose van PTFE AV fistels niet leidt tot een verbeterde doorgankelijkheid, en dat WSR en RD rond de veneuze anastomose niet veranderen. Lage flow en WSR waren geassocieerd met fistel falen.

\section{Algemene discussie (Hoofdstuk 8)}

In dit proefschrift is het effect van een veneuze cuff op de veneuze anastomose van PTFE AV fistels onderzocht. Zowel in proefdierstudies als in klinisch onderzoek vonden we geen vermindering van WSR of RD bij een gecuffte anastomose in vergelijking met een standaard anastomose. In de proefdier studies werd geen vermindering van de ontwikkeling van intima 
hyperplasie gezien. Hoewel in de klinische studie minder trombose optrad in de cuff groep, leidde dit niet tot een verbeterde doorgankelijkheid. Er zijn echter een aantal beperkingen aan dit onderzoek. Er werd een benadering voor de WSR gebruikt, die werd berekend als gemiddelde over de hartcyclus en de diameter. Fluctuaties in WSR in tijd en plaats werden dus niet onderzocht. Ook was het niet mogelijk om WSR en RD in de anastomose zelf te berekenen, waar het grootste effect van de cuff te verwachten is.

Aangezien er geen gunstig effect van de veneuze cuff kon worden aangetoond, moet deze niet routinematig worden toegepast. We toonden wel aan dat vlak voor het falen van een PTFE AV fistel, de flow verminderd is. Routine onderzoek van de fistels kan dreigend falen aan het licht brengen zodat electieve behandeling van stenose mogelijk is, wat kan leiden tot verbetering van de secundaire doorgankelijkheid.

Intima hyperplasie is een multifactorieel probleem en toekomstig onderzoek moet zich richten op (een combinatie van) farmacologische interventie, vermindering van chirurgische schade bij het aanleggen en beïnvloeding van de geometrie van de prothese. 


\section{Dankwoord}

De laatste loodjes wegen het zwaarst, en dat geldt zeker voor het schrijven van een proefschrift. Daarom wil ik alle vrienden en collegae bedanken die bereid waren mijn klaagzang aan te horen over hoe ik weer met frisse tegenzin aan mijn hoofdstukken bezig was. Een aantal mensen wil ik apart bedanken.

Dr. J.H.M. Tordoir, beste Jan, dankzij jouw zijsporen groeide mijn CV in vier jaar enorm, hoewel dat niet altijd goed was voor mijn onderzoek. Soms was je misschien niet streng genoeg, want "volgende week ligt het op je bureau" bleek zeer rekbaar. Maar uiteindelijk is het dan toch af. Bedankt dat je me bent blijven motiveren, vooral in het laatste jaar, toen ik mezelf liever in de kliniek verstopte.

Prof. dr. P.J.E.H.M. Kitslaar, beste Peter, kritisch meekijkend vanaf de zijlijn haalde je altijd weer de structuur terug in mijn vaak ietwat chaotische stukken. Bedankt ook voor je steun en adviezen bij mijn sollicitatieprocedure.

Prof. dr. M.J.A.P. Daemen, beste Mat, mijn "pathologische" begeleider, jij wist me altijd op het juiste moment een schouderklopje te geven, waardoor ik uit mijn dip kon klauteren. Om vervolgens genadeloos uit te halen als ik weer wat steviger in mijn schoenen stond. Met je kritieken op mijn manuscripten was ik niet altijd even blij, maar ze waren altijd constructief.

Prof. dr. A.H.M. Hoeks, beste Arnold, de grootste "roddeloom" van de UM. Als ik na weken zwoegen eindelijk een manuscript bij je inleverde, kwam je het dezelfde dag gecorrigeerd terug brengen, en bleef je meteen even bijkletsen over de laatste geruchten uit AlO-land. Prof. dr. K.M.L. Leunissen, beste Karel, dankzij jouw positieve commentaar hield ik de moed erin. Het kan altijd beter, maar op een gegeven moment moet je ermee stoppen, dus bij deze.

Meiden van het vaatlab, bedankt voor het afspreken en uitvoeren van de extra onderzoeken en voor alle gezelligheid. Monique en Anja, met jullie spraakmakende avonturen was de lunch zo om. Yvonne, in jouw schriftje stond de oplossing voor elk probleem. Laura, door jouw broodjes kon ik's avonds nog uren doorwerken. Simoon, natuurlijk heb ik altijd tijd voor lekkere koffie.

Ineke, mijn paranimf, voor de supervisie van onze voordrachten voor Tours gold: "gedeelde smart is dubbele pret". Bij jou vond ik niet alleen geweldige steun en vriendschap, maar ook nog kost en inwoning. Onder het genot van een glas wijn konden we kletsen tot in de kleine uurtjes. Dat moeten we snel nog eens doen. 
Yvonne Daemen, als iets goed geregeld moest worden kwam ik bij jou. Op het laatste moment kon je altijd nog wel ergens een hotel regelen. Bedankt voor je praktische hulp en morele steun.

Mijn "kamergenoten" Jacques, Lilian en Christine, en mijn studentassistenten Marthe en Rajaa, hoewel ik in het eerste jaar in m'n eentje op de kamer veel productiever was, had ik jullie gezelligheid niet willen missen. Ik denk met genoegen terug aan onze verhitte projectbesprekingen. Marthe, tijdens je Amerikaanse avontuur waren je e-mailtjes een spannend vervolgverhaal. Rajaa, mijn paranimf, af en toe nam je wat teveel hooi op je vork, maar alles is toch nog goed gekomen. Hoewel, ondanks mijn gemopper op het onderzoek ben je toch AIO geworden. Succes.

Jean, na een ietwat stugge start bleek jij mijn steun en toeverlaat bij computer-problemen. Het waterballet bij de in-vitro testen van de Hemodialyse monitor was een aangename afwisseling van het uitwerken van m'n data.

Het PA-lab, mijn adoptie-afdeling, bedankt voor jullie koffie, meeleven en adviezen op zeer uiteenlopende terreinen! Esther, de avondjes uit met jou werden altijd gedenkwaardig. Petra, Monique en Anique, bedankt voor jullie geduld bij het leren snijden en kleuren. Ismene bedankt voor al je coupes. Jan en Cor, dankzij jullie programma's kon ik uren en uren achter de Quantimet.

Richard, op jouw brede schouders kon ik lekker uithuilen, om vervolgens samen de kroeg in te duiken. Your dirty mind is my joy forever.

Mijn geitenstudie op het CPV zit nog vers in mijn neus. Ton, na de proefdiercursus was het DEC-protocol geen probleem meer. Frans en Huub, bedankt voor het verzorgen van mijn geitjes. Mai, je was niet altijd even stipt, maar wel een handige ritselaar. Joyce, over onze belevenissen op het CPV kunnen we boeken schrijven. Bedankt voor je morele en praktische steun en koppelpogingen die nooit lukten (al heeft hij wel mooie ogen).

Alle chirurgen en nefrologen van de deelnemende ziekenhuizen dank ik voor het inlichten en includeren van de patiënten. Door jullie enthousiaste medewerking was het eindaantal van 120 patiënten een jaar eerder dan gepland bereikt.

Dr. H. Burger, beste Hens, jouw betrokkenheid zowel bij je patiënten als bij mij en mijn onderzoek was hartverwarmend. Ik ben erg blij dat je mijn manuscript wilde beoordelen.

Alle verpleegkundigen en secretaresses van de dialyse-afdelingen die aan dit onderzoek hebben meegewerkt, wil ik langs deze weg heel hartelijk bedanken voor jullie inzet en enthousiasme. Zonder jullie waren de follow-up onderzoeken van patiënten hopeloos de mist ingegaan. In het bijzonder bedank ik de volgende personen voor het 
extra werk dat ik ze bezorgde en dat zij altijd zonder morren voor mij hebben gedaan.

Elise, voor het regelen van de onderzoeken en statussen als ik langs kwam. Gusta, voor het trouw bijhouden van alle onderzoeken en het zorgen dat alle patiëntengegevens waren ingevuld, en voor de soep en koffie na mijn lange reis. Magda, voor de gezellige dagjes gegevens bijwerken en bijpraten. Wanneer gaan we nou winkelen in Eindhoven? Marlies en Marita, voor het onderhandelen over Duplex en Angiografie afspraken en het motiveren van de patiënten voor deze extra onderzoeken. Frank, voor het trouw uitvoeren en opsturen van de recirculatie- en veneuze drukmetingen. Marianne, voor het zeer nauwgezet volgen van de geïncludeerde en nog niet geïncludeerde patiënten, en Marie-Claire, voor het waarschuwen wanneer ik weer een angio of Duplex wilde van een overleden patiënt.

Bij het dankwoord staan vaak de belangrijkste personen aan het einde. Daarom bedank ik hier mijn naaste familie, die intens meeleefde met mijn 'ups' en meeleed met mijn 'downs'. In het bijzonder mijn ouders, die mij ondanks hun twijfels altijd met raad en daad steunden. En Mieke, soms meer moeder dan zus, in spannende tijden of als ik het echt niet meer zag zitten hing jij aan de telefoon.

En natuurlijk bedank ik jou, lieve Edwin. Letterlijk en figuurlijk was je de afgelopen jaren mijn rots in de branding. Nu wordt het tijd om jouw wens te vervullen.

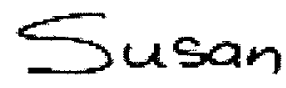




\section{Curriculum Vitae}

Margaretha Suzanna Lemson (Susan) werd op 4 augustus 1967 geboren in het St. Clara Ziekenhuis in Rotterdam. Na het behalen van het Gymnasium$\beta$ diploma aan de Rijksscholengemeenschap Brielle in 1985, begon zij met de studie Geneeskunde aan de Erasmus Universiteit in Rotterdam. In september 1989 haalde zij haar doctoraal examen. Haar keuze onderzoek getiteld "Anaemia among pregnant women in South-India" voerde ze uit aan de Rural Unit for Health and Social Affairs (RUHSA) in Vellore, gelegen in de provincie Tamil Nadu in India, onder leiding van dr. R. Abel en Prof. dr. H.A. Valkenburg.

In februari 1992 behaalde ze het artsexamen waarna ze in april haar eerste schreden zette in de chirurgie als arts-assistent (AGNIO) op de afdeling chirurgie van het St. Clara Ziekenhuis in Rotterdam. Hoofd van deze afdeling was dr. R.A.F. van de Neste. In 1993 was zij arts-assistent (AGNIO) op de afdeling chirurgie van het IJsselland Ziekenhuis te Capelle a/d IJssel met dr. J.W. Merkelbach aan het hoofd, en in 1994 op de afdeling chirurgie van het Ziekenhuis Leyenburg te Den Haag onder leiding van dr. W.M. Oosterwijk. In oktober 1994 werd ze assistent in opleiding tot onderzoeker (AIO) op de afdeling chirurgie van het Academisch Ziekenhuis Maastricht en bij het Cardiovascular Research Institute Maastricht (CARIM). Onder supervisie van de vaatchirurgen dr. J.H.M. Tordoir en Prof.dr. P.J.E.H.M. Kitslaar, patholoog Prof.dr. M.J.A.P. Daemen, nefroloog Prof.dr. K.M.L. Leunissen en biofysicus Prof.dr. A.P.G. Hoeks werd het onderzoek uitgevoerd dat leidde tot dit proefschrift.

Sinds januari 1999 is zij in opleiding tot chirurg in het Diaconessenhuis te Eindhoven met dr. W.J. Prakken als opleider. 